\title{
Function of glial cells in the inhibitory synaptic transmission of the respiratory network
}

\author{
PhD Thesis \\ in partial fulfilment of the requirements \\ for the degree "Doctor of Philosophy (PhD)" \\ in the Neuroscience Program \\ at the Georg August University Göttingen, \\ Faculty of Biology
}

submitted by

Katalin Szőke

born in

Kaposvár (Hungary)

Göttingen 2005 
Advisor, first member of FAC: $\quad$ Priv. Doz. Dr. Swen Hülsmann

Second member of FAC: $\quad$ Prof. Dr. Klaus-Amin Nave

Third member of FAC: $\quad$ Prof. Dr. Diethelm W. Richter

Fourth member of FAC: $\quad$ Prof. Dr. Christian Rosenmund

Date of submission of the PhD thesis: $\quad 26.09 .2005$

Day of thesis defense (disputation): $\quad$ 27.10.2005

Grade: cum laude 
Herewith I declare that I prepared the $\mathrm{PhD}$ thesis

'Function of glial cells in the inhibitory synaptic transmission of the respiratory network' on my own and with no other sources and aids than quoted.

Göttingen, $23^{\text {rd }}$ September 2005

Katalin Szőke 
Dedicated to my parents,

Grateful for their endless patience, love and support during all these years...

Szüleimnek,

Hálából végtelen türlmükért, szeretetükért és támogatásukért e hosszú éveken át... 


\section{Contents}

Abbreviations

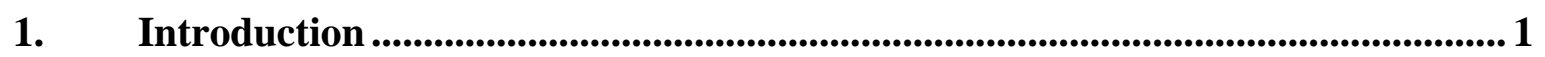

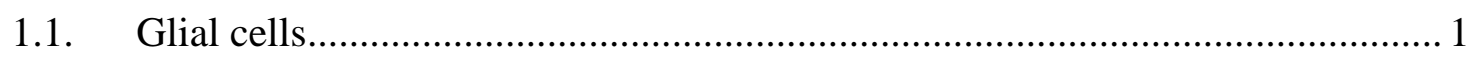

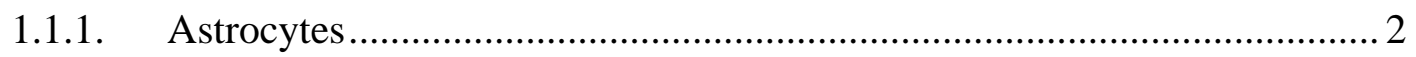

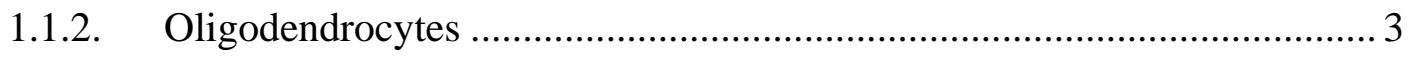

1.1.3. The NG2+ glia- a new glial cell type? .................................................. 3

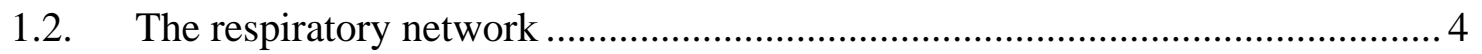

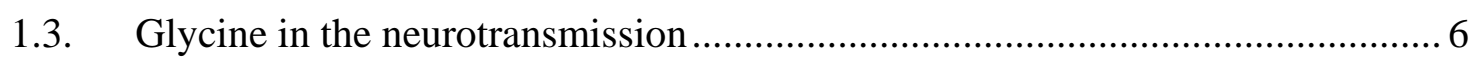

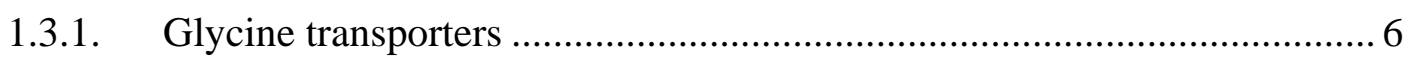

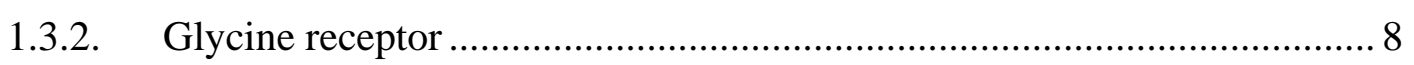

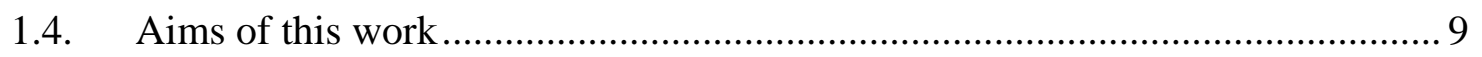

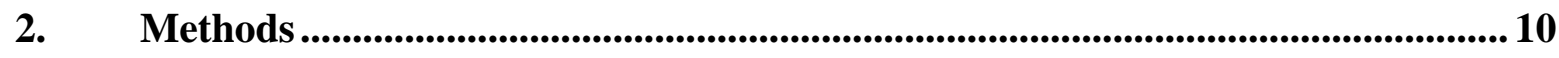

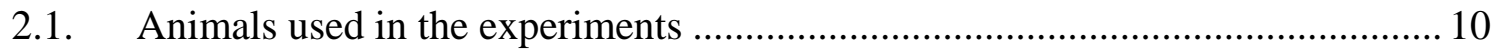

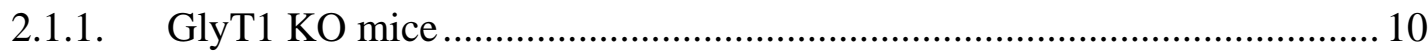

2.1.2. Transgenic mice with fluorescently labelled cells ................................. 10

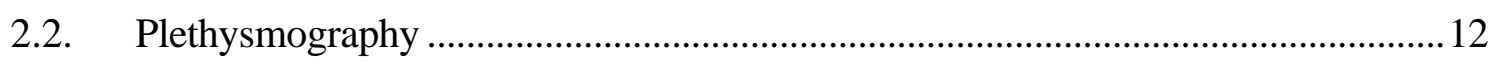

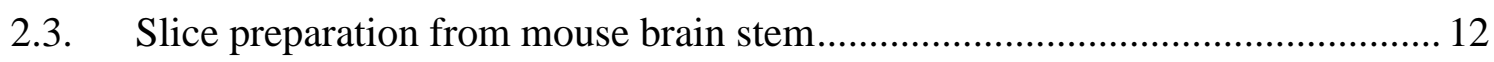

2.4. The "rhythmic slice preparation": recording of the in vitro respiratory rhythm. 14

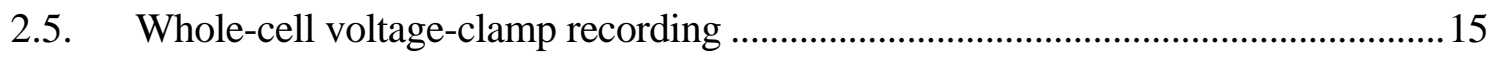

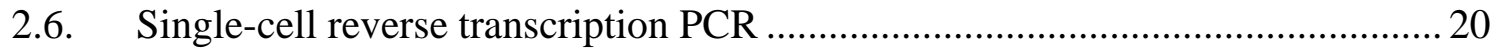

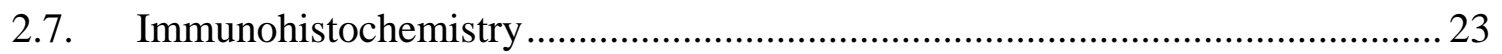

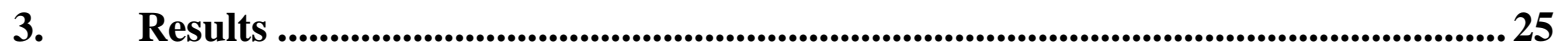

3.1. Functional expression of glycine receptors and transporters on glial cells of the

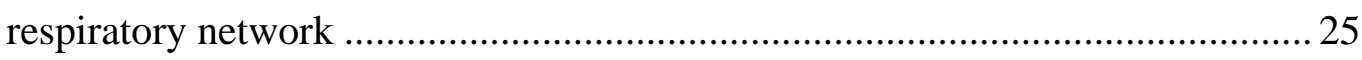

3.1.1. Expression of GlyT1 on astrocytes of the respiratory network.................. 25

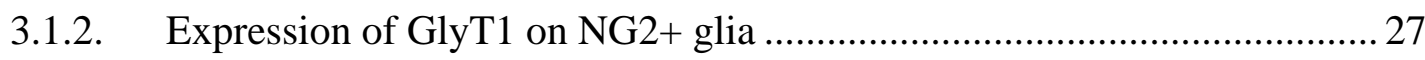

3.1.3. Co-expression of GlyT1 and glutamate transporter on astrocytes ............. 28

3.1.4. Expression of GlyT1 on oligodendrocytes............................................... 29

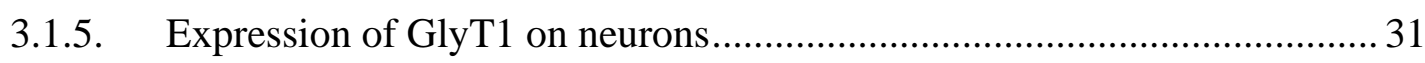

3.1.6. Expression of the mRNA of GlyT1 in glial cells of the respiratory

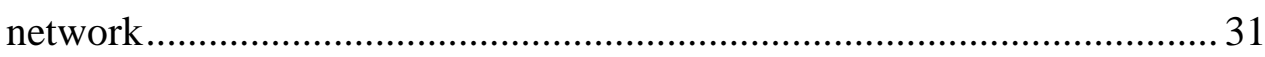

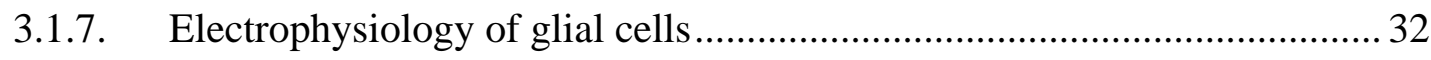


3.1.8. Glycine induced currents in glial cells of the respiratory network 34

3.1.9. Comparison of the glycine induced currents of astrocytes and neurons .... 37

3.1.10. Involvement of coupling in glycine induced currents of astrocytes........... 38

3.1.11. Co-expression of glycine transporter and glutamate transporter currents in astrocytes 40

3.1.12. Expression of glycine receptor in glial cells of the respiratory network.... 40

3.1.13. Comparison of the glycine response of glial cells with the GABA response 44

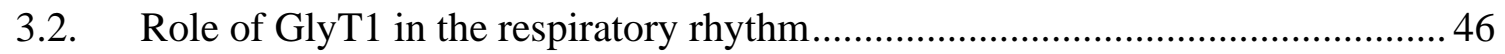

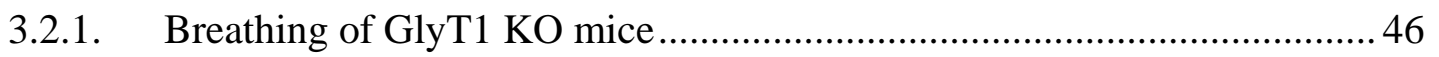

3.2.2. The in vitro respiratory rhythm of GlyT1 KO mice................................. 47

3.2.3. Effect of glycine and sarcosine on the normal in vitro respiratory rhythm 49

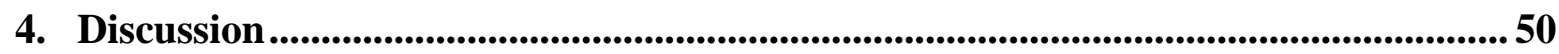

4.1. GlyT1 is expressed in passive and intermediate astrocytes ............................. 50

4.2. GlyT1 function is necessary for the respiratory rhythm generation................... 52

4.3. GlyT1 is glial specific in the respiratory network........................................... 54

4.4. Expression of GlyR in different glial cell types ................................................ 54

4.5. The functional role of glycine receptors on glial cells .......................................5

4.6. Outwardly rectifying astrocytes induce large GABA receptor currents ..............57

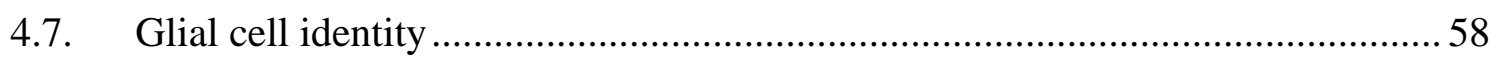

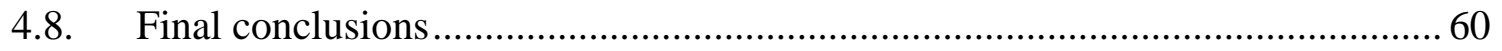

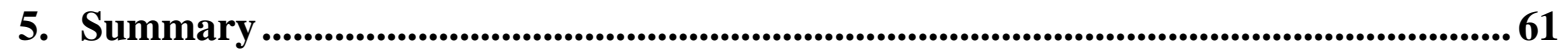

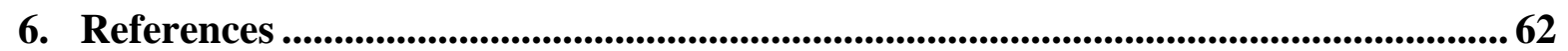

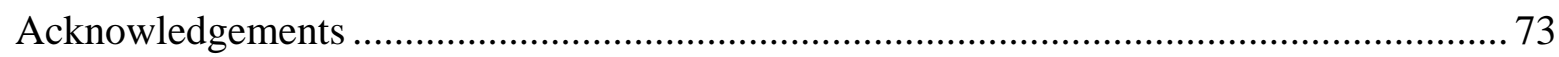

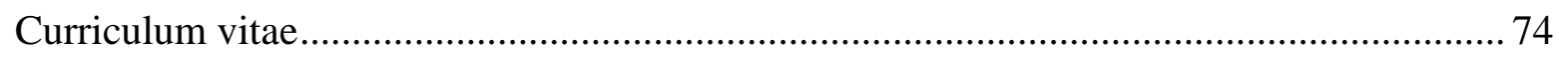

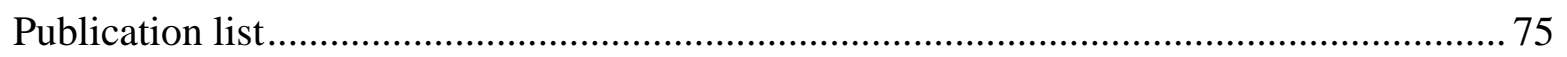




\section{Abbreviations}

AB

ACSF

cDNA

CNS

DNA

dNTPs

DTT

EGFP

EGTA

EYFP

GABA

GFAP

GLAST

GLT

GlyR

GlyT1

GlyT2

HEPES

N. XII

NMDA

Nucl. XII.

PBC

PCR

PLP

PNS

RMS noise

RNA

RT

ScPCR

SD

TTX

VRG antibody

artificial cerebrospinal fluid

complementer DNA

central nervous system

deoxyribonucleic acid

deoxyribonucleozid-triphosphates

Dithiothreitol

enhanced green fluorescent protein

ethylene glycol-bis ( $\beta$-aminoethyl ether)-N,N,N',N'-tetraacetic acid

enhanced yellow fluorescent protein

$\gamma$-amino butyric acid

glial fibrillary acidic protein

glutamate-aspartate transporter

glutamate transporter

Glycine receptor

Glycine transporter 1

Glycine transporter 2

N-2-hydroxyethylpiperazine-N'-2-ethanesulfonic acid

Hypoglossal nerve

N-methyl-D-aspartate

Nucleus hypoglossus

Pre-Bötzinger Complex

polymerase chain reaction

proteolipid protein

peripheral nervous system

root-mean-square noise

ribonucleic acid

reverse transcription

single-cell PCR

standard deviation

tetrodotoxin

Ventral Respiratory Group 


\title{
1. Introduction
}

Within the respiratory network, glial cells are supposed to modulate the neurotransmission, which is involved in rhythm generation. This is suggested for example by experiments in which the blockade of the glial metabolism by fluoroacetate strongly reduced the in vitro respiratory rhythm (Hülsmann et al, 2000). However, the exact function of the glial cells in the process is not yet fully understood. Our goal is to investigate how the different glial cell types of the respiratory network can influence the distinct neurotransmission pathways. The present work is focused on the glycinergic inhibitory neurotransmission.

\subsection{Glial cells}

\author{
„Neurons make up only 10 percent of the \\ brain's cells, yet that's what we've always \\ focused on. There's 90 percent of the brain \\ yet to learn about. It's uncharted area. “
}

Vladimir Parpura and Philip Haydon (1994)

Glial cells were first described by Virchow in 1885 as non-neuronal cells of the nervous system, and named after the Greek word "glios", meaning glue or slime. The development of the Golgi silver-impregnation (1885) and later Cajal's astrocyte-specific gold sublimate staining helped to first visualise different glial cell types. However, glial cells were considered for long time to be simple supportive structural elements of the nervous system, despite the fact that they outnumber neurons at least ten to one in the human brain (Kandel, 2000). Recently it became clear that glial cells have much more interesting functions, many of which are yet to be discovered.

According to the general classification (Table 1) the main glial cell types in the central nervous system are the astrocytes and the oligodendrocytes, known as macroglia, and the mesodermal microglia, which differs in origin from the other cell types of the nervous system, which are ectodermal. Microglia are most likely macrophages of the CNS, which migrated into the brain during the ontogenesis and differentiated there. Recently a possible new macroglia cell type is described according to morphology (Peters A, 2004), localization and function (Butt et al, 2002), considered as the fourth main type of glial cells. 
Central nervous system

1. Macroglia

Astrocytes

Oligodendrocytes

$\mathrm{NG} 2+$ glia

Special cell types: ependymal cells, tanycytes

Müller-cells (retina

pituicytes (pituitary)

Bergmann-glia (cerebellum)

2. Microglia
Periferal nervous sytem

Schwann-cells

Satellite-cells (ganglion cells)

Table1. Classification of glial cells

The table shows the different glial cell types of the central nervous sytem and in the peripheral nervous system

\subsubsection{Astrocytes}

Astrocytes represent the most numerous population of glial cells in the mammalian central nervous system. Their name means star-cells, because of the typical shape observed with the early staining methods. The major identifying characteristic of astrocytes in ultrastructure level is the presence of an intermediary filament protein, GFAP (glial fibrillary acidic protein, Eng et al, 1971, Bignami et al, 1972; for review see Eng et al, 2000), which is present in mature astrocytes.

In transgenic mice expressing the green fluorescent protein under the control of the GFAP promoter (Nolte et al, 2001) different types of astrocytes were described according to their current pattern, the intensity of the fluorescence and the response to the excitatory neurotransmitter glutamate in hippocampus (Matthias et al, 2003), which is comparable to the results obtained in non-fluorescent mice (Zhou and Kimelberg, 2001). Similar characterization of astrocytes was also performed in the respiratory network (Graß et al, 2004). Astrocytes with large passive conductance, linear I/V relationship and without A-type current, termed as "passive” astrocytes, appear preferentially as bright fluorescent cells and express mainly glutamate transporter current. In contrast, astrocytes with outwardly rectifying IV relationship and large A-type current, referred to as “outwardly rectifying” astrocytes, usually appear as dark fluorescent cells and express glutamate receptor current. There are also astrocytes with linear IV relationship at the steady state but with an initial A-type current, termed “intermediate” astrocytes by Graß et al (2004).

Since the glial progenitor marker NG2 labels almost exclusively very dark fluorescent cells, it can be a possible marker of the outwardly rectifying astrocytes (Graß et al, 2004). 


\subsubsection{Oligodendrocytes}

Oligodendrocytes are the glial cells ensheathing axons with myelin in the CNS. Their name comes from the Greek words “oligo” meaning few or scant and “dendron” meaning tree, because through a microscope the cells' projections look like the sparse branches of a tree. While the myelin-forming cells of the PNS (Schwann-cells) myelinate only one axon, a single oligodendrocyte can myelinate several axons (usually 10-15) with processes which wrap themselves around axons to form an insulating sheath. The gaps between myelin sheets formed by different oligodendrocytes are called nodes of Ranvier. A nerve impulse travels along an axon by jumping from one node of Ranvier to the next, a process known as saltatory conduction, which speeds up the conduction and reduces the amount of energy used.

Data of oligodendrocytes in the glycinergic inhibitory neurotransmission are restricted to a few studies. Oligodendrocytes within the spinal cord were shown to express glycine receptors (Pastor et al, 1995, Kirchhoff et al, 1996), as well as oligodedrocyte precursors in cell culture (Belachew 1998a, Belachew 1998b, Belachew et al, 2000), although in oligodendrocyte precursors the glycine-induced current decreased during differentiation. Their role in the glycine transport is controversial: strong sodium-dependent glycine binding was observed in the myelin fraction in rat brain cortex homogenates (Valdes et al, 1977), and oligodendrocyte precursors showed an intracellular $\mathrm{Ca}^{2+}$ influx partially due to sodiumdependent transporters in response to glycine (Belachew et al, 2000) suggesting the role of GlyT1 in oligodendroyctes, but with autoradiography glycine uptake was not observed in oligodendrocytes (Reynolds and Herschkowitz, 1986).

\subsubsection{The NG2+ glia- a new glial cell type?}

NG2 is a cell membrane-associated chondroitin sulphate proteoglycan. Its mouse homologue is called AN2 (Niehaus et al, 1999, Schneider et al, 2001) and the human homologue is the melanoma chondroitin sulphate proteoglycane (Smith et al, 1996). NG2 was described as a marker of oligodendrocyte-type 2 astrocyte progenitor cells in vitro as it was co-expressed with the A2B5 marker (Raff et al, 1983, Raff et al, 1988, Stallcup and Beasley, 1987, for review see Raff, 1989) and oligodendrocyte progenitor cells in vivo (Levine et al, 1993). It was also found in pericytes and smooth muscle cells of the vasculature, and the human homologue in human melanoma cells. 
Recently NG2+ glia was discussed as a fourth main glial cell type in addition to astrocytes, oligodendrocytes and microglia (Butt et al, 2002, Peters, 2004). However, it is not yet clear whether it is a subpopulation of the NG2+ cells which have special functions (as suggested in Butt et al, 2002), or all NG2+ cells form a distinct cell type, which is able to function as oligodendrocyte precursor when needed, as well as fulfill other functions (as suggested in Nishiyama et al, 2002). At least a subpopulation of the NG2+ glia is generally agreed to have special functions at the synapses in the grey matter and at the nodes of Ranvier in the white matter (Ong and Levine, 1999, Bergles et al, 2000, Butt et al, 1999, for review see Butt et al, 2002). Additionally, NG2+ cells were found to differentiate into neurons (Belachew et al, 2003).

\subsection{The respiratory network}

The respiratory network is a neuronal network in the caudal brain stem of mammals, which generates a rhythmic activity, finally controlling respiratory motoneurons. It is formed from a variety of respiratory neurons, which are mostly antagonistically connected (Figure 1; Richter and Spyer, 2001, Richter, 2000). Six classes of respiratory neurons were described according to their firing patterns, membrane potential changes, and synaptic inputs (Bianchi et al, 1995, Richter and Spyer ,2001, Richter, 2000): (1) the pre-inspiratory neurones (Pre-I) which fire at the transition between expiration and inspiration; (2) the early-inspiratory neurones (Early-I), which fire from the beginning to the middle of inspiration; (3) the rampinspiratory neurons (Ramp-I), which fire throughout inspiration; (4) the late-inspiratory neurons (Late-I), which are active at the end of inspiration; (5) post-inspiratory neurons (postI) activated during phase transition between inspiration and expiration (post-inspiration); and finally the (6) expiratory neurones $\left(E_{2}\right)$ working during expiration. The main excitatory neurotransmitter within the network is glutamate, acting on AMPA- and NMDA type receptors, while in the inhibitory neurotransmission two neurotransmitters, GABA and glycine are involved. Pacemaker cells were also described to influence the network activity (Butera et al., 1999, Smith et al, 2000). 


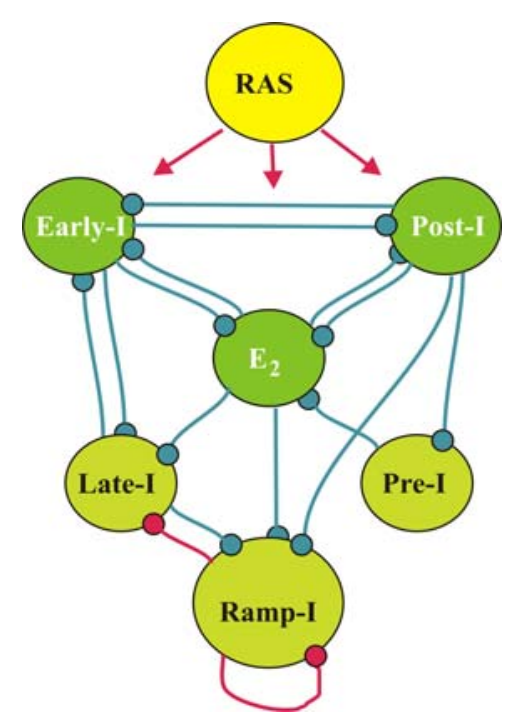

Figure 1. The connections of neurons within the respiratory network

The figure shows the inhibitory (blue) and excitatory (red) connections between the 6 different types of respiratory neurons: pre-inspiratory (Pre-I), early-inspiratory (Early-I), ramp-inspiratory (Ramp-I), lateinspiratory (Late-I), post-inspiratory (Post-I) and exspiratory $\left(\mathrm{E}_{2}\right)$ neurons. The network is driven by the reticular activating system (RAS). Figure taken from Richter (2000).

The respiratory neurons are organized into a dorsal respiratory group (DRG) and a ventral respiratory group (VRG) within the lower brain stem (Bianchi et al, 1995). Only the VRG is essential for rhythm generation (Richter and Spyer, 2001). Neurons in the PreBötzinger Complex (PBC) and neighbouring structures in the VRG are responsible for respiratory rhythm generation (Smith et al, 1991, Onimaru and Homma, 2003). The importance of PBC was confirmed by electrophysiological recordings, pharmacological manipulations, and lesions, both in vitro and in vivo (Gray et al, 2001, Pierrefiche et al, 1998, Smith et al., 1991, Solomon et al., 1999). It contains all classes of neurons necessary for the respiratory rhythm generation, which exist in the ventrolateral medulla (Connelly et al., 1992, Feldman et al., 2003, Rekling and Feldman, 1998, Schwarzacher et al., 1995, Smith et al., 1991).

Recently, glial cells of the network were discovered to play an important role in the rhythm generation. Blockade of glial metabolism reduces the in vitro respiratory rhythm (Hülsmann et al, 2000). Glial cells in the respiratory network are supposed to modulate the synaptic transmission between neurons via their neurotransmitter transporters. The function of glial cells in the excitatory (glutamatergic) neurotransmission within the respiratory network was previously studied (Hülsmann et al, 2000; the effect of glutamate transport blockade already in Greer et al, 1991), and the astrocytes responsible for the glutamate uptake were identified (Graß et al, 2004). 


\subsection{Glycine in neurotransmission}

Glycine is a non-essential amino acid, which acts both as a neurotransmitter, and as a neuromodulator in the mammalian brain. Glycine is the main inhibitory neurotransmitter in the lower brain stem and in the spinal cord, where it participates in a variety of motor- and sensory functions. In the forebrain, which lacks glycine receptors, glycine functions as a neuromodulator. In contrast to the direct neurotransmitter effect, the neuromodulator role is expressed in the excitatory transmission where glycine is a high-affinity coagonist of glutamate at NMDA receptors (Berger et al, 1998, Berger et al, 1999, Supplisson and Roux, 2002).

The importance of glycine in the respiratory rhythm was already supported by the fact that homozygous mutant oscillator mice, which lack the adult isoform of the $\alpha 1$ ligandbinding subunit of the glycine receptor, die at the end of the third postnatal week due to a severe disturbance of the respiratory rhythm. However, deletion of the glycinergic inhibition did not result in a failure of respiratory rhythm: these mice continue to generate a disturbed respiratory rhythm until death. The mutation of this gene in humans, although not lethal, results in a disease called hyperekplexia whose symptoms also include apnoea. (Büsselberg et al, 2001).

\subsubsection{Glycine transporters}

There are two main subtypes of transporters for glycine, encoded by distinct genes: glycine transporter 1 (GlyT1) and glycine transporter 2 (GlyT2). According to the common classification of transporters (Table 2) both of them belong to the $\mathrm{Na} / \mathrm{Cl}$ dependent transporter family.

\section{The glycine transporter 1 (GlyT1)}

GlyT1 can be found widespread in the CNS: in the spinal cord, brain stem, and cerebellum, as well as in the cortex and the hippocampus (Zafra et al, 1995a, Zafra et al 1995b). It is mainly localized on glial cells (Adams et al, 1995, Zafra et al, 1995a), although newly there are increasing data of neuronal GlyT1. GlyT1 was found in neurons in retinal transplants (Sharma, 2000), and newly in cortex and cerebellum (Jones et al, 2004, conference abstract, Cubelos et al, 2005). 


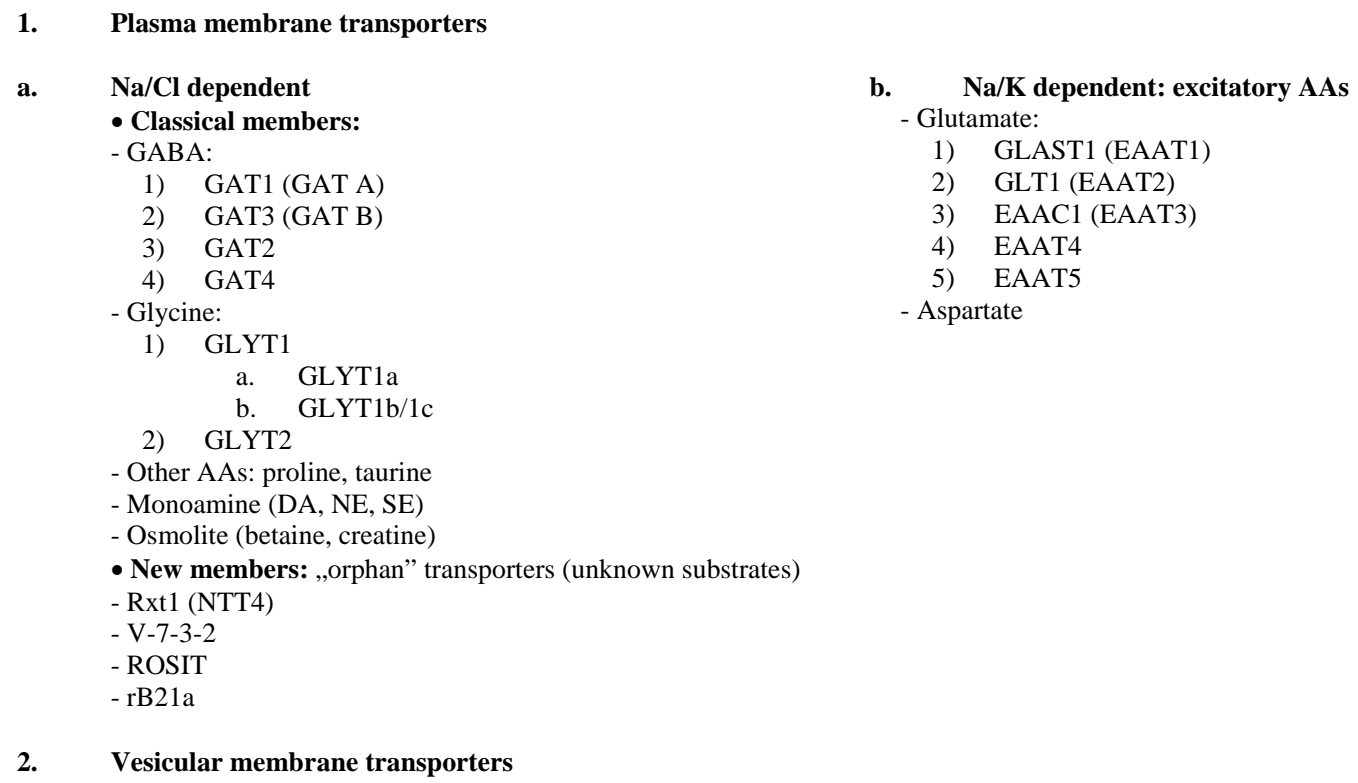

2. Vesicular membrane transporters

b. $\mathrm{Na} / \mathrm{K}$ dependent: excitatory AAs

- Glutamate:

1) GLAST1 (EAAT1)

2) GLT1 (EAAT2)

3) EAAC1 (EAAT3)

4) EAAT4

5) EAAT5

- Aspartate

\section{Table 2. Classification of neurotransmitter transporters}

(as reviewed in Masson et al, 1999 and Jursky et al, 1994)

Three isoforms of GlyT1 have been identified: GlyT1a, GlyT1b and GlyT1c (Adams et al, 1995), which only differ in their N-termini. GlyT1a and GlyT1b are identical except for the first amino acid residues (10 and 15, respectively), which arise from different exons. GlyT1c has the same 15 N-terminal amino acid residues as GlyT1b, but contains a 54 amino acid insert directly afterwards (Borowsky et al, 1993, Liu et al, 1993). The proteins have a molecular mass of 77 to $88 \mathrm{kDa}$.

GlyT1 recently became a subject of many investigations because of its possible role as a target for treatment of schizophrenia. Genetic inhibition of GlyT1 leads to potentiation of the NMDA receptor mediated synaptic transmission through increased extracellular glycine concentration. Therefore, specific GlyT1 inhibitors might be useful against symptoms of schizophrenia due to decreased NMDA activity (Gabernet et al, 2005, Williams et al, 2004, Lipina et al, 2005, Javitt et al, 2005).

\section{The glycine transporter 2 (GlyT2)}

In contrast to the GlyT1, GlyT2 is expressed specifically in neurons. It reflects the distribution of glycinergic neurons in spinal cord and brain stem, and closely follows the distribution of the glycine receptor, therefore thought to be involved in the termination of glycine neurotransmission (Liu et al. 1993, Jursky and Nelson, 1995) and essential for 
replenishing the cytoplasmic pool of glycine in the presynaptic neuron (Zafra et al, 1995a, Spike et al, 1997, Gomeza et al, 2003b).

GlyT2 is 48\% identical to GlyT1 and has a molecular mass of $90 \mathrm{kDa}$. It has a 160 amino acid residue extension of the $\mathrm{N}$-terminus and a 13 amino acid residue extension in the $\mathrm{C}$ terminus in comparison to GlyT1. A new GlyT2 subtype, GlyT2b has been also identified, differing in N-terminus, which appears to be unable to accumulate glycine against a concentration gradient (Ponce et al, 1998).

\subsubsection{Glycine receptor}

The glycine receptor is a member of the nicotinicoid receptor superfamily along with the $\mathrm{GABA}_{\mathrm{A}}$ receptor and the nicotinic acetylcholine receptor (Cascio, 2004). Structurally it is a pentameric membrane glycoprotein, which consists of $48 \mathrm{kDa}(\alpha)$ and $58 \mathrm{kDa}(\beta)$ membrane-spanning subunits, associated with a cytoplasmic polypeptide of $93 \mathrm{kDa}$, named gephyrin after the Greek word of bridge (Graham et al, 1985, Betz et al, 1986, Langosch et al, 1988, Prior $\mathrm{P}$ et al, 1992). Gephyrin is thought to anchor the GlyR to subsynaptic microtubules. The strychnine and ligand binding sites of the glycine receptor reside on the $\alpha$ subunit. Four different $\alpha$ subunit genes have been identified (Grenningloh et al, 1988, 1990, Kuhse et al, 1990, Matzenbach et al, 1994). Furthermore, two variants of the $\alpha 1$ subunit (Malosio et al, 1991) and two variants of the $\alpha 2$ subunit (Kuhse et al, 1991) are generated by alternative splicing. During development, the neonatal $\alpha 2$ subunit is replaced by the adult $\alpha 1$ form within the first two weeks of life in mice (Becker et al, 1988, Gomeza et al, 2003b). The receptor functions as a ligand-gated chloride channel (Reviewed in Lynch, 2004).

There are very few data available about glial GlyRs. Although in cell culture GlyR was described only in neurons, and not in glial cells (Hosli et al, 1981), in spinal cord slice preparation GlyR mediated currents were detected from astrocytes and oligodendrocytes and the mRNA of glycine receptor subunits was also shown by single cell PCR (Pastor et al, 1995, Kirchhoff et al, 1996). Glial progenitor cells also showed glycine receptor currents. Glycine receptors expressed by oligodendrocytes were described to have different pharmacological properties and different molecular structure than neuronal GlyRs (Belachew et al, 1998b). Glycine receptor mediated currents were also described in Müller-cells of the retina together with GlyT1-mediated currents (Du et al, 2002). 


\subsection{Aims of this work}

Our purpose in the present study was to analyze how glial cells affect the glycinergic neurotransmission of the respiratory network. For this, we used two different approaches.

First, the expression of GlyT1 and GlyR was investigated in different glial cells types within the ventral respiratory group using immunohistochemistry to show the expression of the protein, single-cell RT-PCR to show the expression of the mRNA and whole-cell voltageclamp for analysis of functional expression.

Second, we studied the effect of the knock out of GlyT1 on the breathing of mice both in vivo, and in in vitro experiments on rhythmic slices. 


\section{Methods}

\subsection{Animals used in the experiments}

\subsubsection{GlyT1 KO mice}

Mice deficient in the glial GlyT1 protein were generated in Frankfurt in the research group of Heinrich Betz by homologous recombination. These mice died during the first day of their life. Homozygous GlyT1 KO mice showed only weak spontaneous motor activity, and weighed about $15 \%$ less than their control littermates (Figure 2). The newborn mice became gradually weaker and failed to survive, with death occurring 6-14 hours after birth (Gomeza et al, 2003a).

The genotypes of the mice were determined by PCR from $5 \mathrm{~mm}$ tail samples stored frozen on $-20^{\circ} \mathrm{C}$. Genotyping PCR was performed by Volker Eulenburg (Frankfurt).

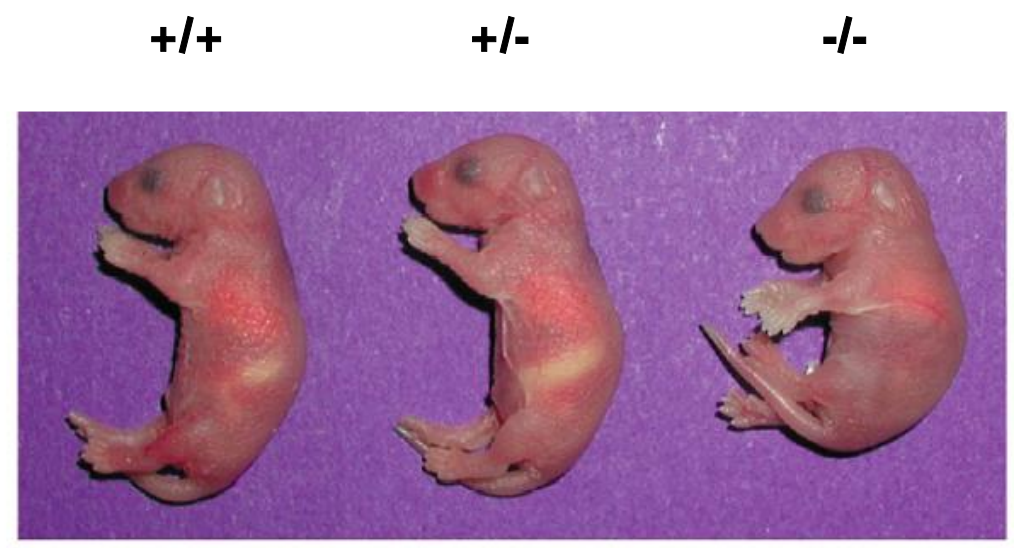

\section{Figure 2. Appearance of newborn GlyT1 KO mice}

A wild-type littermate (+/+), a heterozygous littermate (+/-) and a homozygous GlyT1 KO mouse (-/-) is shown. The homozygous mice have got no milk in their stomach and show a different body posture with drooping forelimbs. Figure taken from (Gomeza et al, 2003a).

\subsubsection{Transgenic mice with fluorescently labelled cells}

Three types of transgenic mice were used for the experiments: TgN (hGFAP/EGFP) mice expressing the enhanced green fluorescent protein (EGFP) under the control of the human glial fibrillary acidic protein (GFAP) promoter (Nolte et al, 2001), TgN (mPLP/DsRed) mice expressing the red fluorescent protein DsRed under the control of the 
mouse proteolipid protein (PLP) promoter and TgN (Thy1.2/EYFP) mice expressing the enhanced yellow fluorescent protein (EYFP) under the control of the Thy1.2 promoter. The TgN (mPLP/DsRed) mice express red fluorescence in oligodendrocytes (Figure 3B), TgN (Thy1.2/EYFP) mice express yellow fluorescence in neurons. Both mice originate from the laboratory of Frank Kirchhoff, Departement of Neurogenetics, Max Planck Institute for Experimental Medicine in Göttingen.

The TgN (hGFAP/EGFP) mice express green fluorescence in astrocytes in various regions of the brain, including the caudal brain stem (Figure 3-A). The density of the labelled cells is high, making them easy to locate. The fluorescence intensity of the cells within a region is diverse, but correlates with the electrophysiological properties of the astrocytes: cells with high level of EGFP expression have passive or intermediate current-voltage (IV) relationship, while dark fluorescent cells frequently show an outwardly rectifying IV curve. (Graß et al, 2004). These properties allow us to easily visualize single astrocytes, thus making the TgN (hGFAP/EGFP) mice useful for electrophysiological analysis of different types of astrocytes.
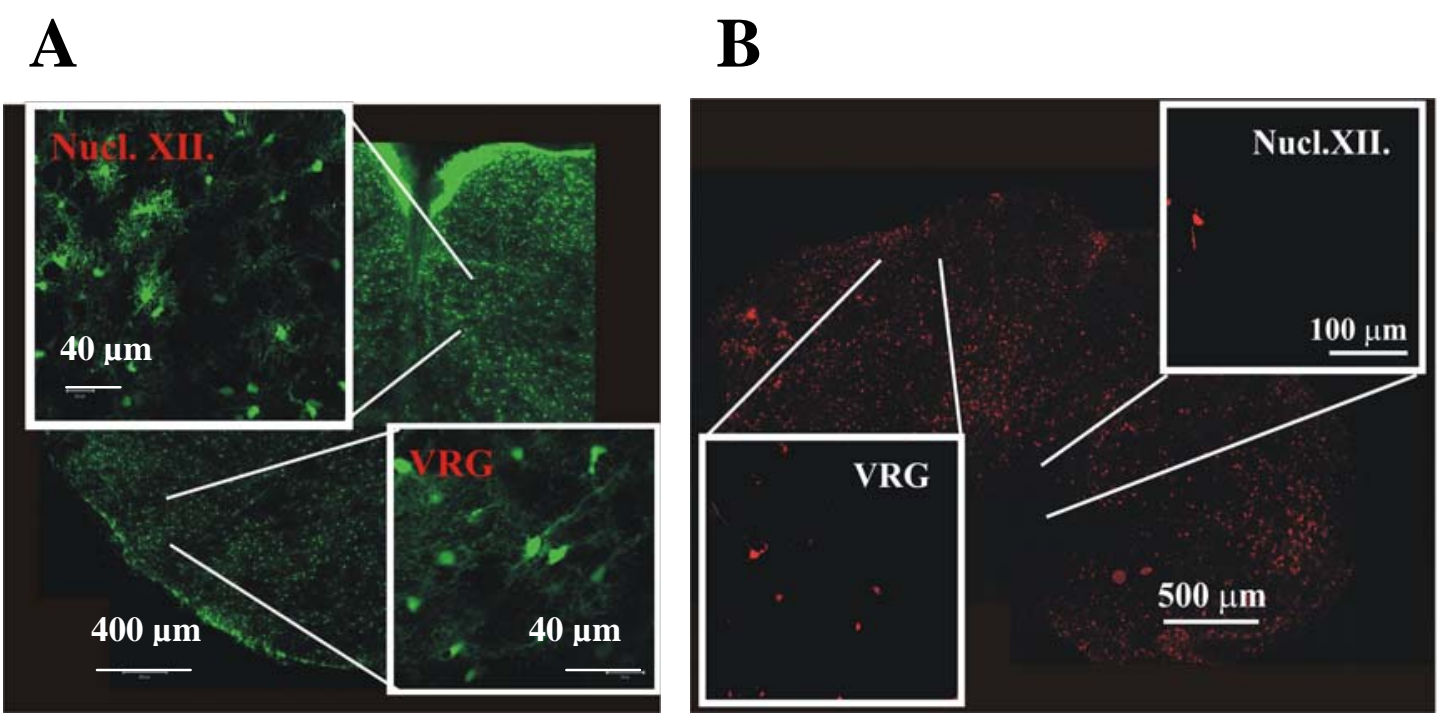

Figure 3. The transgenic mice

(A) shows a confocal image of a slice from the caudal brainstem of the TgN (hGFAP/EGFP) mouse. The ependyma is strongly green as ependyma cells express the GFAP. (B) shows a confocal image of a lower brainstem slice from the TgN (mPLP/DsRed) mouse, at the age of p10. At this age, oligodedrocytes are labelled widespread, including the VRG, while in the Nucleus hypoglossus, labelled oligodendrocytes are rarely seen. 


\subsection{Plethysmography}

To analyze breathing of newborn (p0) mice, plethysmographic measurements were performed at room temperature using a $10 \mathrm{ml}$ whole-body plethysmographic chamber. Whole-body plethysmography allows a noninvasive registration of the breathing, based mainly on the fact that warming up of a gas under constant volume increases the pressure, thus the pressure in the chamber increases during inspiration as the air becomes warmed and humidified, and decreases during expiration (Mortola et al, 1998).

Pressure fluctuations were measured with a differential low pressure transducer (model DP103, Validyne Engineering, Northridge, CA) connected to a sine wave carrier demodulator (CD-15), which enhanced and transformed them into electric voltage signals (Figure 4A). Data were recorded using Clampex 9.2 software (Axon Instruments) and stored for later off-line analysis. Breathing movements were monitored for $3 \mathrm{~min}$. Artifacts originating from spontaneous limb movements were excluded from analysis (Figure 4). The analysis was performed with AxoGraph 4.6 software (Axon Instruments).
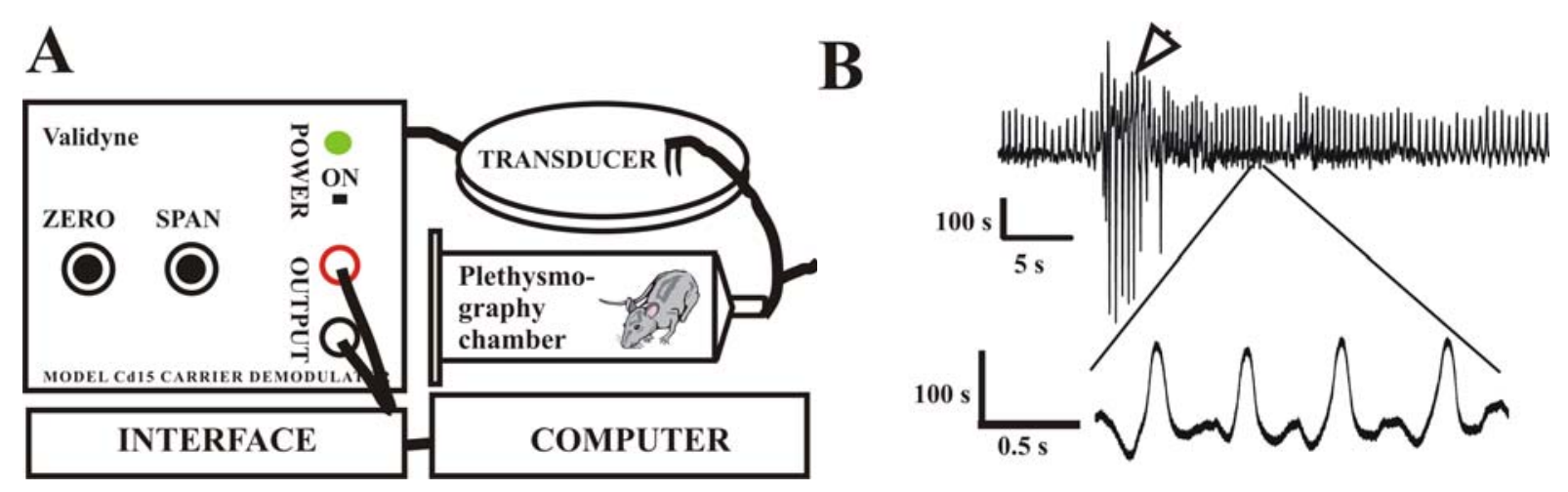

Figure 4. Whole-body plethysmography

(A) shows the system for plethysmographic measurement. The chamber in which the animal is placed is a $10 \mathrm{ml}$ syringe, which is connected to the differential low pressure transducer.

(B) shows a typical recording from a healthy animal, the arrow points to a place with movement artifacts. Below a place without movement artifact is shown at higher magnification.

\subsection{Slice preparation from mouse brain stem}

Brainstem slices were prepared as previously described (Hülsmann et al., 2000). Mice were killed by decapitation. The brain and upper cervical spinal cord were isolated in ice-cold artificial cerebrospinal fluid (ACSF, pH7.4, 310 mOsmol/l, content shown in Table 3), which was saturated with carbogen $\left(95 \% \mathrm{O}_{2}, 5 \% \mathrm{CO}_{2}\right)$. 


\begin{tabular}{|l|l|l|}
\hline Ingredient & Concentration & Origin \\
\hline $\mathrm{NaCl}$ & $118 \mathrm{mM}$ & Merck 1.06404.1000 \\
\hline $\mathrm{KCl}$ & $3 \mathrm{mM}$ & Merck, 1.04936.0500 \\
\hline $\mathrm{CaCl}_{2}$ & $1.5 \mathrm{mM}$ & Sigma, C3881 \\
\hline $\mathrm{MgCl}_{2}$ & $1 \mathrm{mM}$ & Merck, 1.05833.0250 \\
\hline $\mathrm{NaH}_{2} \mathrm{PO}_{4}$ & $1 \mathrm{mM}$ & Merck, 1.06346.0500 \\
\hline $\mathrm{NaHCO}_{3}$ & $25 \mathrm{mM}$ & Fluka Chemika, 71628 \\
\hline D-glucose & $30 \mathrm{mM}$ & Merck, 1.08342.2500 \\
\hline
\end{tabular}

Table 3: Content of the artificial cerebrospinal fluid (ACSF)

The brainstem was isolated, and consecutively glued with a cyano-acrylate glue (RotiColl1, Roth, 0258.1) to an agar block with its rostral end directed upwards and placed over the stage of a vibratome (FTB Vibracut, schematic drawing shown in Figure 5). The medulla was sliced starting from its rostral end. The frontal plane was reclined by approximately $20^{\circ}$ to the horizontal plane (Figure 5). For rhythmic slices, $700 \mu \mathrm{m}$ thick slices were prepared and for whole-cell recording $300 \mu \mathrm{m}$ thick transverse slices were prepared from the medulla in cold oxygenated ACSF. After 30 minutes, these slices were transferred to the recording chamber, placed under a nylon mesh glued to a U-shaped platinum wire and continuously perfused with oxygenated ACSF. Experiments were performed at room temperature, only for the recording of the rhythmic activity did we use ACSF pre-heated at $30^{\circ} \mathrm{C}$.

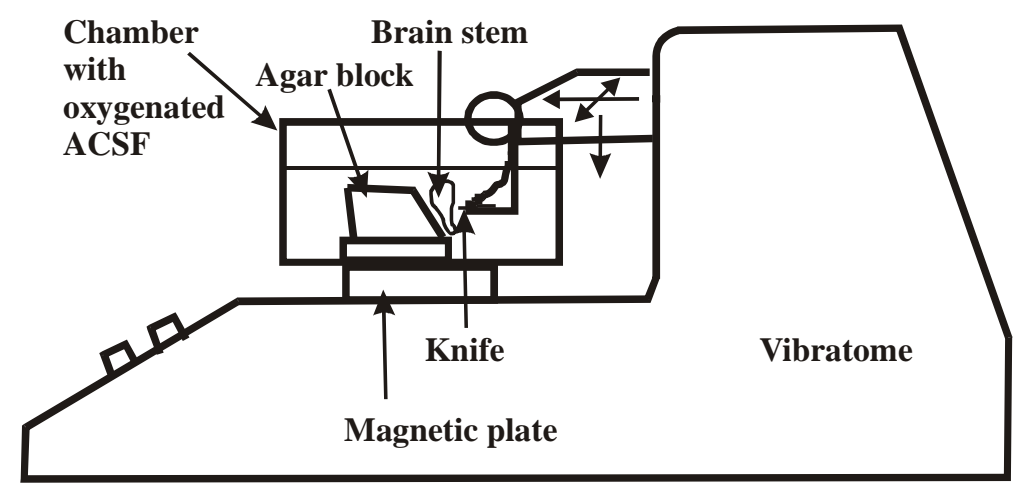

Figure 5. Preparation of the slices

The figure shows the vibratome. The brainstem is placed on its dorsal surface and glued at both sides to an agarblock, which closes an angle with the horizontal plate so that the ventral surface of the brain stem will be vertical. The agarblock is fixed into a chamber, which is filled with oxygenated ACSF in order to keep the cells alive. The blade of the vibratome is replaced between preparations. Transverse slices from the brainstem are prepared moving forward while vibrating to the sides. It moves from rostral to caudal in the brain stem as it is moved from up to down. 


\subsection{The "rhythmic slice preparation": recording of the in vitro respiratory rhythm}

From the caudal brainstem a $700 \mu \mathrm{m}$ thick transverse slices was prepared, which contained the intact pre-Bötzinger complex as rhythm generator and the synaptically connected hypoglossal nucleus as motor output. It was superfused with ACSF pre-warmed to $30^{\circ} \mathrm{C}$, and the amount of the $\mathrm{KCl}$ in the ACSF was increased to $8 \mathrm{mM}$, to stabilize the rhythmic activity. From this slice, a respiration-related rhythmic burst activity was recorded by a surface electrode, either from the hypoglossal rootlets, or from the slice surface that exposed the pre-Bötzinger complex. This represents the in vitro respiratory rhythm. The respiration-related burst discharges were amplified by a custom-made differential amplifier, filtered, rectified and then integrated. Data were recorded with Clampex 9.2 software and analyzed by AxoGraph 4.6 software. Respiratory frequencies were calculated as the reciprocal values of the mean expiratory interval (Figure 6).

Different substances were applied into the bath solution during the recording of the rhythmic activity to modulate different pathways of neurotransmission (Table 4).

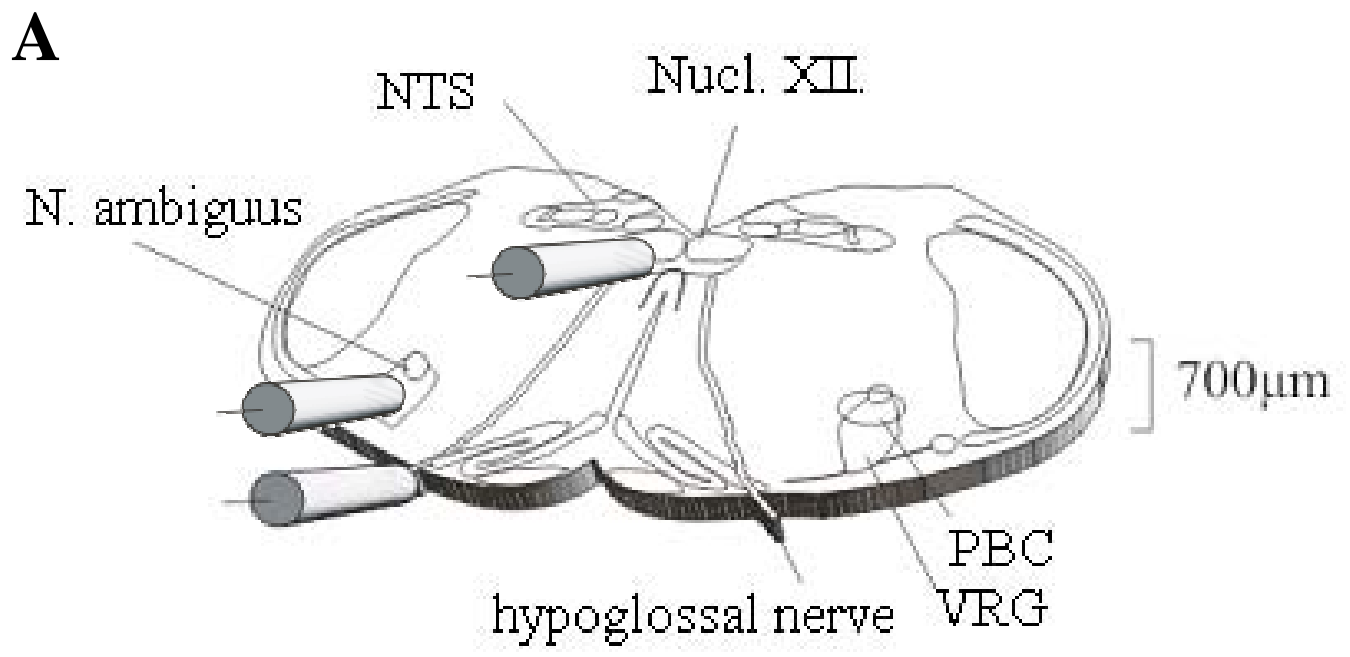

B

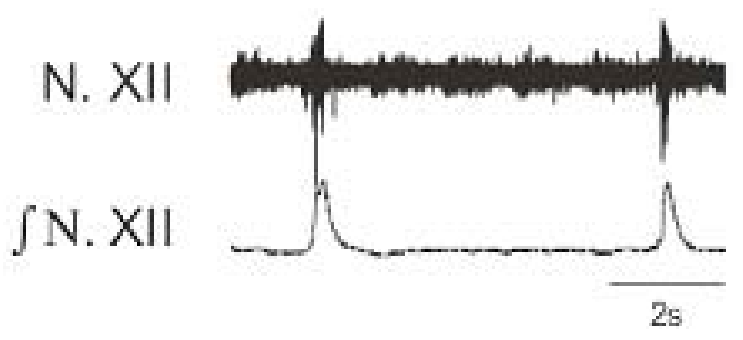

Figure 6. Rhythmic slice

(A) shows the rhythmic slice from the caudal brain stem. Schematic electodes mark the places where rhythmic activity can be recorded by a surface electrode: the hypoglossus nerve (hypoglossus rootlet, electrode left below), the pre-Bötzinger complex (electrode left above) or the Nucleus hypoglossus (electrode right). (B) shows a typical recording of the burst activity and the integral of the bursts are shown. 


\begin{tabular}{|l|l|l|l|}
\hline Drug & Function & Origin & Concentration \\
\hline Bicuculline & GABA $_{A}$ blocker & Sigma, B6889 & $0.2-20 \mu \mathrm{M}$ \\
\hline DL-AP5 & NMDA blocker & Tocris, 0105 & $100 \mu \mathrm{M}$ \\
\hline Glycine & Neurotransmitter & Sigma, G6761 & $1 \mathrm{mM}$ \\
\hline MK801 & NMDA blocker & Tocris, 0924 & $10 \mu \mathrm{M}$ \\
\hline Sarcosine & GlyT1 blocker & Sigma, S9881 & $0.1,0.5,1$ and $2 \mathrm{mM}$ \\
\hline Strychnine & GlyR blocker & Sigma, S8753 & $2 \mu \mathrm{M}$ \\
\hline
\end{tabular}

Table 2-1. Drugs applied in experiments with rhythmic slices

\subsection{Whole-cell voltage-clamp recording}

The patch-clamp technique, developed in 1976 by Erwin Neher and Bert Sakmann and awarded with Nobel Prize in 1991, is an electrophysiological method that allows the recording of macroscopic whole cell or microscopic single-channel currents flowing across biological membranes through ion channels. Patch-clamp can be performed in four different configurations: cell attached, whole cell, inside-out and outside-out, shown in Figure 7.

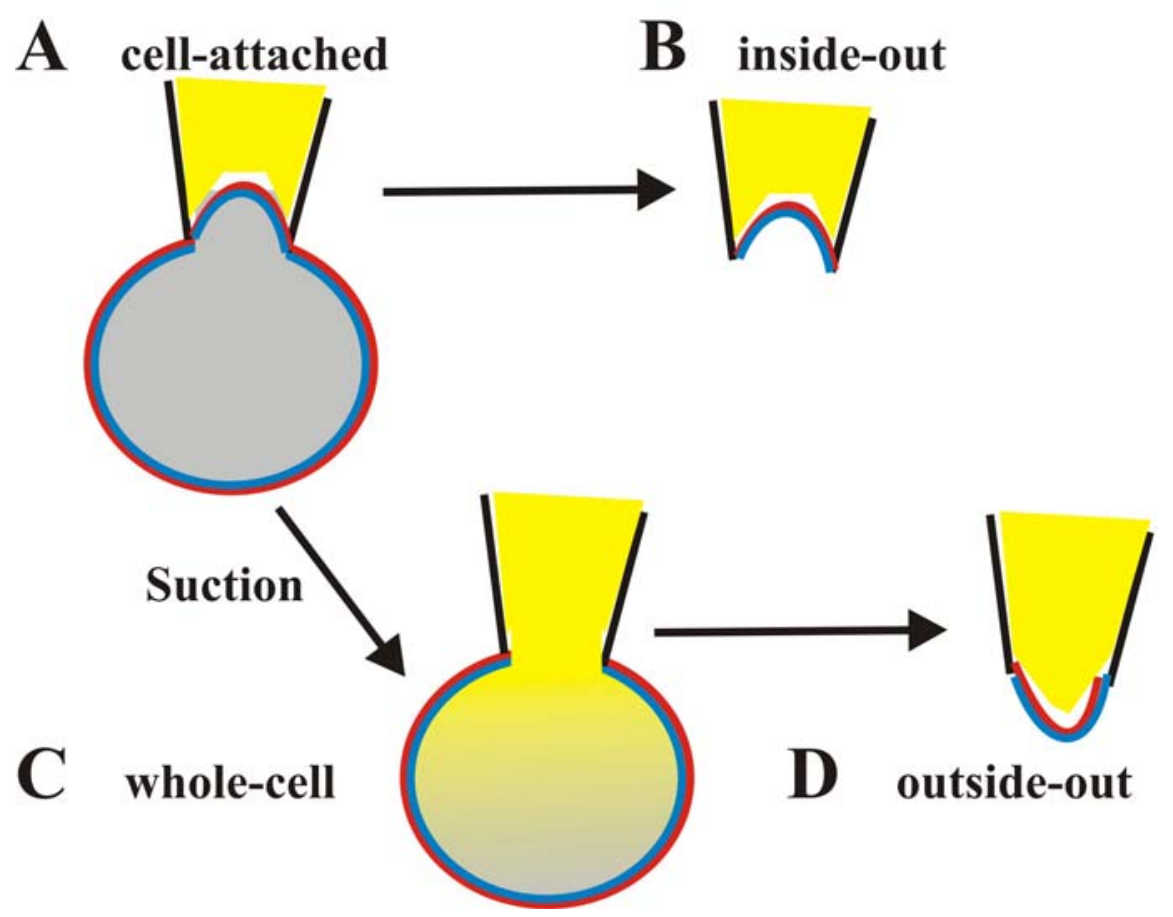

Figure 7. The four configurations of patch-clamp

(A) shows the cell-attached configuration which is in fact a tight seal. From this configuration, an inside-out membrane patch can be excised (B) or by opening the seal, the whole cell configuration is achieved (C). Outside-out membrane patches (D) can be prepared from whole-cell configuration by carefully pulling away the pipette. 
In principle there are two possibilities for patch-clamp recording: voltage-clamp and current clamp. In voltage-clamp the membrane potential is held constant (clamped) at predeterminated levels, which causes current flowing through the membrane. The resulting change in potential is prevented by injecting an equal and opposite amount of current. In current clamp the current flowing through the membrane is held at a constant level, allowing voltage changes.

In this thesis the whole-cell voltage-clamp configuration was used, which allows us to record from cells and modify their internal environment by using a patch-clamp pipette, and is employed to record ion currents of the entire cells. The patch-pipette was connected to the current-measuring electrical circuit through an $\mathrm{Ag} / \mathrm{AgCl}$ electrode, which was in contact with the electrolyte in the pipette.

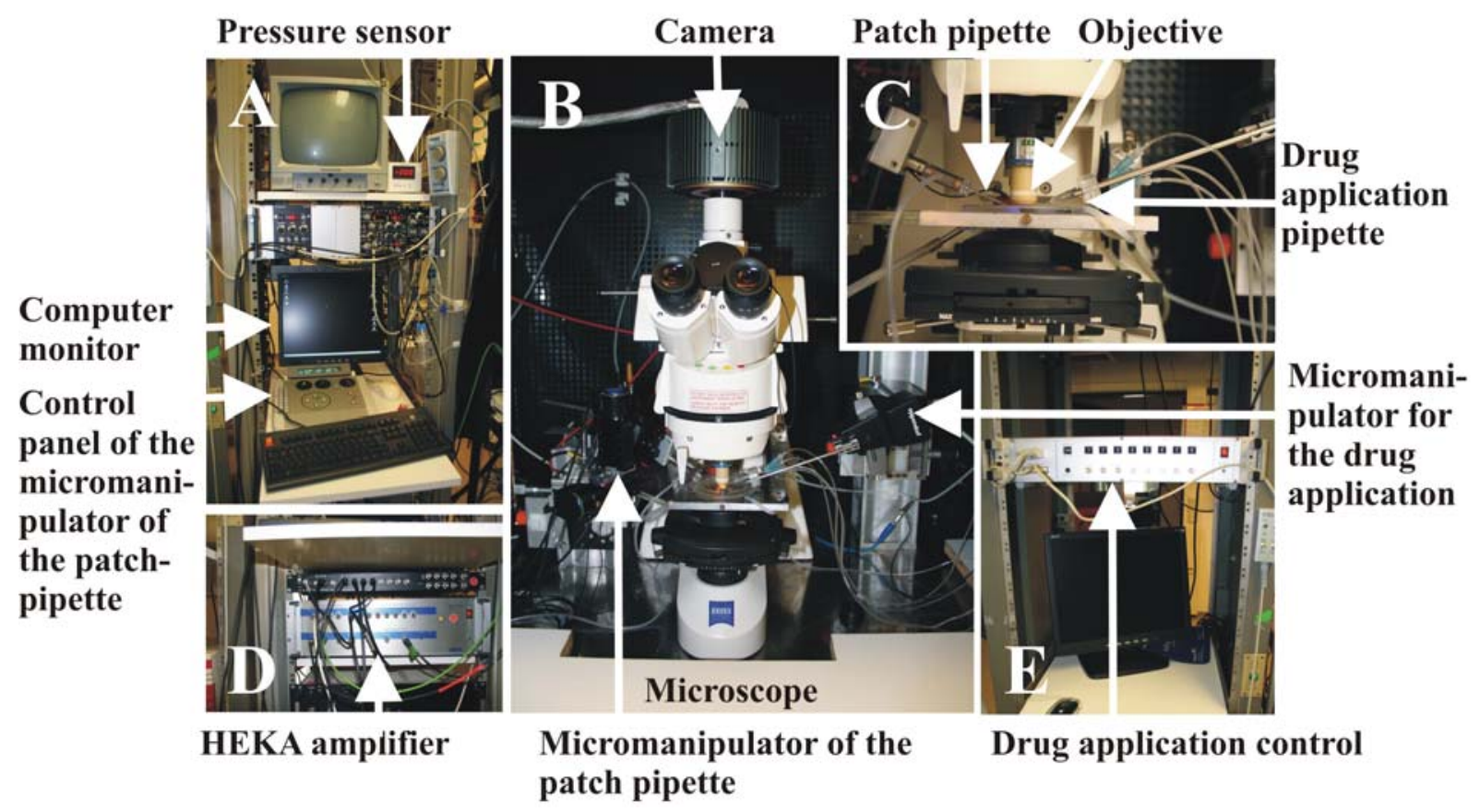

Figure 8. The patch-clamp setup

Pictures are shown from different parts of the patch-clamp setup used for the experiments. In (B) the microscope is shown, the patch electrode is placed on the left side while the drug application pipette is on the right side. (C) shows in higher magnification the objective immersed into the recording chamber and the patch pipette and drug application pipette. In (E) the control of the drug application system is shown, in (D) the HEKA amplifier and in (A) different other parts of the patch-clamp setup including a pressure sensor and the control panel of the micromanipulator for the patch pipette. 
Figure 8 shows the different parts of the patch-clamp setup used for the experiments. The perfusion chamber (Figure 8C) was mounted on the stage of an upright microscope (Axioscope FS 2, Zeiss, Göttingen, Germany; Figure 8B). Astrocytes or oligodendrocytes were identified by their characteristic color in the epi-fluorescent illumination (Figure 3). A computer-controlled monochromator based on a galvanometric scanner (Polychrome II, TILL Photonics, Munich, Germany) was connected to the microscope via quartz fiber optics (diameter $1.25 \mathrm{~mm}$, NA 0.25) to allow fluorescent excitation at $460 \mathrm{~nm}$ for astrocytes and $546 \mathrm{~nm}$ for oligodendrocytes (objective Achroplan W 63', 0.9 W).

Voltage-clamp recordings were obtained in whole cell configuration and signals were amplified using an EPC-9 amplifier (HEKA, Lambrecht, Germany; Figure 8D). Patch electrodes were pulled from borosilicate glass capillaries (o.d. $=1.5 \mathrm{~mm}$, i.d. $=0.86 \mathrm{~mm}$, Biomedical Instruments, Germany) on a programmable pipette-puller (Zeitz; Germany). They had tip diameters of about $2 \mu \mathrm{m}$ and were filled with electrode solution (content shown in Table 5, pH adjusted to 7.0 with $\mathrm{KOH})$. Electrodes had resistances of 3-6 $\mathrm{M} \Omega$.

\begin{tabular}{|l|l|l|}
\hline Ingredient & Concentration & Origin \\
\hline $\mathrm{KCl}$ & $140 \mathrm{mM}$ & Merck, 1.04936.0500 \\
\hline $\mathrm{CaCl}_{2}$ & $1 \mathrm{mM}$ & Sigma, C3881 \\
\hline $\mathrm{EGTA}$ & $10 \mathrm{mM}$ & Sigma E4378 \\
\hline $\mathrm{MgCl}_{2}$ & $2 \mathrm{mM}$ & Merck, 1.05833.0250 \\
\hline $\mathrm{Na}_{2} \mathrm{ATP}$ & $4 \mathrm{mM}$ & Sigma, A2383 \\
\hline $\mathrm{HEPES}$ & $10 \mathrm{mM}$ & Biomol, 05288 \\
\hline
\end{tabular}

Table 5. Content of the pipette solution

When mentioned, potassium chloride was replaced by potassium gluconate (Sigma, G4500).

Positive pressure was applied to the recording pipette before immersing it in the bath to prevent any drebris touching the tip of the pipette. After the pipette has entered the bath the offset potential between pipette and reference electrode was corrected. The pipette was then lowered under microscopic control and advanced toward the cell using an electronic micromanipulator (Eppendorf InjectMan NI2, Hamburg, Germany, or Luigs and Neumann SM5, Ratingen, Germany; control panel shown in Figure 8A, the micromanipulator in Figure $8 \mathrm{~B})$. The process of seal formation was monitored by observing currents in response to test pulse (10 $\mathrm{mV}$ and $-10 \mathrm{mV}$ for $5 \mathrm{~ms}$ ). The gigaseal was obtained after releasing the pressure, following in some case by gentle application of negative pressure. After forming the gigaseal, 
the pipette potential was changed toward the resting membrane potential, $-80 \mathrm{mV}$. Fast capacitance compensation was done to cancel the transient caused by the capacitance of the pipette holder and pipette wall. The patch of membrane enclosed within the tip of the pipette was ruptured by applying short suction or by applying short hyperpolarizing voltage pulses (about 1 V, 10-500 $\mu \mathrm{s}$; zapping). Electrical access to cell interior was indicated by a sudden increase in the capacitive transients from the test pulse and a change in the current response to the test pulse. This reflects the contribution of the cell membrane to the pipette capacitance.

To define the cells according to electrophysiological criteria, a voltage step protocol was applied from $-160 \mathrm{mV}$ to $+70 \mathrm{mV}$ in 24 steps, increasing the voltage in $10 \mathrm{mV}$ intervals. Each step had a duration of $200 \mathrm{~ms}$, after which the potential reversed to the original holding potential for $200 \mathrm{~ms}$ until the next voltage step was performed (Figure 9).

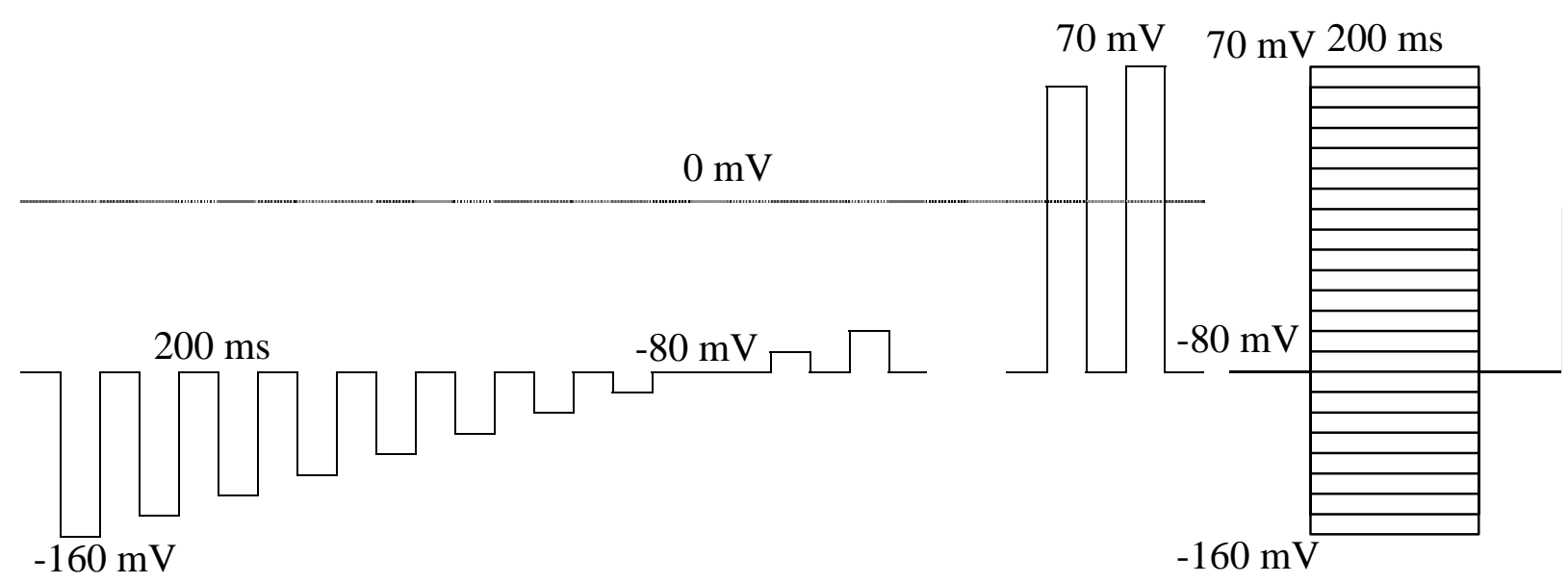

\section{Figure 9. The voltage-step protocol}

The figure shows the voltage-step protocol used for analysis of the IV relationship of the cell: $200 \mathrm{~ms}$ long voltagesteps from $-160 \mathrm{mV}$ to $70 \mathrm{mV}$ in $10 \mathrm{mV}$ steps. On the right a schematic figure is shown how it is commonly depicted as overlay figure. Similar overlay figures were used for the presentation of the recorded currents (IV curve).

Drugs (Table 6) were applied either to the bath or locally by pressure ejection from a micropipette or by a fast application system into the perfusion chamber next to the cell.

For pressure ejection, we used a PDES-O2D device (npi electronics, Tamm, Germany). Drugs were applied using 2 bar pressure and $20 \mathrm{~ms}$ application time from a micropipette, identical to the patch pipette, placed approximately in $10 \mu \mathrm{M}$ distance from the cell. Three consecutive recordings were averaged (Oku et al, 1999).

For fast application, a PF-8 8-channel perfusion system (ESF electronic, Göttingen, Germany; the control panel is shown in Figure 8E) was used, by which the fluid flow in an application capillary (Figure 8C) could be quickly changed from one substance to another. 


\begin{tabular}{|l|l|l|l|l|}
\hline Drug & Function & Origin & Concentration & Application \\
\hline Bicuculline & GABA A blocker & Sigma, B6889 & $20 \mu \mathrm{M}$ & Bath \\
\hline CGP55845 & GABA B blocker & Tocris, 1248 & $10 \mu \mathrm{M}$ & Bath \\
\hline D-Aspartate & GLT substrate & Sigma, A8881 & $200 \mu \mathrm{M}$ & Bath \\
\hline DL-AP5 & NMDA blocker & Tocris, 0105 & $100 \mu \mathrm{M}$ & Bath \\
\hline DNQX & AMPA blocker & Tocris, 0189 & $20 \mu \mathrm{M}$ & Bath \\
\hline GABA & Neurotransmitter & Sigma, A5835 & $200 \mu \mathrm{M}$ & Bath \\
\hline Glycine & Neurotransmitter & Sigma, G6761 & $1 \mathrm{mM}$ & Bath \\
\hline Glycine & Neurotransmitter & Sigma, G6761 & $2 \mathrm{mM}$ & Perfusion \\
\hline Glycine & Neurotransmitter & Sigma, G6761 & $100 \mathrm{mM}$ & Pressure ejection \\
\hline Strychnine & GlyR blocker & Sigma, S8753 & $10 \mu \mathrm{M}$ & Bath \\
\hline Strychnine & GlyR blocker & Sigma, S8753 & $20 \mu \mathrm{M}$ & Perfusion \\
\hline TTX & Postsynaptic block & Alomone labs T-500 & $500 \mathrm{nM}$ & Bath \\
\hline
\end{tabular}

Table 6.: Drugs applied in whole-cell voltage-clamp experiments

Recordings were digitized at $10 \mathrm{kHz}$ using an interface of the EPC-9 (ITC-16, HEKA, Germany) and Pulse software (v 8.10, HEKA, Lambbrecht, Germany). Current responses were additionally stored at the same time for off-line analysis using the AxoGraph software (v 4.6, Axon). Whole-cell currents were filtered at $2.8 \mathrm{kHz}$ with a Bessel filter. Current responses to voltage-step protocol were analysed with IGOR Pro (Wavemetrics, Oregon, USA). Maximal current responses after application of a substance were manually determinated using AxoGraph 4.6 in the case of bath application, or with IGOR Pro in the case of pressure ejection or fast application. Results are expressed as means \pm standard deviation (SD), significance was determined by Sigma Plot software (SPSS, Chicago, USA) using the Student's T-test. 


\subsection{Single-cell reverse transcription PCR}

The polymerase chain reaction (PCR) method was invented in 1986 by Kary Mullis, and awarded with the Nobel Prize in 1993. PCR is used to amplify a short, well-defined part of a DNA strand, usually up to $10 \mathrm{~kb}$. The process consists of a series of twenty to thirty cycles, with each cycle consisting of three steps carried out in a thermal cycler: (1) denaturation $\left(94-96^{\circ} \mathrm{C}\right)$, when the strands of the DNA are separated, (2) annealing $\left(45-60^{\circ} \mathrm{C}\right.$, depending on the primers), when the primers attach to the single DNA strands, and (3) elongation $\left(72^{\circ} \mathrm{C}\right)$, when the new DNA strand is synthesized. Figure 10 shows the amplification within the first 3 cycles of PCR.

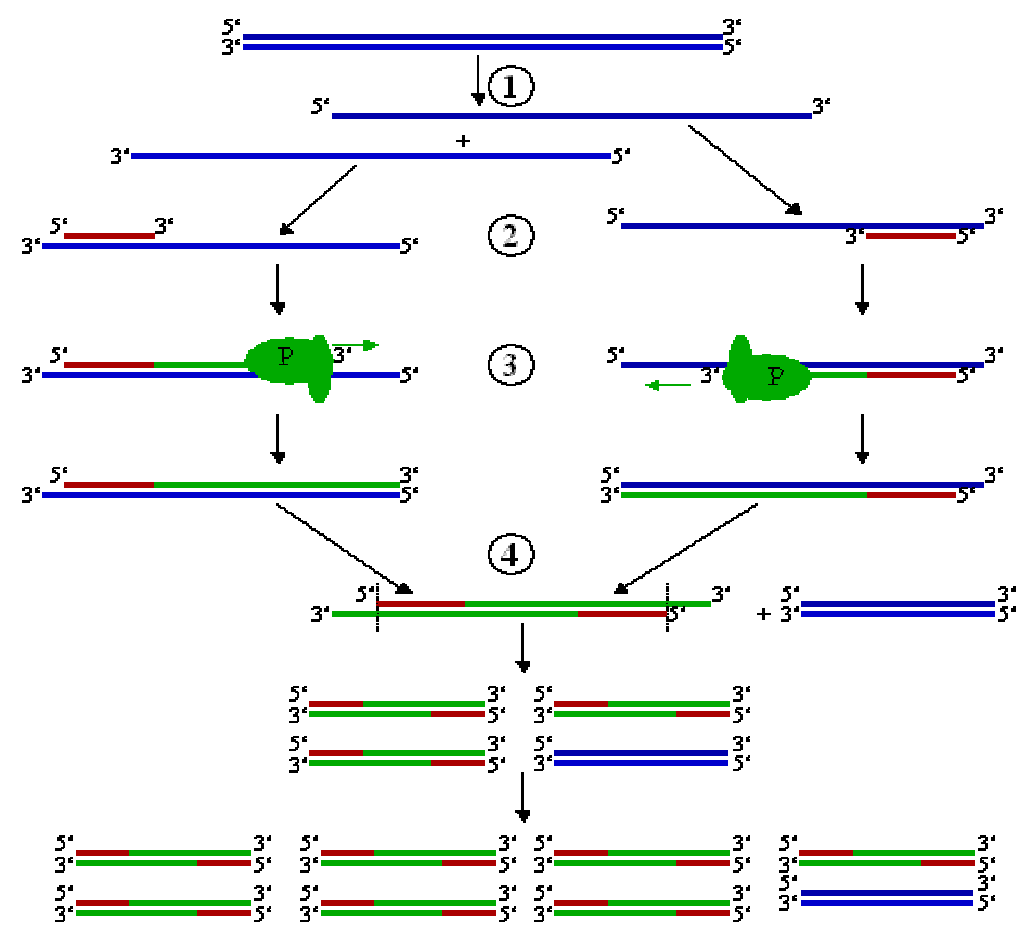

\section{Figure 10. The amplification of DNA during the PCR process}

The figure shows the amplification of the original DNA (blue) during 3 cycles of PCR. Already after the first three cycles most of the DNA is newly synthesized (Green is the newly synthesized DNA, red is the primer DNA). Figure from: http://de.wikipedia.org/wiki/Bild:PCR-pcr.png.

In our experiments we performed PCR using cDNA acquired from reverse transcription of the RNA content of a single cell. Multiplex nested PCR was carried out in two steps, which ensures a sufficient amplification to detect the presence of the cDNA transcribed from the mRNA of the investigated protein in a sample from a single cell. Primers were intron-spanning to detect only mRNA but no genomic DNA. 
Cells were whole-cell voltage clamped. After recording the IV-curve to define the cell type, the cytoplasm was harvested by careful suction into the recording pipette. Successful harvesting was confirmed by obvious change in the fluorescence of the cell and detection of fluorescence in the tip of the pipette (Figure 11).
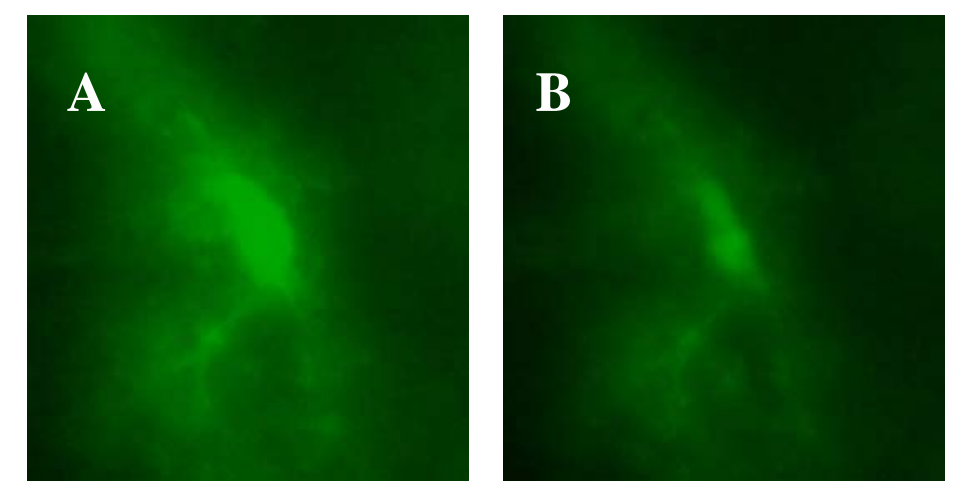

Figure 11. Harvesting cells for single-cell RT-PCR

The figure shows a bright fluorescent astrocyte before (A) and after (B) harvesting. The decrease of the fluorescence can be observed as the cytoplasm of the cell is sucked into the pipette.

The pipette content was transferred into a PCR tube (cap strips, Eppendorf, 0030127.498) filled with $5 \mu$ l reverse transcription reaction mix by breaking the tip of the pipette and expelling approximately $5 \mu \mathrm{l}$ solution under positive pressure.

The reaction mix contained: $2.0 \mu \mathrm{l}$ random nonamer primer (DNA facility of the Max Planck Institute for Experimental Medicine),

$0.5 \mu \mathrm{l}$ dNTPs (each 2mM; Boehringer-Mannheim),

$1.0 \mu \mathrm{l} 51^{\text {st }}$ strand buffer (Invitrogen ${ }^{\mathrm{TM}} 18064-014$ ),

$1.0 \mu \mathrm{LTT}$ (0.1M, Invitrogen $\left.{ }^{\mathrm{TM}} 18064-014\right)$, and

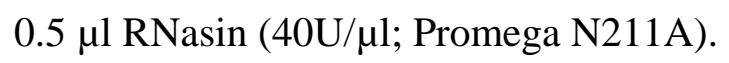

The RT reaction was initiated immediately by addition of $0.5 \mu$ l SuperScript ${ }^{\mathrm{TM}}$ II reverse transcriptase (200 U/ml; Invitrogen ${ }^{\mathrm{TM}}$ 18064-014). Single-strand cDNA synthesis was performed at $42^{\circ} \mathrm{C}$ for $1 \mathrm{~h}$. cDNA samples were stored at $-80^{\circ} \mathrm{C}$.

A two-round PCR was performed, using the product obtained after the first round as a template for the second round. The first PCR was run after adding the PCR mix to the RT product and adjusting it to the final volume, $50 \mu \mathrm{l}$. 
The PCR mix contained: $5.0 \mu \mathrm{l}$ 10x PCR buffer (Sigma D5684),

$5.0 \mu \mathrm{l}$ dNTPs (each $2 \mathrm{mM}$; Boehringer-Mannheim),

$2.5 \mu \mathrm{l} \operatorname{RedTaq}^{\mathrm{TM}}$ polymerase (1 U/ml; Sigma D5684) and

$1.0 \mu \mathrm{l}$ of the corresponding primers $(10 \mathrm{pmol} / \mu \mathrm{l}$, DNA facility of the Max Planck Istitute for Experimental medicine)

The PCR was carried out in a Tetrad ${ }^{\mathrm{TM}}$ thermocycler (MJ Research, BioRad). Fortyfive cycles were performed (denaturation at $94^{\circ} \mathrm{C}, 30 \mathrm{~s}$; annealing at $49^{\circ} \mathrm{C}, 2 \mathrm{~min}$ for the first 5 cycles, and $45 \mathrm{~s}$ for the remaining cycles; extension at $72^{\circ} \mathrm{C}, 25 \mathrm{~s}$; final elongation at $72^{\circ} \mathrm{C}$, 7 min). The primer pairs used in the first PCR round are shown in Table 7.

\begin{tabular}{|l|l|l|}
\hline & For GlyT1 & For actin \\
\hline Sense primer & CAGCCCCAGCGAGGAGTA & GATATCGCTGCG-CTGGTCGTC \\
\hline Antisense primer & GGGAAGCAGCGTGAGAGC & CATGGCTGGGGTGTTGAAGGTC \\
\hline
\end{tabular}

Table 7. Primers used in the first PCR round

An aliquot $(3 \mu \mathrm{l})$ of the product of the first round was used as template for the second PCR (25 cycles; annealing at $57^{\circ} \mathrm{C}$ (GlyT1) and $54^{\circ} \mathrm{C}$ (actin); first 5 cycles, 2 min; remaining cycles, $45 \mathrm{~s}$ ) using nested primers. The primer pairs used in the second PCR round are shown in Table 8.

\begin{tabular}{|l|l|l|}
\hline & For GlyT1 & For actin \\
\hline Sense primer & GGCGTCTCCTGGGTGGTT & CGTGGGCCGCCCTAGGCACCA \\
\hline Antisense primer & CGAAGCCGGCGTAGAGC & CTTAGGGTTCAGGGGGG \\
\hline
\end{tabular}

Table 8. Primers used in the first PCR round

The reaction conditions were the same as those in the first round. Products were identified by agarose gel electrophoresis (1.5\%; stained with ethidium bromide) using a 100 bp molecular weight marker. The expected fragment lengths were 355 bp for GlyT1 and 238 bp for actin. 


\subsection{Immunohistochemistry}

The immunostaining process, which is called immunocytochemistry in the case of cultured cells and immunohistochemistry in the case of histological preparations, is based on an antibody binding to its epitope on the antigen. The antibody is used to link a cellular antigen specifically to a stain that can be seen under a microscope (Figure 12).

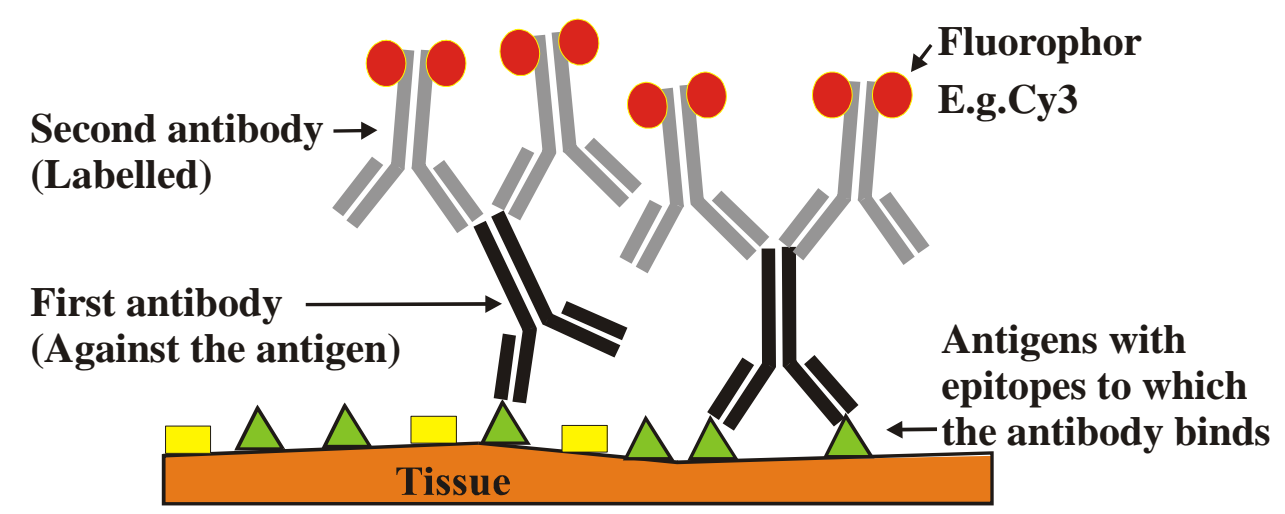

Figure 12. The principle of the immunostaining

A schematic figure of the two-step indirect method of the immunohistochemistry, which was used in our experiments. The unconjugated first antibody binds to its epitope . The fluorescent dye or enzyme labeled second antibody is raised against immunglobulins in a species-specific manner. Directed against the species in which the first antibody was raised, it will bind to the first antibody.

Immunostaining on brainstem slices from the transgenic mice was performed as described in Zafra et al (1995a).

$250 \mu \mathrm{m}$ acute slices were prepared from brainstem of transgenic animals at the age of p0 to p7 similar to patch-clamping, and fixed in 4\% paraformaldehyde (Sigma HT5014). 100 $\mu \mathrm{m}$ slices were prepared from the paraformaldehyde-perfused brain of a p10 TgN (mPLP/DsRed) mouse, similar to methods described in Graß et al (2004).

In the first step, the slices were washed (3x1 min and 2x15 min) in PBS, which contained: $\quad 158.0 \mathrm{mM} \mathrm{NaCl}$ (Merck, 1.06404.1000),

2.7 mM KCl (Merck, 1.04936.0500),

$8.1 \mathrm{mM} \mathrm{Na}_{2} \mathrm{HPO}_{4}$ (Roth, P030) and

$1.4 \mathrm{mM} \mathrm{KH}_{2} \mathrm{PO}_{4}$ (Roth, P018), $\mathrm{pH}$ adjusted to 7.4.

To neutralize the aldehyde groups remaining from the paraformaldehyde fixation, the slices were incubated for $30 \mathrm{~min}$ in a buffer containing:

1.0 M ethanolamine (Sigma, E6133) and

$0.1 \mathrm{M} \mathrm{NaH}_{2} \mathrm{PO}_{4}$ (Merck, 6346), $\mathrm{pH}$ adjusted to 7.4. 
washed for 1 min in PBS, and

incubated in Tris-buffer supplemented with 10\% fetal calf serum (FCS). The buffer contained:

$0.3 \mathrm{M} \mathrm{NaCl}$ (Merck, 1.06404.1000) and

0.1 M Tris-HCl (Roth, $5429+\mathrm{HCl}$ ), $\mathrm{pH}$ adjusted to 7.4.

Slices were incubated overnight $\left(12 \mathrm{~h}\right.$ at room temperature, or $24 \mathrm{~h}$ at $\left.4^{\circ} \mathrm{C}\right)$ with first antibodies in Tris-buffer supplemented with 1\% FCS. Antibodies were diluted for GlyT1 1:200 (final concentration about $2 \mathrm{ng} / \mu \mathrm{l}$ ), for GlyR, NG2 and connexin 43 (Sigma C6219) 1:100 and for GLAST (Chemicon, AB1782) 1:1000. After incubation, slices were washed (3x1 min and 2x15 min) in Tris-buffer with 1\% FCS, and incubated for 1h with fluorescently labeled (Cy3 and Cy5 conjugated) second antibodies (Dianova, Jackson ImmunoResearch Lab Inc). Table 9 shows the first and second antibody pairs we used for the experiments. Finally slices were washed in Tris-buffer ( $3 \times 1 \mathrm{~min}$ and 2x $15 \mathrm{~min}$ ), rinsed in PBS and mounted in Aqua Poly/Mount (Polysciences Inc., 18606). The embedded slices were analyzed under a Zeiss LSM 510 Meta confocal laser scanning microscope.

\begin{tabular}{|l|l|l|l|}
\hline First antibody & Second antibody & Co-staining first AB & Co-staining 2 $^{\text {nd }}$ AB \\
\hline Anti-GlyT1 & Anti-Rabbit Cy3 & - & - \\
\hline Anti-GlyT1 & Anti-Rabbit Cy5 & - & - \\
\hline Anti-GlyT1 & Anti-Rabbit Cy3 & Anti-NG2 & Anti-Rat Cy5 \\
\hline Anti-GlyT1 & Anti-Rabbit Cy5 & Anti-NG2 & Anti-Rat Cy3 \\
\hline Anti-GlyT1 & Anti-Rabbit Cy3 & Anti-GLAST & Anti-Guinea Pig Cy5 \\
\hline Anti-GlyT1 & Anti-Rabbit Cy5 & Anti-GLAST & Anti-Guinea Pig Cy3 \\
\hline Anti-Connexin & Anti-Rabbit Cy3 & Anti-NG2 & Anti-Rat Cy5 \\
\hline Anti-GlyR & Anti-Mouse Cy3 & - & - \\
\hline Anti-GlyR & Anti-Mouse Cy3 & Anti-GlyT1 & Anti-Rabbit Cy5 \\
\hline Anti-GlyR & Anti-Mouse Cy3 & Anti-NG2 & Anti-Rat Cy5 \\
\hline
\end{tabular}

Table 9. Antibodies used for the experiments

In the case of GlyR-NG2 co-staining, the anti-mouse second antibody interacted with the rat NG2 first antibody, as they were from related species. To prevent cross-reaction, the NG2 staining was performed consecutively after the GlyR staining.

The GlyT1 antibody was kindly donated by Fransisco Zafra (Madrid), the GlyR antibody against both $\alpha 1$ and $\alpha 2$ subunits was a gift from Heinrich Betz (Frankfurt) and the NG2 antibody was a gift from Jacqueline Trotter (Mainz). 


\section{Results}

\subsection{Functional expression of glycine receptors and transporters on glial cells of the} respiratory network

\subsubsection{Expression of GlyT1 on astrocytes of the respiratory network}

To study the expression of GlyT1 on the different glial cell types of the respiratory network, immunocytochemistry was performed on acute slices from the caudal brainstem of transgenic mice expressing fluorescently labelled astrocytes or oligodendrocytes. The region of the ventral respiratory group was studied under a confocal laser-scanning microscope.

The GlyT1 expression on astrocytes was examined using TgN (hGFAP/EGFP) mice as a tool to visualize astrocytes. Immunohistochemistry was performed on acute slices from different ages (p0-p6). The antibody against GlyT1 stained preferentially cells with high EGFP expression level ("bright cells”)(Figure 13), which are electrophysiologically passive and intermediate cells (Graß et al, 2004). The staining was localized at the membrane, both at the soma and at the processes (Figure 14).

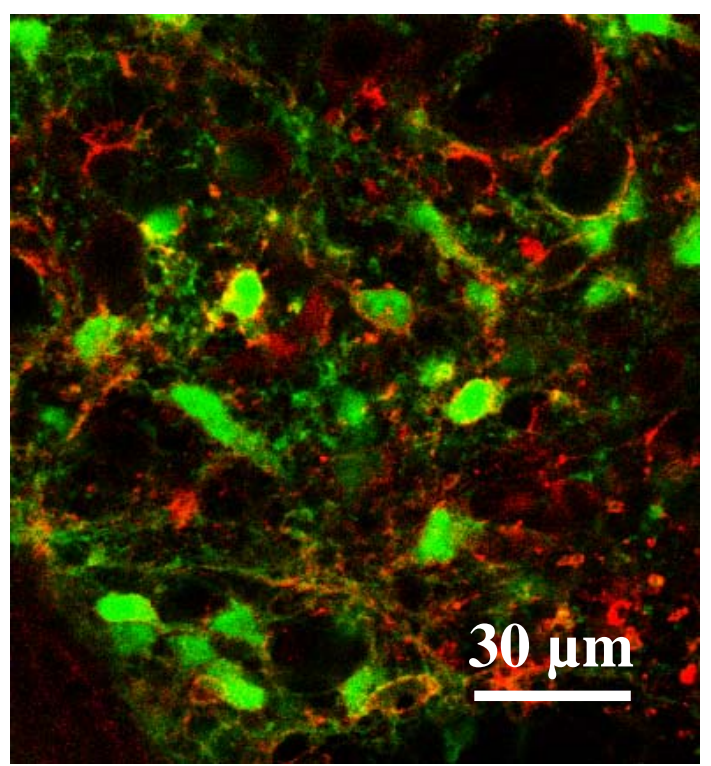

Figure 13. GlyT1 immunohistochemistry on acute slices from TgN (hGFAP/EGFP) mice

The figure shows an overview of the GlyT1 immunostaining (Cy3, red) on an acute slice of a p0 TgN (hGFAP/EGFP) mouse. GlyT1 expression can be observed predominantly on bright fluorescent astrocytes. 

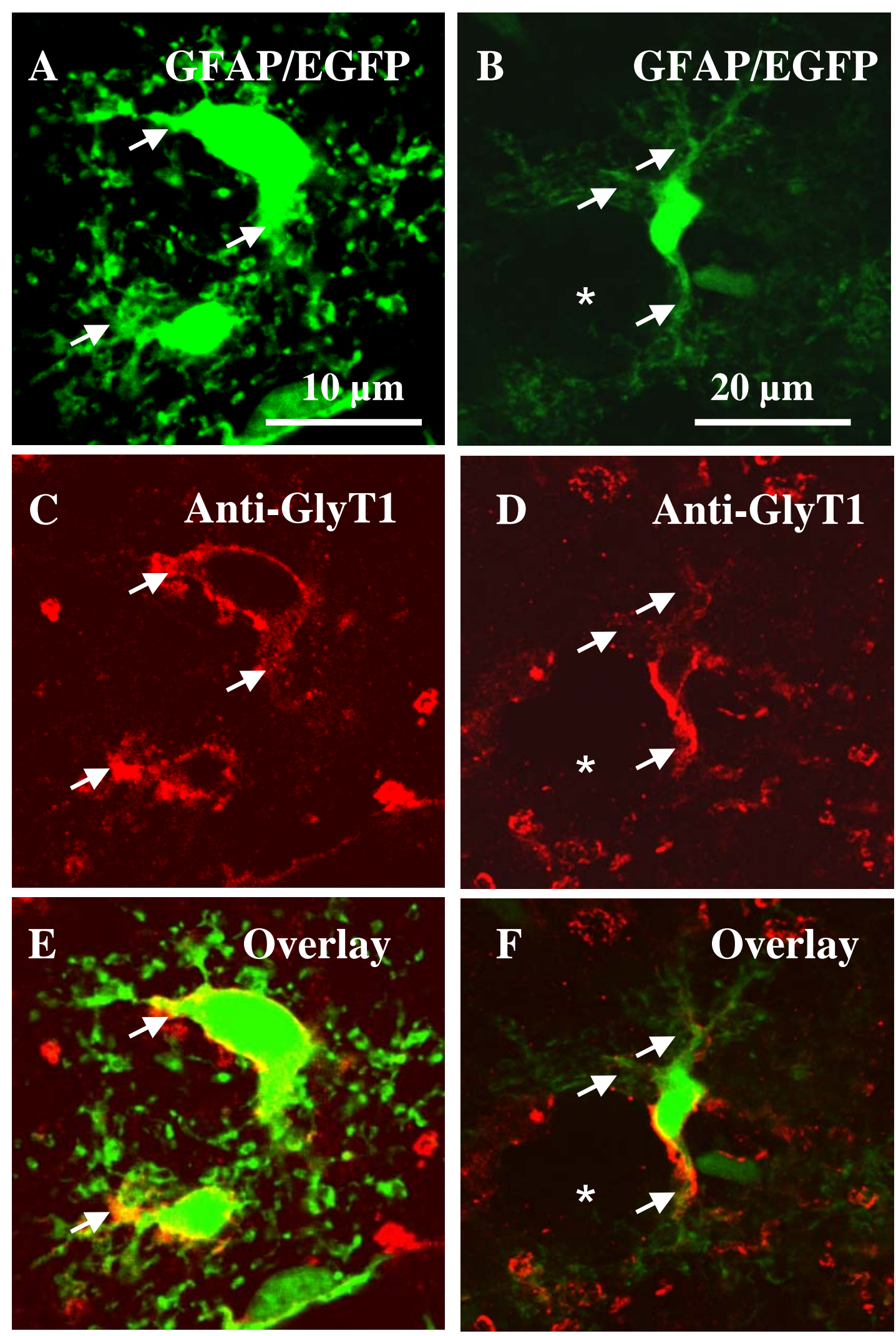

Figure 14: GlyT1 is expressed on processes of green fluorescent astrocytes

(A) and (B) show the EGFP fluorescence of astrocytes from the TgN (hGFAP/EGFP)mice, (C) and (D) the GlyT1 staining (Cy3, red) and (E) and (F) the overlay. The arrows point to processes where GlyT1 is expressed. The age of the animal was p5 in (A), (C), (E) and p6 in (B), (D), (F). The processes of the bright cell and the following GlyT1 staining shown in (B), (D), (F) surround a not labelled round area (labelled with asterix) which might represent a big neuron or a blood vessel. 


\subsubsection{Expression of GlyT1 on NG2+ glia}

NG2, a glial progenitor marker, was found to be expressed on cells with lower expression levels of EGFP (Graß et al, 2004). About half of these “dark cells” were electrophysiologically outwardly rectifying (Graß et al, 2004). Co-staining was performed for GlyT1 and NG2 in p1 and p2 mice to determine whether NG2+ cells express GlyT1, and no GlyT1/NG2 co-staining was found in green fluorescent cells (Figure 15).
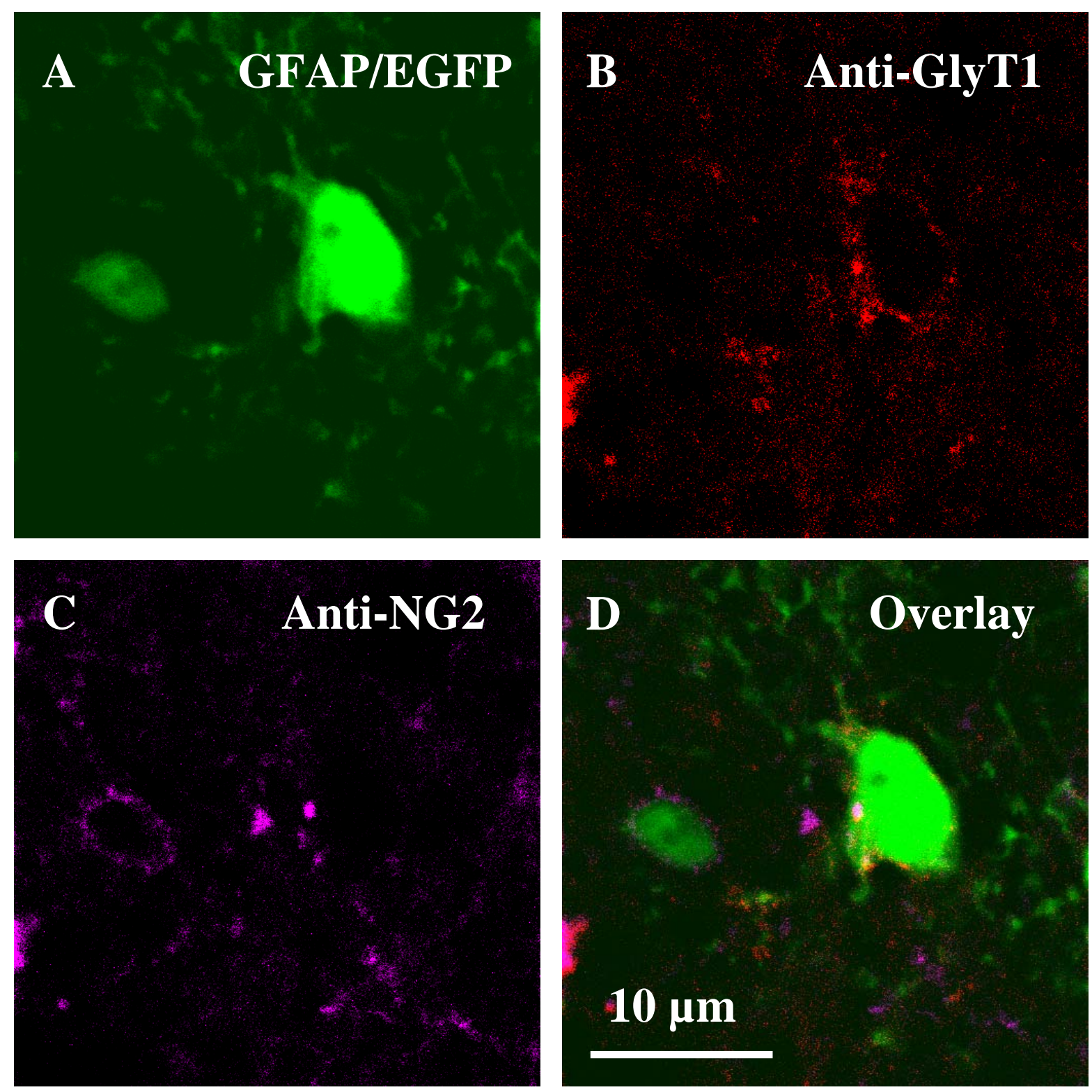

Figure 15: GlyT1/NG2 co-staining shows no GlyT1 staining on NG2+ cells

(A) shows the EGFP fluorescence of a bright and a dark fluorescent cell in a slice from the TgN (hGFAP/EGFP) mouse. (B) shows GlyT1 immunostaining on the bright cell, but not on the dark cell. (C) shows NG2 immunostaining (Cy5) on the dark cell but not on the bright cell. (D) shows the overlay. The age of the animal was 1 1. 


\subsubsection{Co-expression of GlyT1 and glutamate transporter on astrocytes}

Bright fluorescent cells in the TgN (hGFAP/EGFP) mouse, which are eletrophysiologically passive and intermediate astrocytes, were shown to express glutamate trasporters both by immunohistochemistry and by electrophysiology (Graß et al, 2004, Matthias et al, 2003). We performed co-staining on acute slices from p1 and p2 animals with the glutamate transporter GLAST, to define whether astrocytes can co-express glutamate transporter and the GlyT1. GlyT1-GLAST co-staining was found on bright fluorescent cells (Figure 16).
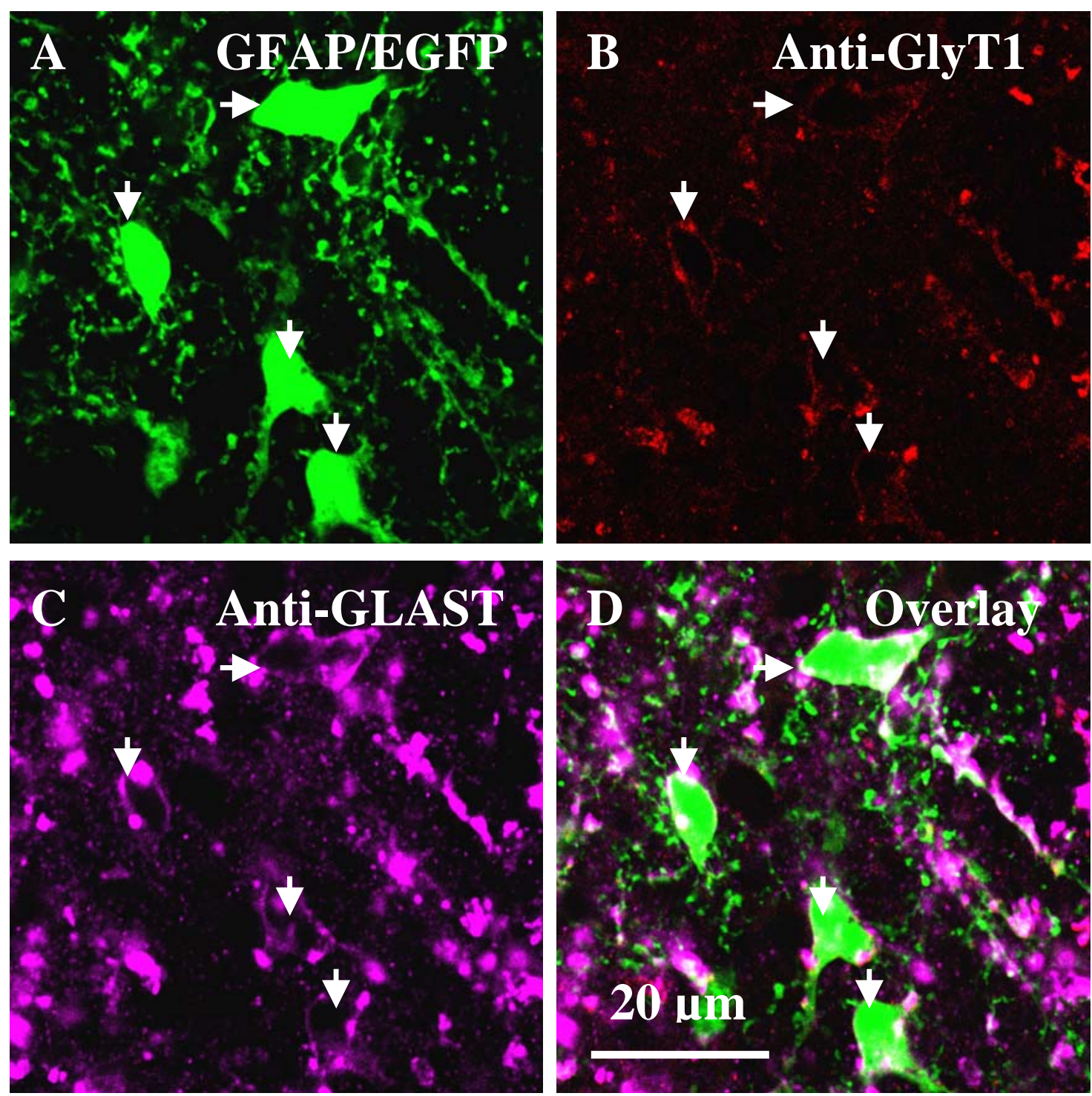

Figure 16. GlyT1/GLAST co-staining, showing co-staining on bright fluorescent astrocytes

(A) shows the green fluorescent astrocytes of the TgN (hGFAP/EGFP) mice. (B) shows the GlyT1 immunostaining (Сy3) on bright fluorescent cells (arrows point to the cells), (C) shows the GLAST immunostaining (Cy5) on the same cells. Figure D shows the overlay. The age of the animal was p1. 


\subsubsection{Expression of GlyT1 on oligodendrocytes}

To visualize oligodendrocytes, TgN (mPLP/DsRed) mice were used and immunocytochemistry was performed on slices from different ages (p2-p10).

In very young mice (p2-p4) the majority of the labelled cells were localized at the area ventral to the Nucleus hypoglossus, probably at the area of Nucleus raphe and rarely found in the ventral respiratory group, making analysis extremely difficult. However, no GlyT1 staining was found on fluorescently labelled cells in the regions where labelled oligodendrocytes could be found.

In older mice (P7-p10), when this strong region specificity disappeared, allowing us to study oligodendrocytes within the VRG, we could show possible membrane staining on a few labelled oligodendrocytes. However, these results were weak in comparison to the strong staining of the brightly labelled astrocytes, and the majority of the fluorescently labelled cells did not show GlyT1 expression (Figure 17). Data on double transgenic mice with both green fluorescent astrocytes and red fluorescent oligodendrocytes showed that the GlyT1 immunostaining is stronger on astrocytes than on oligodendrocytes. It also showed however that the density of fluorescently labelled oligodendrocytes is much lower than that of the fluorescently labelled astrocytes, which makes it more difficult to locate the cells (Figure 18).
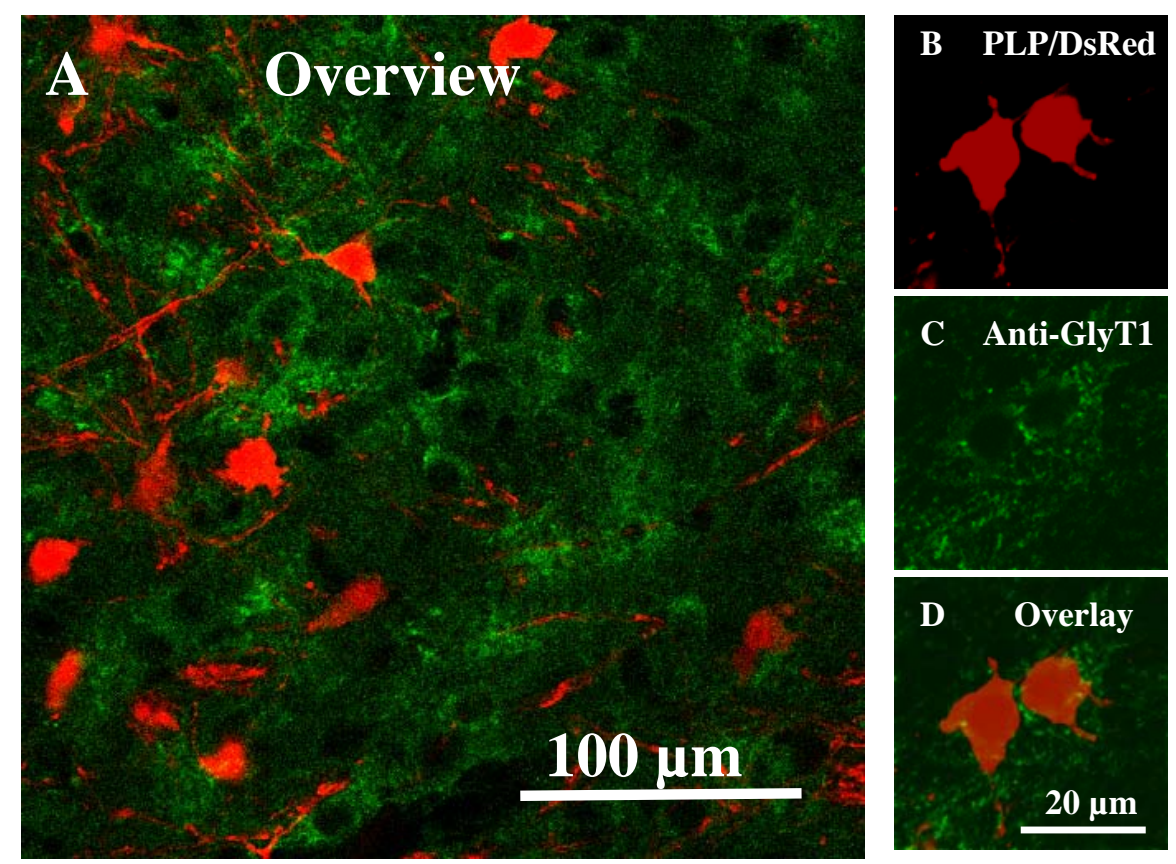

Figure 17: GlyT1 immunohistochemistry on oligodendrocytes

(A) shows the overview of GlyT1 staining (Cy5) on a slice from a TgN (PLP/DsRed) mouse, where the GlyT1 staining is localized mainly to not labelled cells. (B) shows the DsRed labelling of two oligodendrocytes. (C) shows the weak GlyT1 staining of two cells, (D) the overview. The slice was prepared from the perfused brain of a p10 animal. 

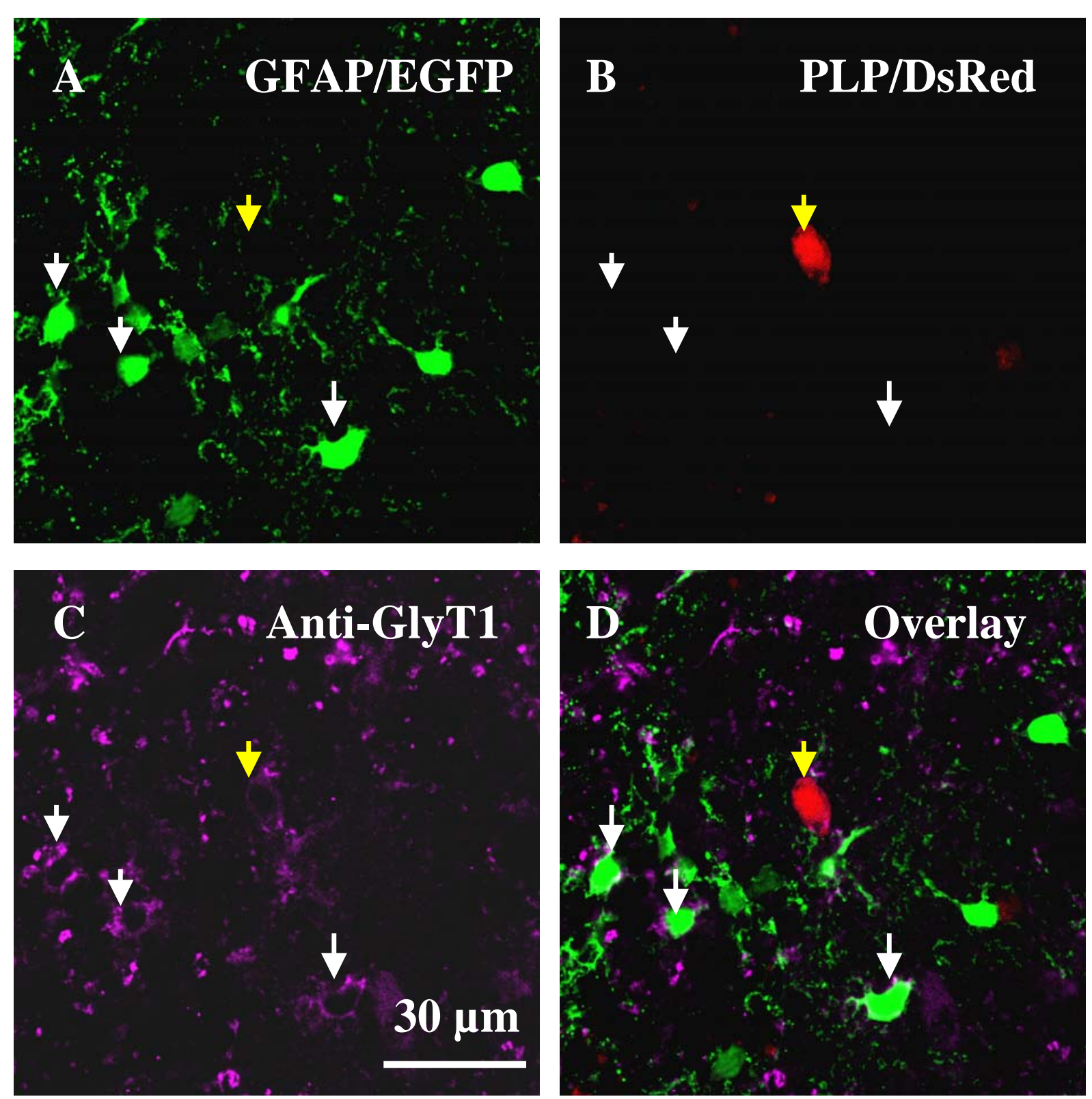

Figure 18: GlyT1 immunohistochemistry on slice from double-trasgenic mice

(A) shows the green fluorescent astrocytes, expressing EGFP under the control of the GFAP promoter. (B) shows a red oligodendrocyte expressing DsRed under the control of the PLP promoter. (C) shows the GlyT1 staining (Cy5). The white arrows point to the strong GlyT1 staining on bright fluorescent astrocytes, while the yellow arrow to the weaker staining on the oligodendrocyte. (D) shows the overlay. The age of the animal was p7. 


\subsubsection{Expression of GlyT1 on neurons}

Although GlyT1 is mainly glia specific, neuronal GlyT1 was also described in retinal transplants (Sharma, 2000) and recently in the cerebellum and in the cortex (Jones et al., 2004, conference abstract, Cubelos et al, 2005). To check the possibility of neuronal GlyT1 in the respiratory network, slices from a p7 TgN (Thy1.2/EYFP) mouse were also stained against GlyT1. These mice express yellow EYFP fluorescence in neurons, including respiratory neurons in the VRG (Winter et al, 2005, conference abstract). GlyT1 staining was restricted to nonfluorescent cells, no circular membrane staining was found in fluorescently labeled neurons (Figure 19).
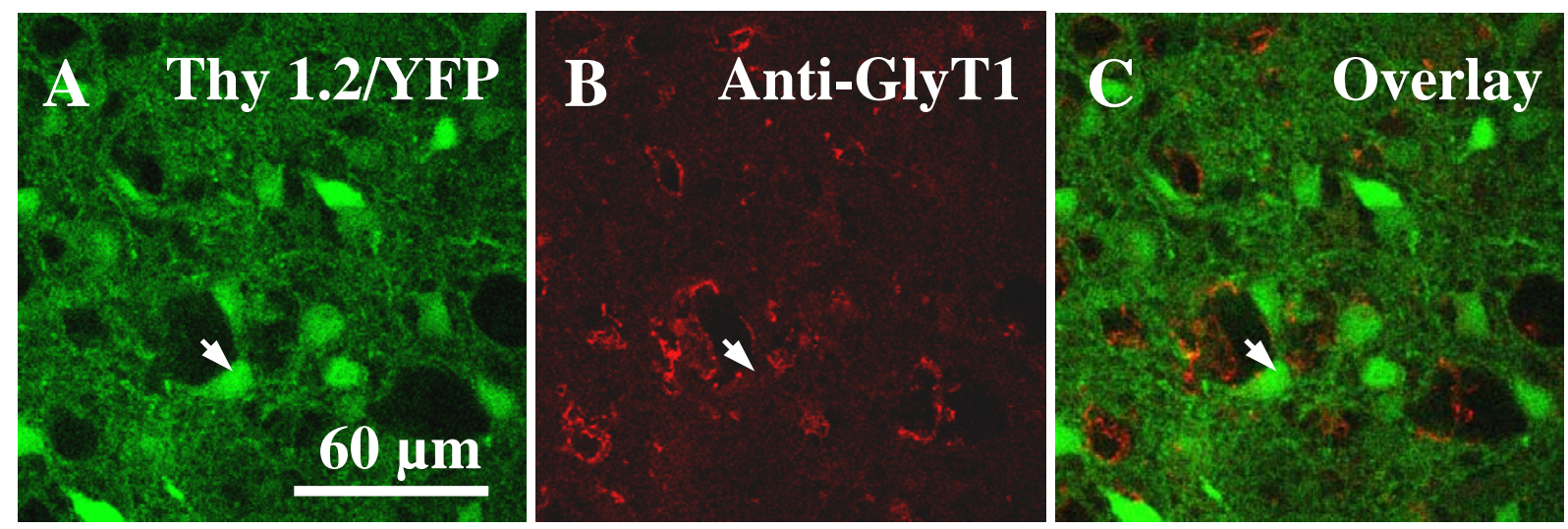

Figure 19. GlyT1 immunohistochemistry shows no expression of GlyT1 on fluorescently labeled neurons

(A) shows neurons labeled by yellow fluorescence, (B) the GlyT1 staining (Сy3) and (C) the overlay. The arrow shows a fluorescently labelled neuron, which is not stained, with stained nonfluorescent cells in the neighbourhood.

\subsubsection{Expression of the mRNA of GlyT1 in glial cells of the respiratory network}

The expression of GlyT1 mRNA in different glial cells of the respiratory network was investigated by single-cell RT-PCR experiments. Cytoplasm was harvested from fluorescent cells of the VRG in transgenic mice. The cells were defined by electrophysiological criteria. After cDNA synthesis a multiplex nested PCR was performed for GlyT1 and as a control for actin. Actin mRNA was detected in $96.7 \%$ of the samples (59 of 61 cells).

Expression of GlyT1 mRNA (results shown in Figure 18) was found both in passive (15 of 21 cells, $71.4 \%$ ) and intermediate (12 of 13 cells, 92.3\%) astrocytes, but also in 7 of 10 outwardly rectifying astrocytes (70.0\%). GlyT1 mRNA was shown also in oligodendrocytes (12 of 15 cells, $80.0 \%$ ). 


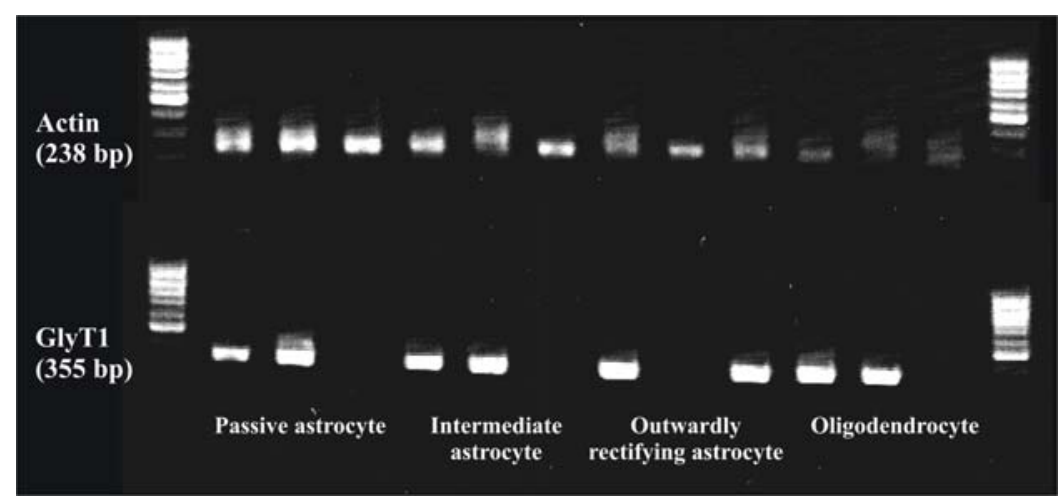

Figure 20. GlyT1 mRNA expression in astrocytes and oligodendrocytes

The figure shows picture of a gel with the results of the sc PCR. The GlyT1 PCR is shown for 3 samples of each cell type, as well as the actin PCR for the same samples.

\subsubsection{Electrophysiology of glial cells}

Fluorescently labeled cells of TgN (hGFAP/EGFP) and TgN (mPLP/DsRed) mice were whole-cell voltage clamped and defined according to the voltage-dependent current profile. A voltage-step protocol from -160 to $+70 \mathrm{mV}$ was recorded and the IV relationship of the cell was defined. Three different types of astrocytes were described in the respiratory network according to electrophysiological criteria (Graß et al, 2004): (1) passive astrocytes with passive currents and a linear IV relationship (Figure 21A), (2) intermediate astrocytes with a linear IV relationship at the steady state but with an initial A-type current (Figure 21B), and (3) outwardly rectifying astrocytes with outwardly rectifying currents (Figure 21C). Oligodendrocytes showed similar IV relationship as passive astrocytes (Figure 21D)

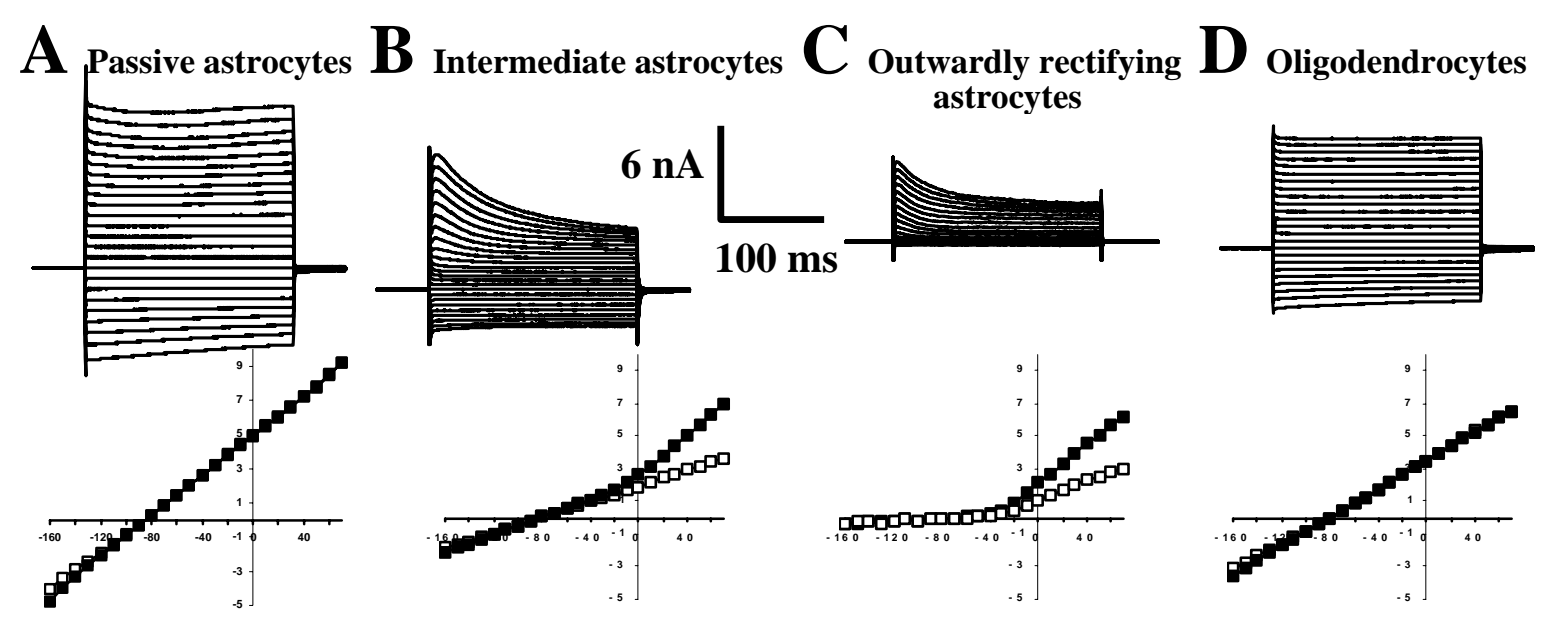

Figure 21. Electrophysiological properties of different glial cell types

The figure shows an example for typical IV relationships of the three different types of astrocytes and of the oligodendrocytes. In the transgenic mouse bright fluorescent cells are usually passive or intermediate astrocytes, while outwardly rectifying astrocytes generally appear as dark fluorescent cells. 
Similar to the results described in Grass et al (2004), bright fluorescent astrocytes were passive and intermediate in our experiments, while both outwardly rectifying astrocytes and passive and intermediate astrocytes were found among the dark cells.

Outwardly rectifying astrocytes were described to have significantly larger input resistance and less negative membrane potential than passive and intermediate cells (Graß et al, 2004). In Figure 22, the statistical analysis of the membrane potential and the input resistance is shown. The membrane potential and input resistance was not significantly different in passive and intermediate astrocytes, $-83.9 \pm 2.6 \mathrm{mV}$ membrane potential and 40.0 $\pm 11.5 \mathrm{M} \Omega$ input resistance for passive astrocytes $(\mathrm{n}=18)$ and $-81.3 \pm 7.0 \mathrm{mV}$ membrane potential $(\mathrm{p}=0.25)$ and $36.3 \pm 2.8 \mathrm{M} \Omega$ input resistance $(\mathrm{p}=0.2)$ for intermediate astrocytes $(n=19)$, respectively. Outwardly rectifying astrocytes showed significantly different membrane potentials, $-54.5 \pm 13.9 \mathrm{mV}(\mathrm{n}=12, \mathrm{p}<0.001)$. The input resistance was about 10 times larger in each cell $(465.9 \pm 265.1 \mathrm{M} \Omega, \mathrm{p}<0.001)$.

Oligodendrocytes $(\mathrm{n}=18)$ showed similar input resistance than passive and intermediate astrocytes, $32.1 \pm 10.4 \mathrm{M} \Omega$, but their membrane potential was less negative, $75.7 \pm 5.5 \mathrm{mV}$, and this difference was significant $(\mathrm{p}<0.01)$. As expected, the data from oligodendrocytes were significatly different from outwardly rectifying astrocytes for both the input resistance and the membrane potential $(\mathrm{p}<0.001)$.
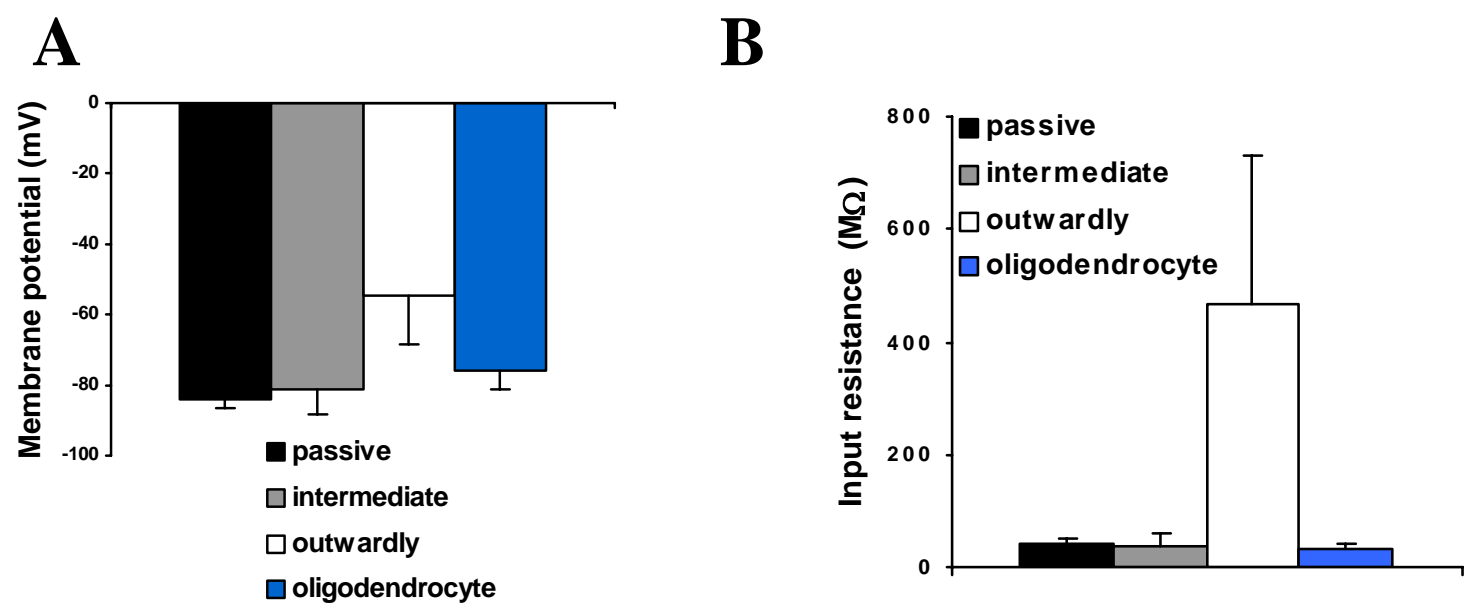

Figure 22. Membrane potential and input resistance of different glial cells

(A) shows the statistical analysis of the membrane potential in the different types of astrocytes and in oligodendrocytes. (B) shows the input resistance. Data are shown as mean \pm SD. 


\subsubsection{Glycine induced currents in glial cells of the respiratory network}

The functional expression of the GlyT1 and glycine receptor on glial cells of the respiratory network was studied in whole-cell voltage clamp experiments performed on different glial cell types of the ventral respiratory group.

Bath application of $1 \mathrm{mM}$ glycine evoked inward currents in passive and intermediate astrocytes without significant difference (142.7 \pm 58.6 pA in passive cells, $n=14$, and $147.1 \pm$ $76.8 \mathrm{pA}$ in intermediate astrocytes, $\mathrm{n}=11, \mathrm{p}=0.87$ ), but did not elicit a current in outwardly rectifying astrocytes $(n=11)$. The main part of the glycine-induced current was shown to be receptor-related, as it could be blocked by the glycine receptor blocker strychnine (10 $\mu \mathrm{M})$. However, in passive astrocytes $22.3 \pm 10.5 \%(n=7)$, in intermediate astrocytes $18.8 \pm 18.2 \%$ $(n=8)$ of the original current was strychnine insensitive. This current can be related to glycine transporter (GlyT1) (Figure 23).

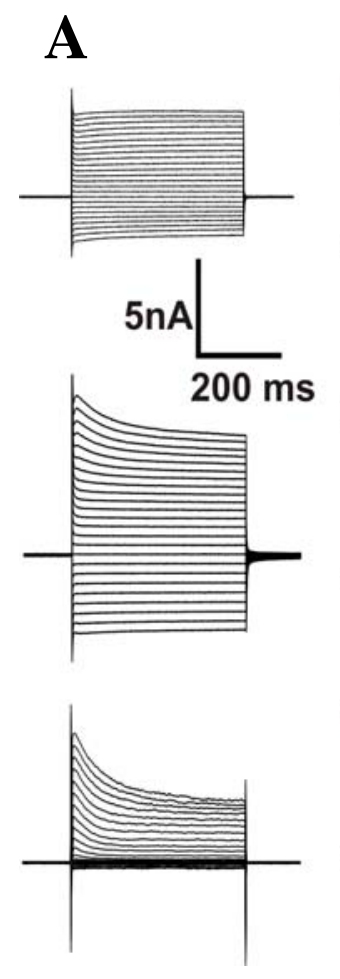

\section{passive astrocyte}
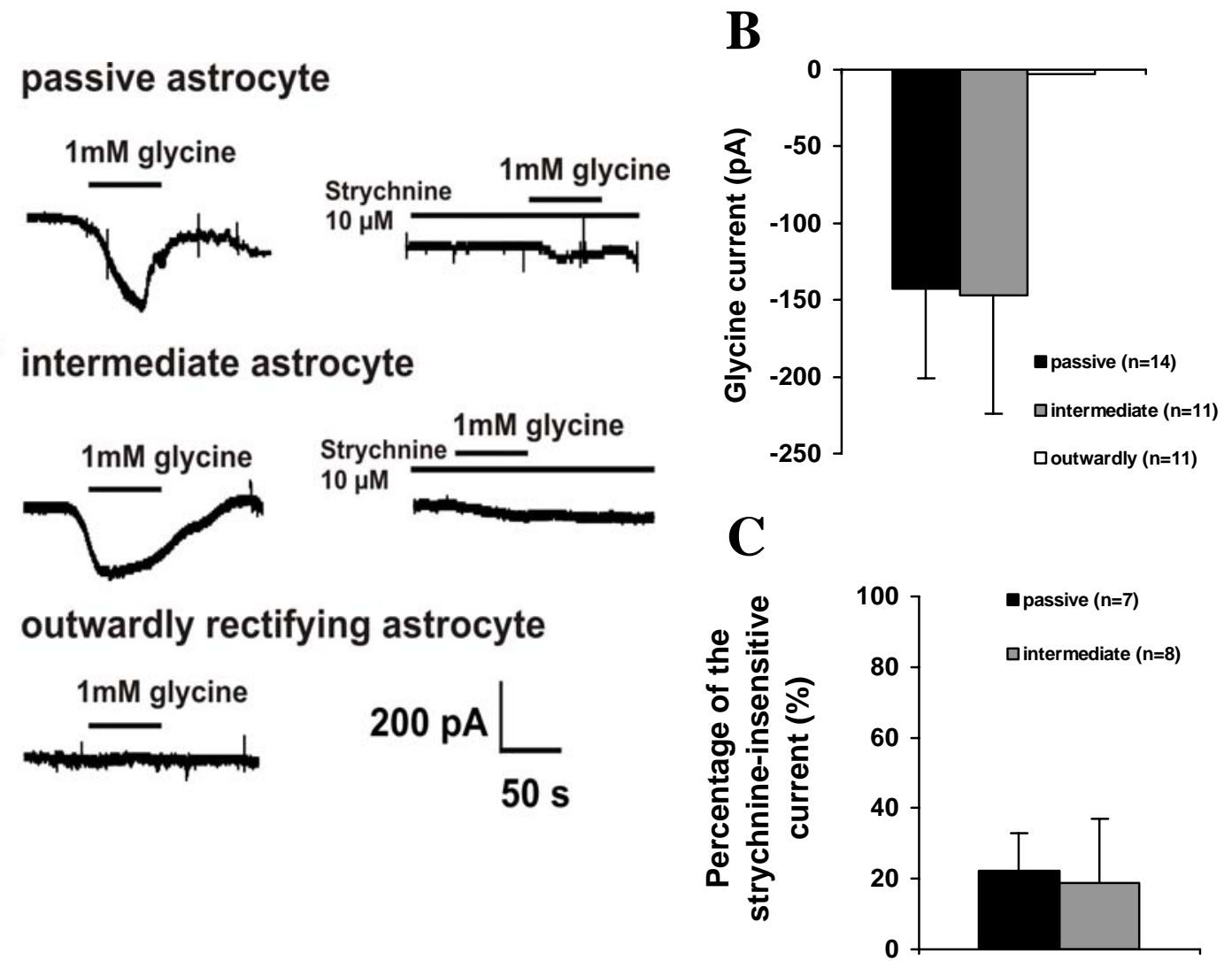

Figure 23.Glycine induced currents expressed in different types of astocytes

(A) shows the IV curves and glycine induced current traces from up to down from a passive, an intermediate and an outwardly rectifying astrocyte. On the left, the IV curves are shown; the middle traces show the whole glycine current, the right traces the current induced in the presence of $10 \mu \mathrm{M}$ strychnine. (B) shows the statistical analysis of the whole glycine current, $(\mathrm{C})$ the percentage of the strychnine-insensitive current. Data are shown as mean \pm SD. 
Since bath application is slow and the applied substance exerts its effect on all of the cells of the glia syncitium, we used a fast perfusion system for local application in which the fluid flow could be changed quickly between control and substance-containing solution. With the application capillary placed close to the cell, and using application time of 10 seconds and 2mM glycine, local application elicited similar responses as bath-application: in passive astrocytes $-136.3 \pm 23.1 \mathrm{pA}(\mathrm{n}=4)$, more variable in intermediate astrocytes $-228.8 \pm 155.0$ pA ( $n=6)$, but the difference was not significant ( $\mathrm{p}=0.28)$. After strychnine application $10.0 \pm$ 5.5 and $15.2 \pm 19.6 \%$ remained, respectively (Figure 24 ).

To study the receptor related current, our goal was to make the glycine application very short, to simulate to the synaptic transmission. When the duration was reduced to $1 \mathrm{~s}$ however, the recorded currents were close to the detection limit. Only in a very few cases were similar currents recorded as in the case of longer application time. Similar strong decrease in glutamate-induced currents with reduced application time was also observed (Data not shown).

A

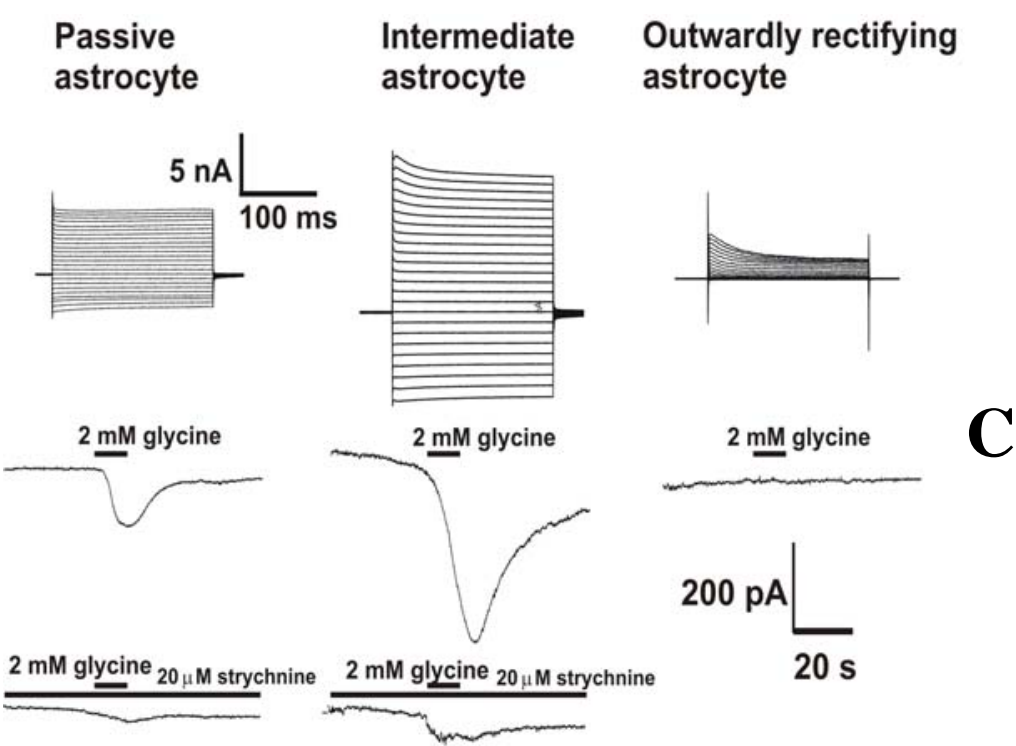

\section{B}
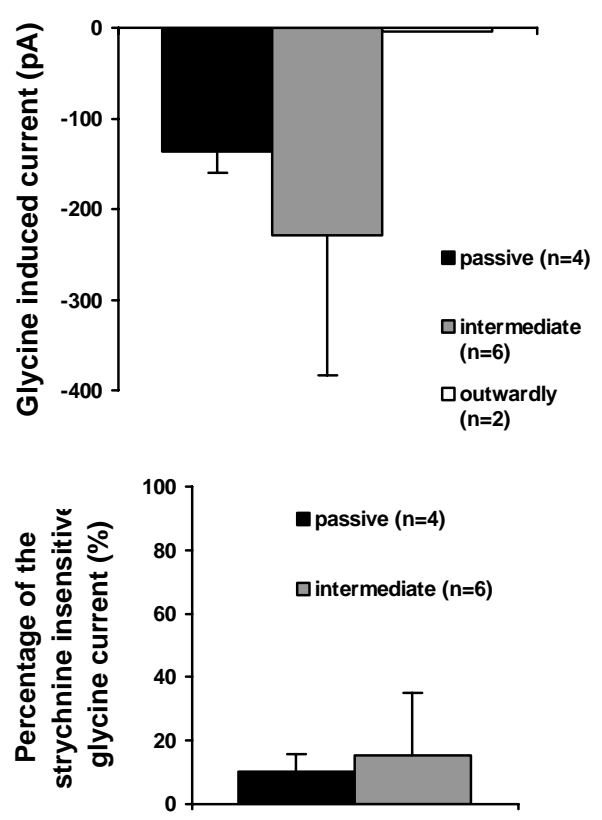

Figure 24. Currents induced by glycine from a fast drug application system

(A) shows currents evoked by $2 \mathrm{mM}$ glycine in the different types of astrocytes before and after application of 20 $\mu \mathrm{M}$ strychnine. The IV protocol of the example cell is also shown. (B) shows the statistical analysis of the whole glycine currents, (C) shows the percentage of the glycine currents remaining after application of $20 \mu \mathrm{M}$ strychnine. Data are shown as mean $\pm \mathrm{SD}$. 
Finally, to prove that the glycine response is not indirect, experiments were also

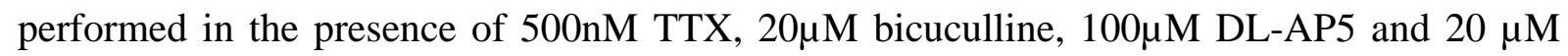
DNQX for blockade of the synaptic transmission (TTX blocks the voltage sensitive sodium channels), GABA receptors and NMDA and AMPA/kainate type glutamate receptors, respectively. To apply the glycine directly to the cell, pressure-ejection application was performed from an other pipette placed next to the cell (in approximately $10 \mu \mathrm{m}$ distance). $100 \mathrm{mM}$ glycine was applied for $20 \mathrm{~ms}$ using 2 bar pressure (Oku et al, 1999). Glycine induced currents were recorded from passive (-26.5 $\pm 12.8 \mathrm{pA})$ and intermediate $(-36.5 \pm 28.2$ pA) astrocytes but, as expected from the previous data, not from outwardly rectifying astrocytes. However, in comparison to the bath application, the glycine induced currents were smaller and artefacts probably due to the pressure were also registered (Figure 25).

A

B
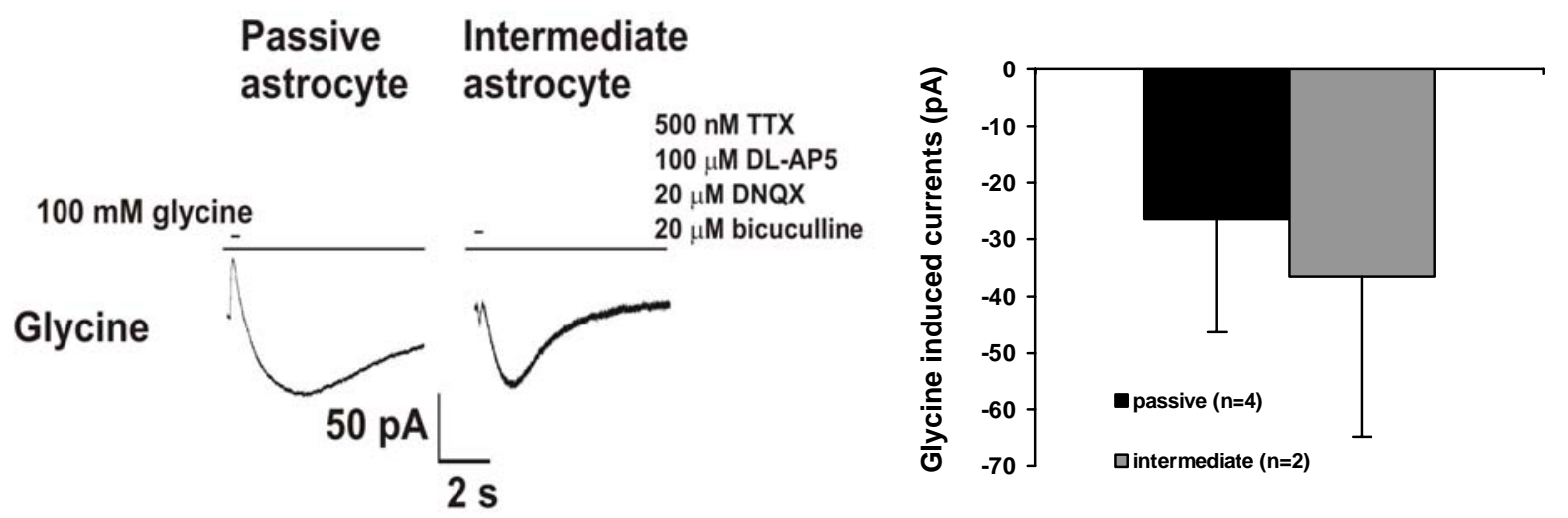

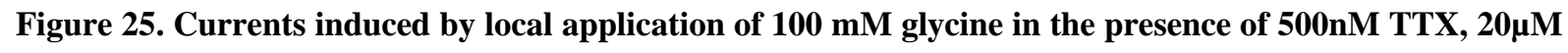

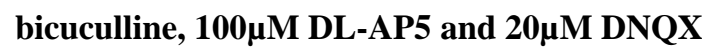

(A) shows the average currents induced by 3 consecutive application of glycine to a passive and an intermediate astrocyte, pressure artefacts, which were not counted in the analysis, can be observed at the beginning of the recording. (B) shows the statistical analysis of the total glycine current. Data are shown as mean \pm SD.

Glycine induced currents were also tested in fluorescently labelled oligodendrocytes. In these cells, similar currents were evoked upon bath application of glycine than in passive or intermediate astrocytes: $133.3 \pm 22.9$ pA whole glycine current was recorded and $20.6 \pm 6.0$ \% was strychnine resistant ( $\mathrm{n}=10)$. Figure 26 shows an example result. 


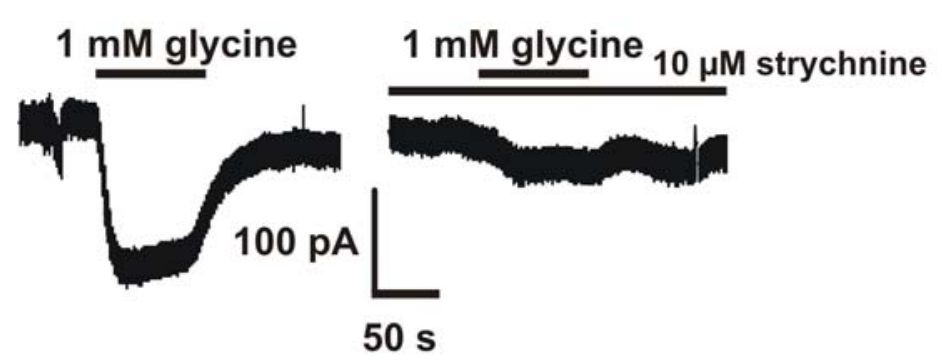

Figure 26. Glycine induced currents in oligodendrocytes

The figure shows the current evoked by $1 \mathrm{mM}$ glycine in an oligodendrocyte (left) and the current in the same cell evoked in the presence of $10 \mu \mathrm{M}$ strychnine (right).

\subsubsection{Comparison on the glycine induced currents of astrocytes and neurons}

Although passive and intermediate astrocytes respond to glycine with mainly receptor related currents, these currents are low. When we compared the current upon glycine application expressed by astrocytes with that of neurons, we found that glycine induced more than ten times larger larger currents in neurons. Astrocytes expressed glycine currents in a pA range, just in very few cases exceeding 200 pA, while neurons expressed currents in the nArange. Figure 27 shows the glycine response of a neuron in comparison to glycine response recorded in a selected astrocyte.

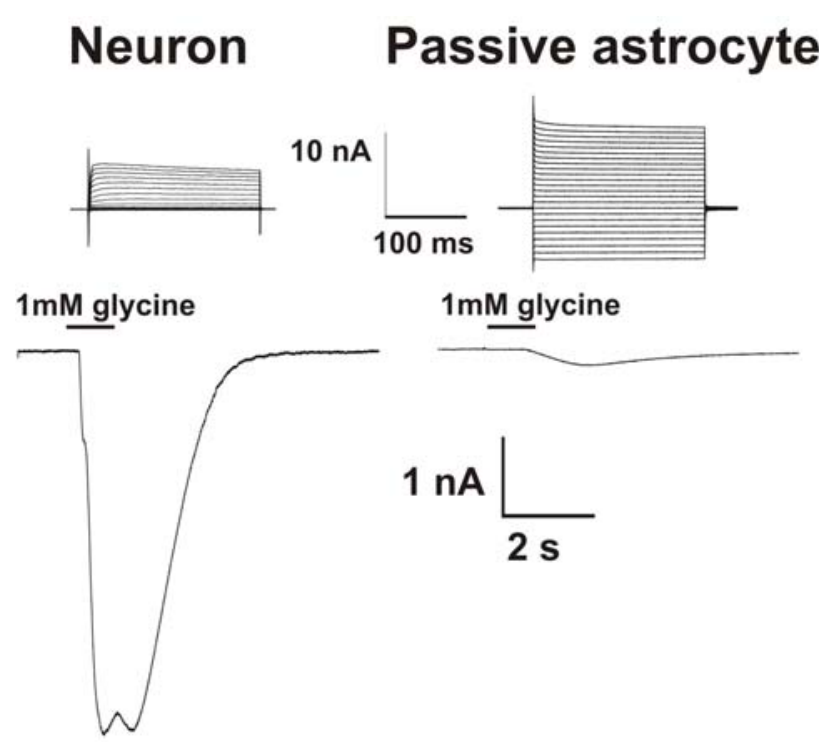

Figure 27. Comparison of the glycine response between a neuron and an astrocyte

The figure shows currents evoked by application of $1 \mathrm{mM}$ glycine from the fast perfusion system on a neuron and on a passive astrocyte. IV curves of the cells are shown above the current recording. Recorded in the presence of $500 \mathrm{nM}$ TTX. 


\subsubsection{Involvement of coupling in glycine induced currents of astrocytes}

Bath application of drugs exerts widespread effects in the tissue. Therefore, it is important to know in voltage-clamp experiments whether the cells examined are coupled through gap junctions. If this is the case, the currents response represents the currents from nearby coupled cells also.

To analyze potential coupling of astrocytes, immunohistochemistry was performed on slices from TgN (hGFAP/EGFP) mouse against connexin 43 (Cx43) and NG2. The Cx43 staining was localized on astrocytes with high EGFP expression level. There was no costaining of Cx43and NG2 on fluorescently labelled astrocytes, indicating that outwardly rectifying astrocytes do not express connexin 43 (Figure 28).
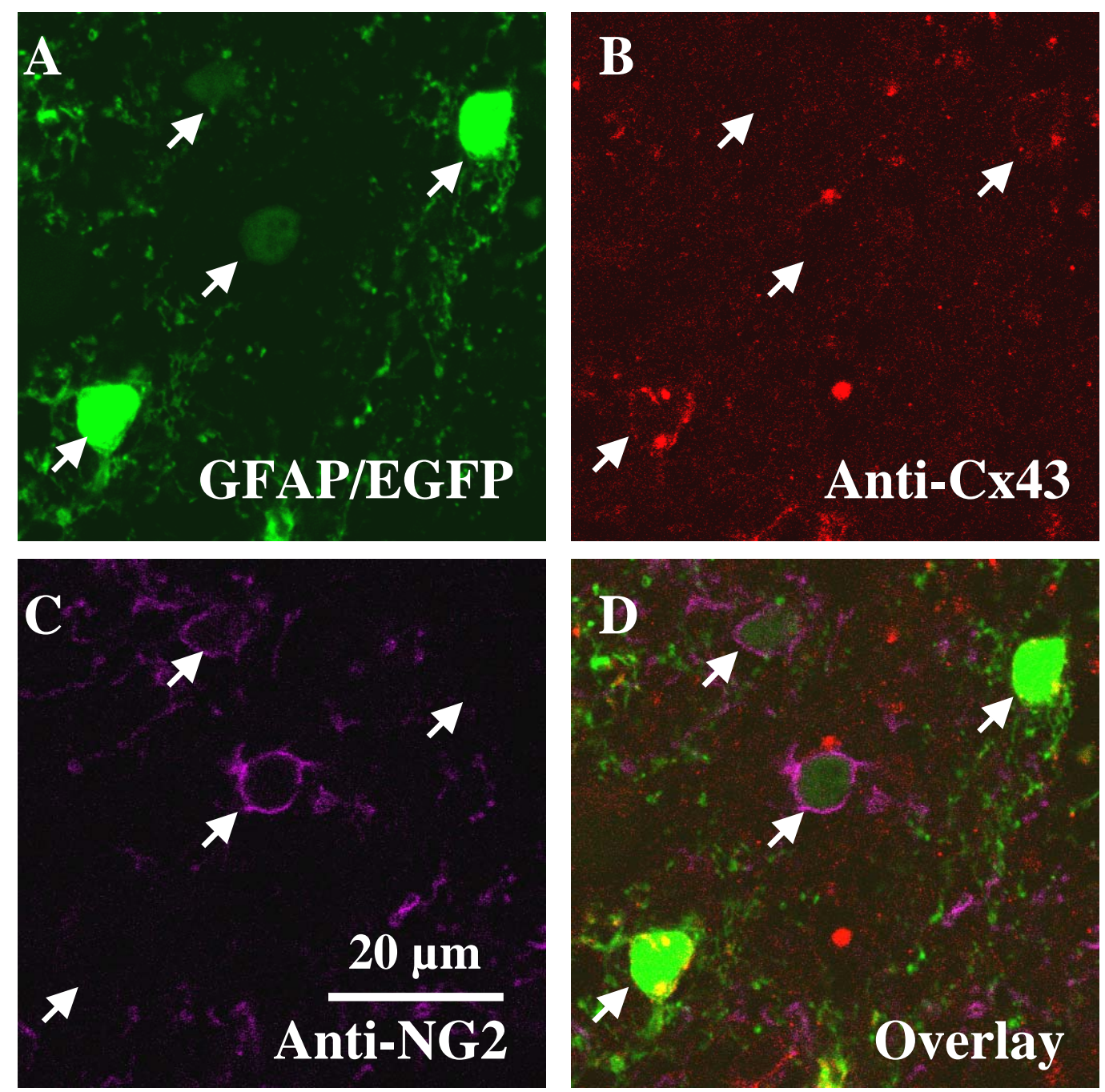

Figure 28. Connexin 43/NG2 co-staining showing no connexin 43 staining on NG2+ cells

(A) shows the EGFP fluorescence of two bright and two dark fluorescent cells in a slice from the TgN (hGFAP/EGFP) mouse, the white arrows point to the cells. (B) shows connexin 43 immunostaining (Cy3) on the bright cells but not on the dark cells. (C) shows NG2 immunostaining (Cy5)on the dark cells but not on the bright cells. (D) shows the overlay. The age of the animal was p2. 
Passive astrocytes were described to form a syncitium connected together by gapjunctions (Wallraff et al, 2004). The involvement of the astrocytic syncitium in the glycine response was studied in whole-cell voltage clamp experiments using a different intracellular solution, in which the potassium chloride was replaced by potassium gluconate. Under this condition, the chloride-mediated currents of the cell should be reduced due to the fact that the chloride equilibrium potential $(-77 \mathrm{mV})$ is very close to the holding potential at which the cell is clamped $(-80 \mathrm{mV})$. Passive $(\mathrm{n}=33)$ and intermediate $(\mathrm{n}=7)$ astrocytes were examined. Each of them showed strychnine sensitive glycine currents. The amplitudes of the glycine induced currents were not significantly different from the glycine induced currents recorded with chloride containing intracellular solution (In the case of passive astrocytes, $-163.9 \pm 85.6 \mathrm{pA}$, $\mathrm{p}=0.2$; in the case of intermediate astrocytes, $-182.0 \pm 33.6 \mathrm{pA}, \mathrm{p}=0.3)$. After application of strychnine $22.8 \pm 13.4 \%$ and and $17.8 \pm 6.4 \%$ remained, indicating that surprisingly large part of the glycine current was strychnine sensitive receptor current (Figure 29). This suggests that coupled cells where the chloride equilibrium potential probably has not changed contribute to the glycine receptor currents.
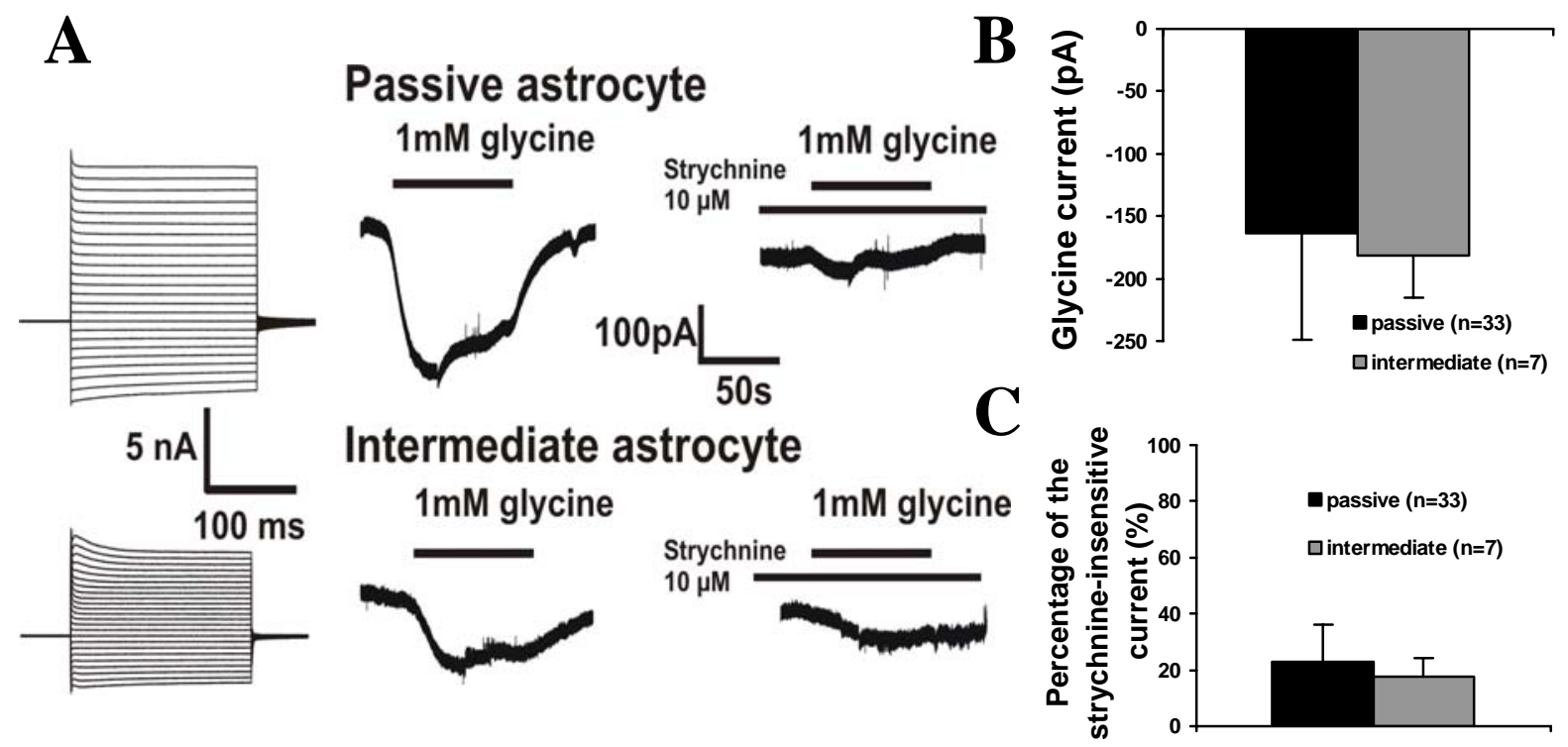

Figure 29. Glycine receptor and transporter currents with potassium gluconate containing intracellular solution

(A) shows the IV curves (left) and currents evoked by $1 \mathrm{mM}$ glycine in a passive and an intermediate astrocyte whole-cell voltage-clamped with potassium gluconate containing intracellular solution. The middle traces show the whole glycine current and the right traces the current in the same cell evoked in the presence of $10 \mu \mathrm{M}$ strychnine.(B) shows the statistical analysis of the whole glycine current, (C) the percentage of the strychnineinsensitive current. Data are shown as mean \pm SD. 


\subsubsection{Co-expression of glycine transporter and glutamate transporter currents in astrocytes}

Since immunohistochemistry showed that the same cells express GlyT1 and glutamate transporter GLAST, we also tested whether the same cells express glycine transporter and glutamate transporter currents. Passive astrocytes $(n=7)$ were tested using the potassium gluconate-containing intracellular solution. Glycine $(1 \mathrm{mM})$ was applied in the presence of 10 $\mu \mathrm{M}$ strychnine, followed by the application of D-aspartate $(200 \mu \mathrm{M})$, a substrate of glutamate transporters. Both glycine and D-aspartate evoked inward currents in each cells, $-29.9 \pm 8.0$ pA in the case of glycine and $-203.1 \pm 115.7$ pA in the case of D-aspartate (Figure 30).

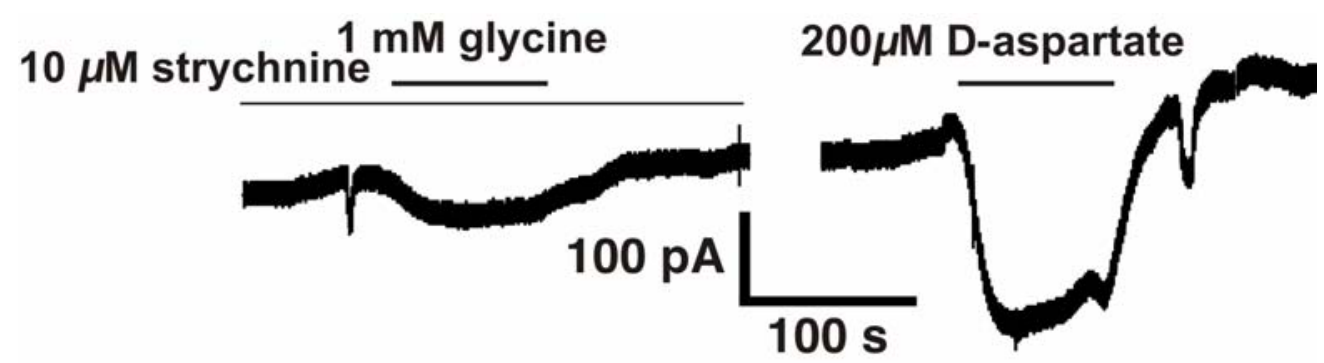

Figure 30. Glycine and glutamate transporter currents in passive astrocytes

The figure shows an example registration of the glycine induced and D-aspartate induced currents of the same passive astrocytes.

\subsubsection{Expression of glycine receptor in glial cells of the respiratory network}

Since the main part of the glycine induced current was receptor related, immunohistochemistry was also performed against glycine receptor on slices from transgenic mice with fluorescently labelled glial cells to study the GlyR expression on the different glial cell types.

GlyR immunostaining was preferentially found in non-fluorescent large cells, supposedly on neurons. In contrast to the GlyT1 immunohistochemistry, anti-GlyR antibody not only stained cells with high level of EGFP expression in the TgN (hGFAP/EGFP), dark fluorescent cells were stained as well. Mice of age p3-p6 were examined. (Figure 31) 

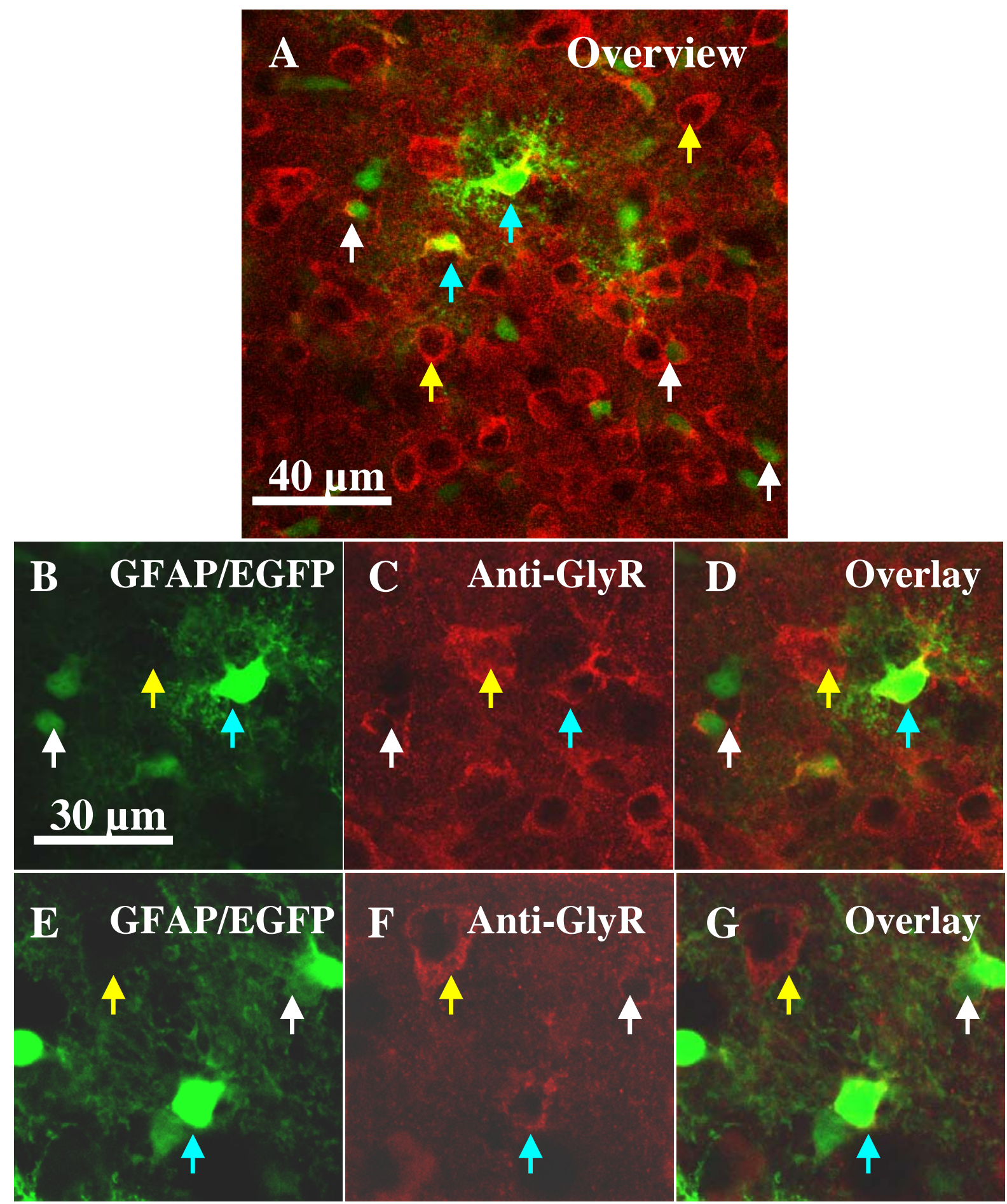

Figure 31. GlyR immunohistochemistry on slices from TgN (hGFAP/EGFP) mice

(A) shows an overview of the GlyR staining (Cy3, red) on green fluorescent astrocytes, showing GlyR expression on both dark and bright fluorescent cells. The white arrows point to dark cells, the blue arrows point to bright cells, and the yellow arrows on large non-fluorescent stained cells, probably neurons. (B), (C) and (D) show GlyR staining at higher magnification in a dark and a bright fluorescent astrocyte; it shows the EGFP fluorescence, the Cy3 labelled GlyR and the overlay, respectively. (E), (F), (G) show 3 bright and two dark cells, one of the dark cells and one of the bright cells is stained against GlyR; it shows the EGFP fluorescence, the Cy3 labelled GlyR, and the overlay respectively. Notice in this figure that bright and dark fluorescent cells are found in close proximity. The age of the animal was p6. 
The glycine induced currents suggested co-expression of GlyT1 and GlyR on passive or intermediate astrocytes. Therefore, GlyR/GlyT1 co-staining was performed on slices from a p6 animal, and indeed some bright fluorescent cells were found to show both GlyR and GlyT1 staining (Figure 32).
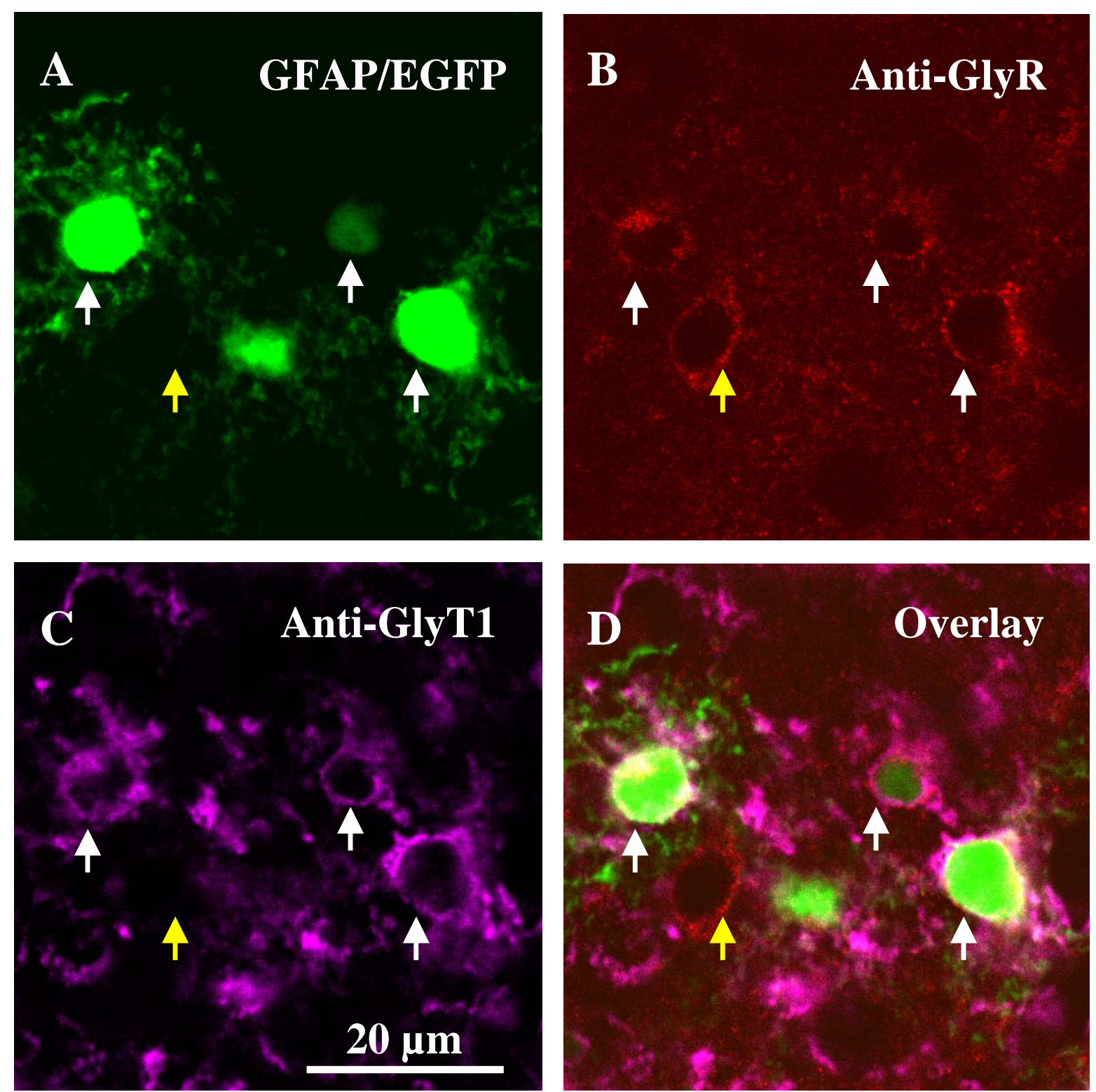

Figure 32. GlyR/GlyT1 co-staining showing co-expression of GlyT1 and GlyR on bright fluorescent astrocytes

(A) shows the EGFP fluorescence in slice from the TgN (hGFAP/EGFP) mouse. (B) shows GlyR staining (Cy3) on 2 bright fluorescent cells, a dark fluorescent cell, and a nonfluorescent cell, (C) shows GlyT1 staining (Cy5) on the same fluorescent cells but not on the nonfluorescent cell, (D) shows the overlay. The white arrows point to the three green fluorescent cells with GlyT1/GlyR co-staining, the yellow arrow points to the non fluorescent GlyR+ but GlyT1- cell, which is probably a neuron. The age of animal was p6. 
According to the electrophysiology, outwardly rectifying astrocytes do not express functional glycine receptors. This is in discrepancy with the previous finding that dark fluorescent cells show glycine receptor immunostaining. To investigate whether the dark cells stained against GlyR might be outwardly rectifying astrocytes, or just dark passive or intermediate cells, co-staining with NG2 was also performed. Surprisingly, some of the NG2+ dark cells seemed to show a weak GlyR staining, but most of the fluorescent cells did not show GlyR-GlyT co-staining (Figure 33).
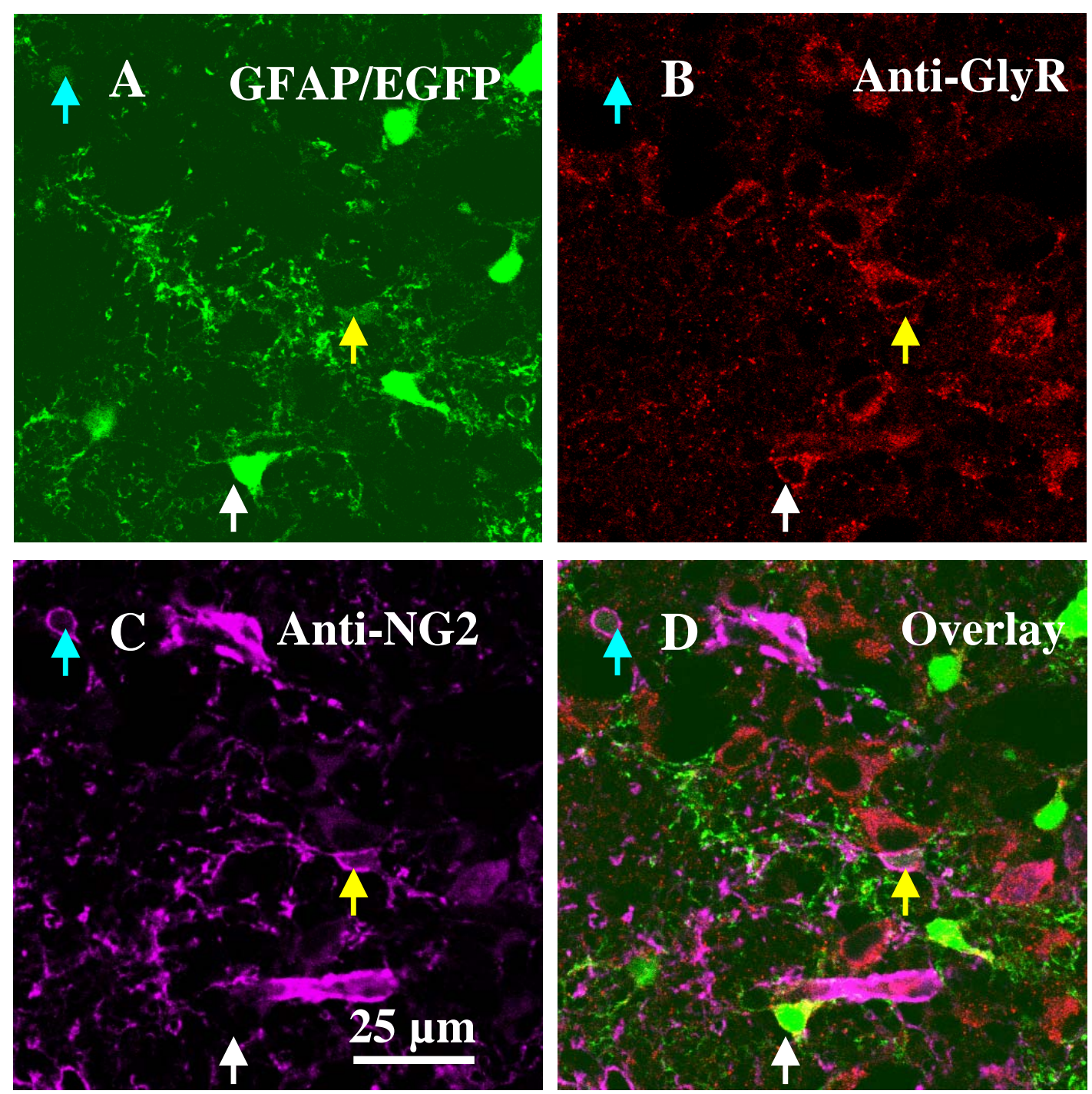

\section{Figure 33. GlyR/NG2 co-staining}

(A) shows the EGFP fluorescence, (B) the GlyR staining (Cy3), (C) shows NG2 staining (Cy5), (D) the overlay. The white arrow points to a bright fluorescent astrocyte with GlyR staining but no NG2 staining, the yellow arrow to an NG2 positive cell with a weak GlyR staining, and the blue arrow to an NG2 positive cell with no GlyR staining. The age of the animal was p3 


\subsubsection{Comparison of the glycine response of glial cells with the GABA response}

In whole cell experiments, currents induced by the other main inhibitory neurotransmitter, the $\gamma$-amino butyric acid (GABA) were also studied. In passive and intermediate astrocytes GABA induced similar inward currents as glycine (-125.0 \pm 97.7 pA with $\mathrm{n}=4$ and $-281.9 \pm 179.9$ with $\mathrm{n}=6$, respectively, $\mathrm{p}=0.15)$. Interestigly, in contrast to glycine GABA evoked significantly larger currents in outwardly rectifying astrocytes ($1179.2 \pm 438.5$ pA, $n=7 ; p<0.001$ ). Oligodendrocytes showed similar response to GABA than passive astrocytes $(-177.7 \pm 66.7 \mathrm{pA})$ (Figure 34).

Outwardly rectifying astrocytes were described to express glutamate receptor currents (Graß et al, 2004, Matthias et al, 2003). The same cells were found to show GABAergic EPSCs (Jabs et al, 2004, conference abstract), and NG2+ precursor cells were described to develop into GABAergic neurons (Belachew et al, 2003), suggesting that outwardly rectifying astrocytes might express also GABA receptors. Therefore, we tested how much of the GABA induced current was receptor-related by blocking the two main GABA receptors, $\mathrm{GABA}_{\mathrm{A}}$ with bicuculline and $\mathrm{GABA}_{\mathrm{B}}$ with CGP55845. While the remaining currents were not significantly different among the different cell types, in the case of passive astrocytes a large part of the GABA current (40,5\% in mean) was remaining after the receptor blockade. In contrast, the large GABA current of the outwardly rectifying astrocytes is mainly receptor related as only $17.5 \%$ was remaining after the receptor blockade. 

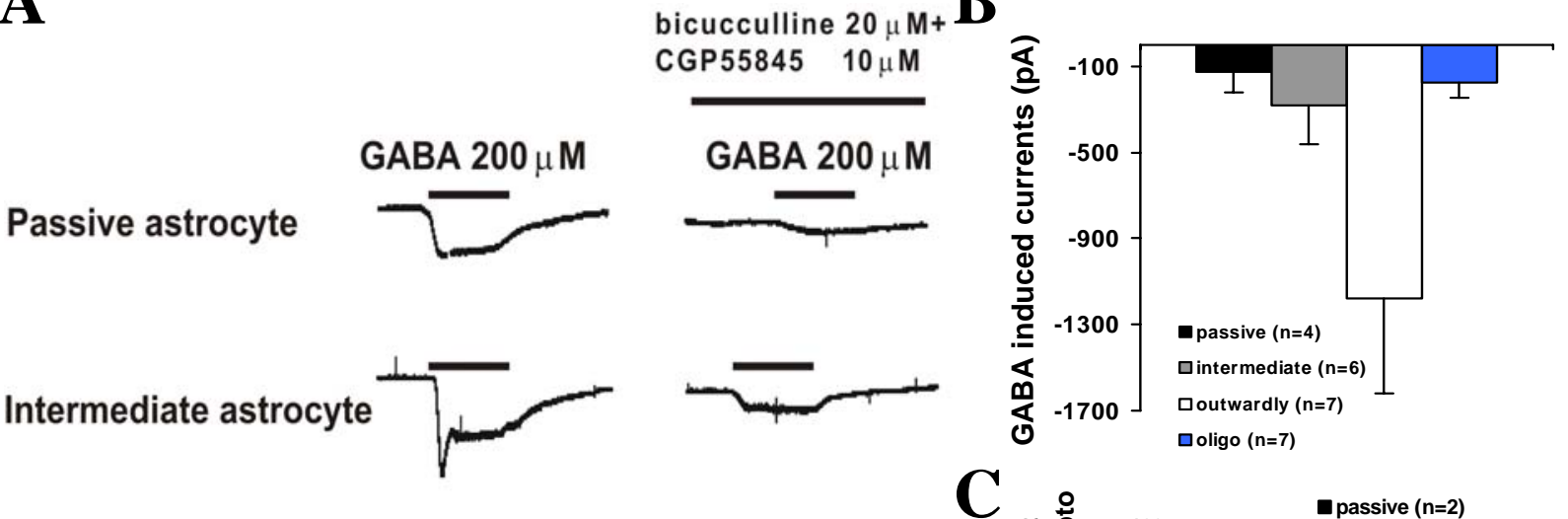

\section{Outwardly rectifying astrocyte}

Oligodendrocyte
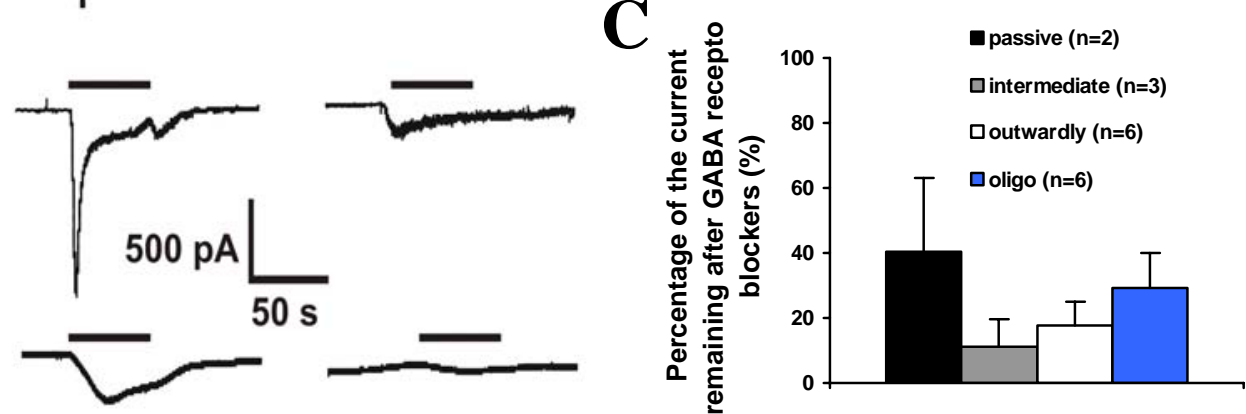

Figure 34. GABA induced currents in different glial cells

(A) shows current recordings from different glial cell types upon application of $200 \mu \mathrm{M}$ GABA before and after application of $20 \mu \mathrm{M}$ bicuculline and $10 \mu \mathrm{M}$ CGP55845. (B) shows the statistical analysis of the GABA induced currents without receptor blockade, (C) shows the statistics of the percentage of the current remaining after receptor blockade. Data are shown as mean \pm SD. 


\subsection{Role of GlyT1 in the respiratory rhythm}

\subsubsection{Breathing of GlyT KO mice}

Genetically inactivation of GlyT1 revealed that homozygous GlyT1 KO mice appeared externally normal but died on the day of birth (Gomeza et al, 2003a). One possible reason of this would be a respiratory failure. Therefore, newborn mice were examined for breathing phenotype and in vitro respiratory network activity.

First, breathing was analyzed in living animals by plethysmography. Wild type and heterozygous animals showed regular breathing. The breathing patterns and respiratory frequencies were not significantly different between both genotypes (For wild type, $2.53 \pm$ 0.58, $\mathrm{n}=8$, for heterozygous $2.07 \pm 1.04, \mathrm{n}=9, \mathrm{p}=0.48$ ). In contrast, homozygous GlyT1 KO mice exhibited severe disturbances of breathing, with characteristic breathing pattern including prolonged expiratory intervals and "double-breaths" (two single breath events, the one with smaller amplitude immediately following the one with larger amplitude, Figure 35 A). GlyT1 KO animals displayed a severe depression of respiratory frequencies to $16 \%$ (0.34 $\pm 0.20, n=16, p<0.001$ ) of those of wild-type (Figure $35 \mathrm{~B}$ ), and the breathing was much more irregular as shown by the 4 -fold increase $(\mathrm{p}<0.001)$ of the coefficient variation of the expiratory interval $(0.23 \pm 0.11$ for wild-type, $0.35 \pm 0.22$ for heterozygous and $1.04 \pm 0.36$ for KO, Figure $35 \mathrm{C}$ ).
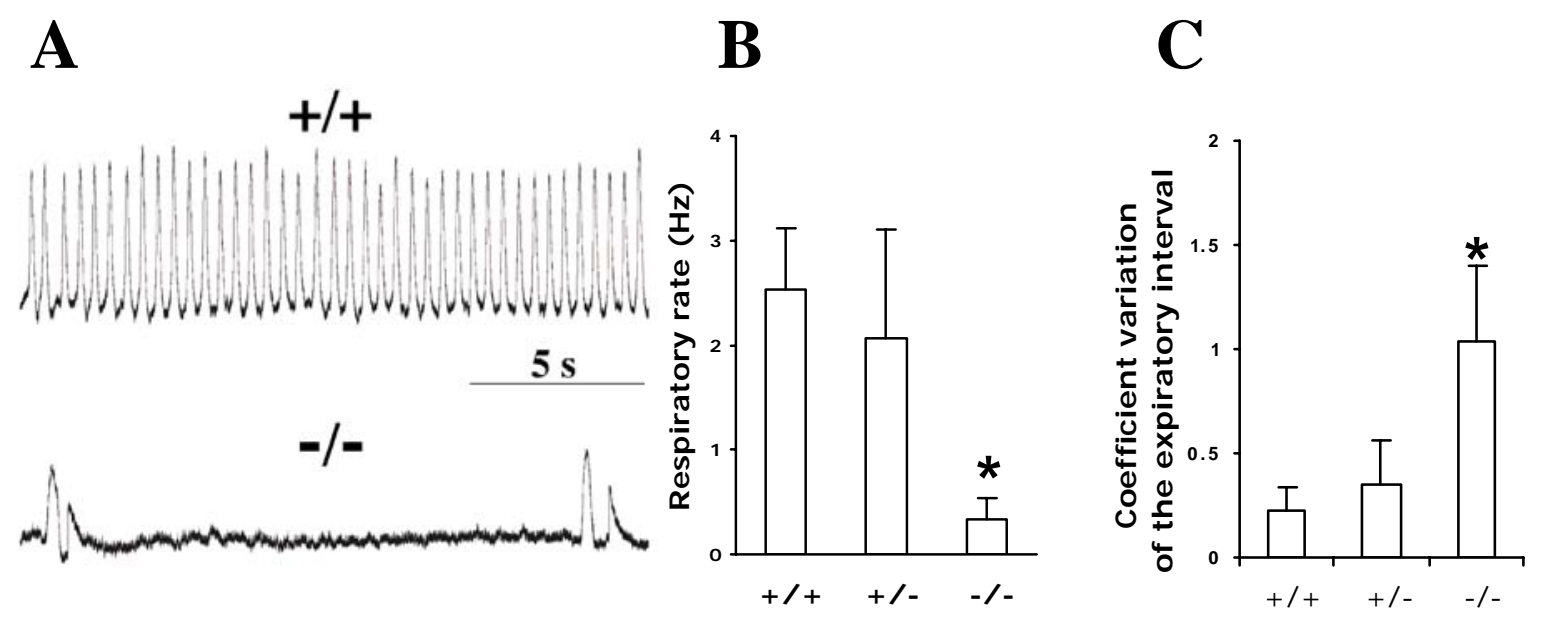

Figure 35. Breathing of wild type, heterozygous and homozygous Glyt1 KO newborn mice

(A) shows recording of breathing from a wild type (above) and a Glyt1 KO (below) mouse. (B) shows the frequency of the breathing, $\mathrm{C}$ the coefficient variation of the expiratory intervals of homozygous, heterozygous and wt mice. Results are shown as mean \pm SD. Asterix marks the data significantly different from control condition. 


\subsubsection{The in vitro respiratory rhythm of GlyT1 KO mice}

The in vitro respiratory activity was further analysed by recording the neuronal activity of rhythmic slices from the caudal medulla containing the PBC and the nucleus hypoglossus. Preparations from wild-type animals showed a regular rhythmic bursting (Figure $36 \mathrm{~A}, \mathrm{E}$ ) at a frequency of $0.22 \pm 0.08 \mathrm{~Hz}$ (mean $\pm \mathrm{SD}, \mathrm{n}=8$ ). The results were similar in heterozygous mice (frequency $0.16 \pm 0.07 \mathrm{~Hz}, \mathrm{n}=8, \mathrm{p}>0.05$ ), while in homozygous $\mathrm{KO}$ animals (Figure $36 \mathrm{C}$, E) prolonged periods of inactivity were registered, and burst frequency was only $0.06 \pm 0.04 \mathrm{~Hz}(\mathrm{n}=10, \mathrm{p}<0.001)$.

The lack of glial glycine uptake due to the inactivation of the GlyT1 possibly leads to increased glycine concentration. The question arised whether the strongly reduced in vitro respiratory rate of the GlyT1 KO mice depends on the effect of the increased synaptic glycine. Since glycine can act as neurotransmitter on glycine receptors, or as neuromodulator on NMDA receptors, the effect of blockade of both was tested. In the presence of the glycine receptor blocker strychnine $(2 \mu \mathrm{M})$, the reduced respiratory burst activity of the homozygous GlyT1 KO animals increased 3.6 fold, leading to a frequency $(0.27 \pm 0.09 \mathrm{~Hz}, \mathrm{n}=5, \mathrm{p}=0.002)$ comparable to that seen under control conditions in wild-type mice (Figure $36 \mathrm{D}, \mathrm{E}$ ). In preparations from wild-type animals strychnine did not change the burst frequency (Figure 36 B, E).

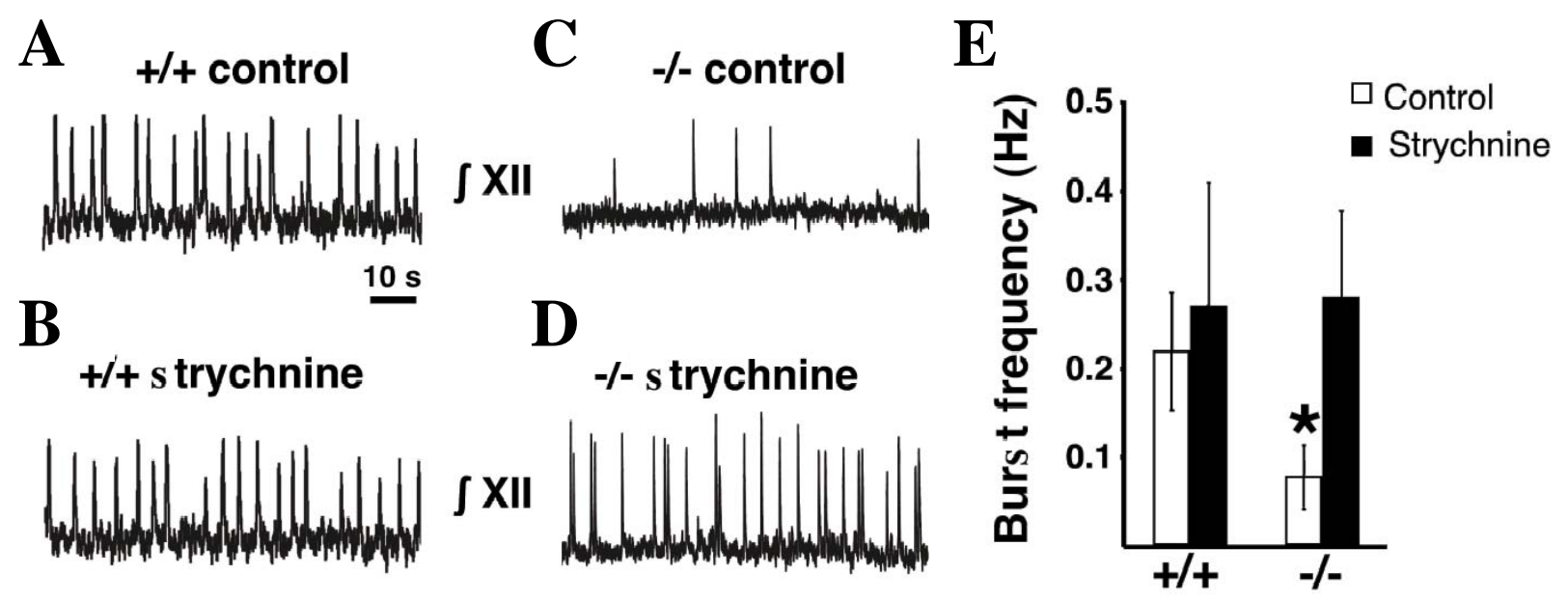

Figure 36. In vitro respiratory activity of GlyT1 KO mice

The figure shows the in vitro respiratory rhythm of a wild-type (A, B) and a Glyt1 KO (C, D) newborn mouse before $(A, C)$ and after $(B, D)$ treatment with $2 \mu \mathrm{M}$ strychnine. The integral of the burst activity recorded from acute rhythmic slices is shown. (E) shows the statistical analysis of the changes of the in vitro respiratory frequency in wild type and GlyT1 KO mice in response to $2 \mu \mathrm{M}$ strychnine. Data are shown as mean \pm SD, asterix indicates significant difference. 
In contrast to the strychnine, the NMDA receptor blockers AP5 (100 $\mu \mathrm{M})$ and MK801 $(10 \mu \mathrm{M})$ did not induce regular rhythm in slices from GlyT1 KO animals; even in the presence of both drugs, burst frequencies were unaltered $(0.03 \pm 0.04 \mathrm{~Hz}, \mathrm{n}=3$; Figure 37)

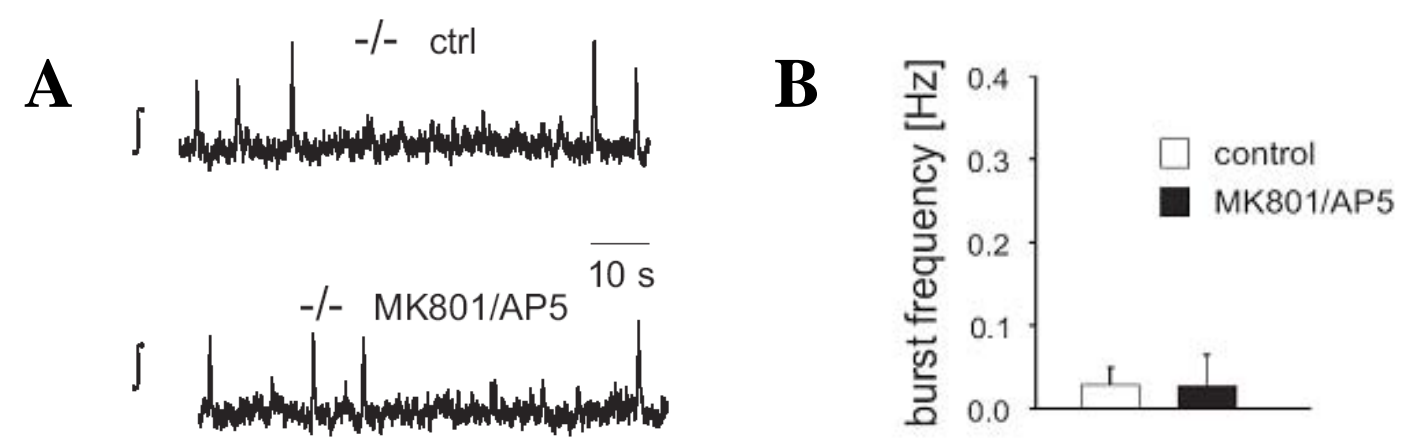

Figure 37. Effect of the NMDA receptor blockers on the in vitro respiratory rhythm of GlyT1 KO mice

(A) shows the in vitro respiratory rhythm of a GlyT1 KO mouse before (above) and after (below) the application of $10 \mu \mathrm{M}$ MK801 and $100 \mu \mathrm{M}$ AP5. (B) shows the statistical analysis of the effect of $10 \mu \mathrm{M}$ MK801 and 100 $\mu \mathrm{M}$ AP5 on the in vitro respiratory rhythm of GlyT1 KO mice. Data are shown as mean \pm SD.

$2 \mathrm{mM}$ strychnine was shown to block $\mathrm{GABA}_{\mathrm{A}}$ receptors as well (Jonas et al, 1998). Therefore we tested the effect of $\mathrm{GABA}_{\mathrm{A}}$ receptor blockade too. In contrast to strychnine, bicuculline did not reverse the respiratory rhythm in slices from GlyT1 KO animals. Although high concentration induced a slight increase in the frequency in all 3 slices after an initial decrease at low concentrations of bicuculline (in the case of application of $20 \mu \mathrm{M}$ bicuculline from $0.025 \pm 0.026 \mathrm{~Hz}$ to $0.044 \pm 0.047 \mathrm{~Hz}, \mathrm{p}=0.56, \mathrm{n}=3$ ), the change was not significant in contrast to the effect of strychnine $(0.23 \pm 0.093, \mathrm{p}=0.03, \mathrm{n}=2)$ (Figure 38).
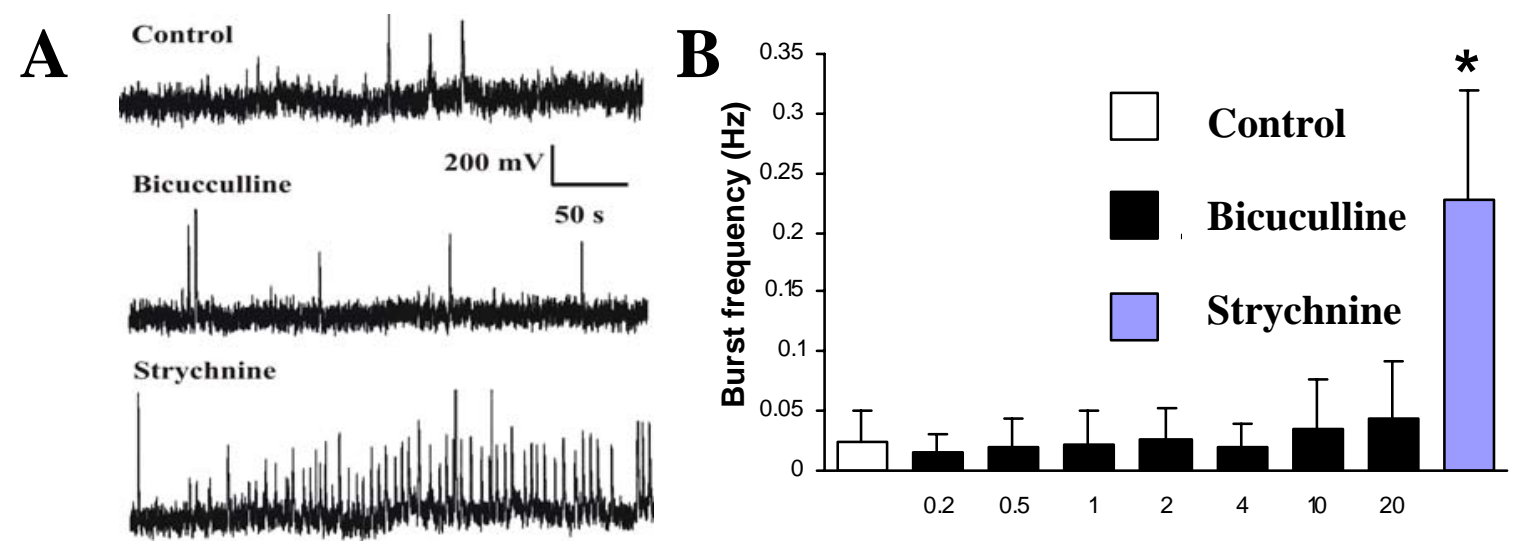

Figure 38. Effect of bicuculline on the in vitro respiratory rhythm of GlyT1 KO mice

(A) shows the in vitro respiratory rhythm of a GlyT1 KO mouse before and after application of $20 \mu \mathrm{M}$ bicuculline and finally after application of $2 \mu \mathrm{M}$ strychnine. (B) shows the statistical analysis of the effect of different concentrations of bicuculline on the frequency of the in vitro respiratory rhythm of GlyT1 KO mice. In comparison, the strychnine effect is also shown on the same slices. Data are shown as mean \pm SD. Asterix marks the significant difference. 


\subsubsection{Effect of glycine and sarcosine on the normal in vitro respiratory rhythm}

The previous data suggest that the effect of the genetical inactivation of GlyT1 in the homozygous GlyT1 KO mice is due to effect of glycine on glycine receptors. Therefore we also examined the effect of glycine on the in vitro respiratory rhythm of wild type mice. Furthermore we examined the effect of the GlyT1 inhibitor sarcosine.

In wild-type slices $1 \mathrm{mM}$ glycine, the same concentration as used for recording GlyR and GlyT mediated currents, produced a strong suppression of in vitro respiratory activity to $3.2 \%$ of that seen under control conditions $(n=3)$ which recovered upon washout (Figure 39)
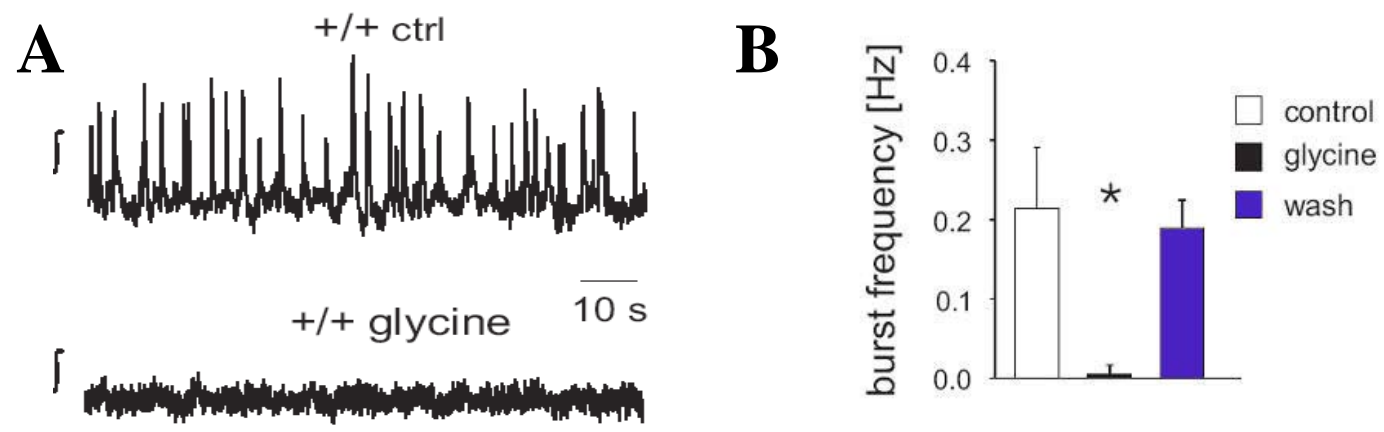

Figure 40. Effect of glycine on the in vitro respiratory rate of newborn mice

(A) shows the in vitro respiratory rhythm of a wild-type mouse before and after the application of $1 \mathrm{mM}$ glycine.

(B) shows the statistical analysis of the glycine effect and recovery after washout. Data are expressed as mean \pm standard deviation, asterix indicates significant difference.

Finally, application of the GlyT1 inhibitor sarcosine also produced a dose-dependent slowing of the rhythmic burst pattern in preparations from wild-type mice. At a concentration of $2 \mathrm{mM}$, sarcosine reduced the network activity to $15.2 \%$ of control $(\mathrm{n}=4)$. (Figure 40 ).
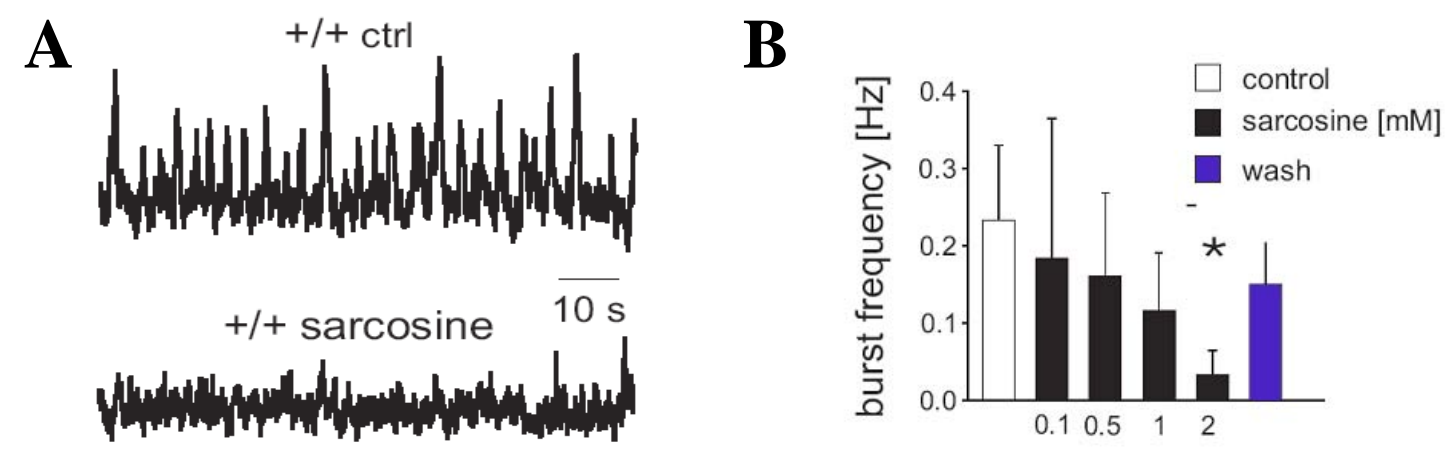

Figure 40. Effect of sarcosine on the in vitro respiratory rate of newborn mice.

(A) shows the in vitro respiratory rhythm of a wild-type mouse before and after the application of $2 \mathrm{mM}$ sarcosine. (B) shows the statistical analysis of the effect of different concentrations of sarcosine and the recovery after washout. Data are expressed as mean \pm standard deviation, asterix marks significantly different. 


\section{Discussion}

\subsection{GlyT1 is expressed in passive and intermediate astrocytes}

So far, GlyT1 immunohistochemistry and in situ hybridization was performed in mice in which no fluorescent marker was used to differentiate between the different cell types (Zafra et al, 1995a). According to morphological features, glial cells were described to express GlyT1. We used different transgenic mice to analyze the GlyT1 expression in cells identified by fluorescent markers. In TgN (hGFAP/EGFP) mice GlyT1 was found in astrocytes with high EGFP expression in the ventral respiratory group. These bright fluorescent cells are almost exclusively the passive and intermediate astrocytes. In contrast, GlyT1 was not expressed on very dark cells, which are supposed to be the outwardly rectifying astrocytes. The fact that no co-staining was found with the NG2 marker, which is thought to be a marker of outwardly rectifying astrocytes (Graß et al, 2004), supports that outwardly rectifying astrocytes do not express GlyT1.

In whole-cell voltage clamp experiments, passive and intermediate astrocytes showed glycine induced inward currents similar to that of described in astrocytes of spinal cord identified by morphological criteria (Pastor et al, 1995). In contrast to their results, in our experiments outwardly rectifying astrocytes did not show any response to glycine. Although the largest part of this glycine current was receptor related, similar to that in the spinal cord, one part of the current remained after the complete blockade of glycine receptors with strychnine, which is considered as transporter current. This shows the functionality of the GlyT1, which was described in the immunohistochemistry experiments on passive and intermediate astrocytes. Similar to the GlyT1 related currents previously described in retinal Müller-cells together with receptor-currents (Du et al, 2002), and in cerebellar Bergmann-glia (Huang et al, 2004), the transporter current was quite small, under 50 pA.

Astrocytes with high levels of EGFP expression were reported to express glutamate transporters according to the immunocytochemistry. Passive and intermediate astrocytes showed also glutamate transporter currents supporting the fact that these cells express glutamate transporters (Graß et al, 2004). According to our results these cells express also glycine transporters. GlyT1 co-staining performed with one of the glutamate transporters, GLAST, supported this view as strong co-localization was found in bright fluorescent astrocytes, showing that the same cells express transporters for both glutamate and glycine. Whole-cell voltage-clamp experiments also confirmed this, as passive astrocytes expressed both glycine transporter currents and glutamate transporter currents. Concluding these data, 
passive and intermediate astrocytes seem to be important for the uptake of various neurotransmitters including glycine and glutamate, thereby modulating the synaptic transmission. Our still preliminary results indicate also a similar role for GABA.

In contrast to astrocytes, the majority of the labelled oligodendrocytes in the TgN (mPLP/DsRed) mice did not show GlyT1 staining. In the few oligodendrocytes which did show GlyT1 staining, the staining was weak. The fact, that strong staining could be found in non-labelled cells, makes it improbable, that the different fluorescent markers of the cells and of the second antibodies would be the reason. Also, in double fluorescent slice with both green astrocytes and red oligodendrocytes, oligodendrocytes showed no staining or comparably weaker staining than astrocytes. Important to mention is that the density of the labelled oligodendrocytes is significatly less than that of the labelled astrocytes, which makes it more difficult to find many labelled oligodendrocytes to analyze, thus increasing the chance not to find stained cells. These results indicate that although oligodendrocytes might express GlyT1, the expression is very weak in comparison to astrocytes. Despite the poor immunohistochemistry results, oligodendrocytes expressed similar glycine transporter currents as passive and intermediate astrocytes, suggesting a possible role in glycine uptake. This glycine transporter current is different from the results obtained in spinal cord where all of the glycine current was receptor-mediated (Pastor et al, 1995). Although autoradiography did not confirm glycine uptake in oligodendrocytes (Reynolds and Herschkowitz, 1986), there are some other data also showing glycine transport: strong sodium-dependent glycine biding was observed in the myelin fraction in rat brain cortex homogenates (Valdes et al, 1977), and oligodendrocyte precursors showed an intracellular Ca2+ influx partially due to sodiumdependent transporters in response to glycine (Belachew et al, 2000). Our finding of glycine transporter current in oligodendrocytes is new and the functional role is yet to be discovered, it might contribute however in extrasynaptic glycine uptake.

GlyT1 mRNA expression was also analyzed by single-cell reverse transcription PCR. Passive and intermediate astrocytes, as expected, showed GlyT1 mRNA expression. Oligodendrocytes, and unexpectedly, 7 of 10 outwardly rectifying astrocytes also expressed GlyT1 mRNA. However, we should consider that the presence of mRNA does not mean the expression of the functional protein, and that the single-cell PCR is not quantitative: as the amplification is very high, it cannot show the possible differences in the mRNA amount. The fact that one of the two hypoglossus motoneurons, which were additionally analyzed (data not shown), also showed GlyT1 mRNA expression by single cell PCR, indicates that single cell PCR can show mRNA expression even in cells where the functional protein is not present, 
because according to the immunostaining on slices from TgN (Thy1.2/YFP) mice, neurons of the respiratory network were supposed not to express GlyT1. It is important to mention a similar contradiction in the case of the glutamate transporter: while, in contrast to passive and intermediate astrocytes, outwardly rectifying astrocytes did not show glutamate transporter current and glutamate transporter immunostaining (Graß et al, 2004, Matthias et al, 2003), glutamate transporter mRNA was also shown in outwardly rectifying astrocytes with singlecell PCR (Matthias et al, 2003).

\subsection{GlyT1 function is necessary for the respiratory rhythm generation}

Genetic ablation of GlyT1 in homozygous GlyT1 KO mice led to death of the newborn mice within the first day of life, showing that GlyT1 is vital at this age. As the macro- and microanatomical structure of the mice appeared normal, the cause of the lethal phenotype should be a functional failure. Measuring the breathing, we found that the respiration of these mice was decreased in frequency and much more irregular in comparison to the normal breathing of heterozygous and wild-type littermates. These results suggest that the reason of the death of the newborn mice is respiratory failure. As GlyT1 is considered glial specific, this result supports the view that contribution of glial cells by modulation of the neurotransmission of the respiratory network is also necessary for the proper respiratory rhythm generation, which came from experiments showing that glial metabolism blockade reduced the respiratory rhythm (Hülsmann et al, 2000).

Studying the in vitro respiratory rhythm recorded from rhythmic slices from the caudal brain stem, similar differences were found in the frequency than in the breathing (in vivo respiration). The in vitro preparation allowed us to study the different neurotransmission pathways. As application of glycine also reduced the in vitro respiratory rhythm of GlyT1 KO mice, the effect of GlyT1 inhibition is thought to be due to increased extracellular glycine concentration. Glycine can act either on glycine receptors as an inhibitory neurotransmitter, or on NMDA receptors as a co-agonist of glutamate (neuromodulator role). Both pathways were tested in our experiments. The glycine receptor inhibitor strychnine increased the strongly reduced in vitro respiratory rate of the homozygous GlyT1 KO mice near to normal levels, while the NMDA receptor blocker MK801 and AP5 had no effect, showing that GlyT1 inhibition expresses its effect on the respiratory rhythm through glycine receptors, rather than through NMDA receptors. Whole-cell voltage-clamp recordings of glycinergic currents showed decreased frequency and increased decay time of glycinergic IPSCs in GlyT1 KO 
mice, along with a significantly increased RMS noise, which was reduced with strychnine, supporting the role of GlyRs in accomplishing the effect of GlyT1 inhibition (Gomeza et al, 2003a). The differences in the glycinergic IPSCs were similar to that observed in spinal cord neurons using the selective GlyT1 antagonist Org 24598 (Bradaia et al, 2004), showing that the effects of pharmacological and genetic blockade are similar.

Chloride-mediated inhibition does not seem to be essential for respiratory rhythmogenesis in newborn mice according to experiments, which show no effect of the glycine receptor blocker strychnine or the $\mathrm{GABA}_{\mathrm{A}}$ receptor blocker bicuculline on the in vitro respiratory rhythm of wild-type mice at this age (Ritter and Zhang 2000, Paton and Richter 1995). In contrast to newborn mice, in adults the blockade of $\mathrm{GABA}_{\mathrm{A}}$ and glycine receptors greatly disturbs or abolishes respiratory rhythm, implying that synaptic inhibition is critically important in respiratory rhythmogenesis (Richter and Spyer, 2001). Our experiments on newborn mice indicate a dramatic depression of respiratory activity in homozygous GlyT1 KO mice, which seems to be mediated through glycine receptors, pointing to a critical effect of increased inhibition in newborn mice. Data from respiratory neurons (Ritter and Zhang, 2000) and hypoglossal motoneurons (Singer et al., 1998) have suggested that the chloride equilibrium potential is depolarizing in neonatal mice. This could be the reason that transient activation of glycine receptors during the normal synaptic transmission does not influence the respiratory network activity. However, persistent GlyR activation by excess glycine leads to inhibition and thereby depression of the network activity.

Strychnine in high concentration was reported to block GABA receptors too (Jonas et al, 1998). Although we did not use a very high concentration in these experiments, the concentration was high enough to have an effect on $\mathrm{GABA}_{\mathrm{A}}$ receptors. Therefore we decided to also investigate the effect of bicuculline, the blocker of $\mathrm{GABA}_{\mathrm{A}}$ receptors. In contrast to strychnine, bicuculline did not increase the reduced respiratory rhythm of the GlyT1 KO mice significantly. An extremely high concentration $(20 \mu \mathrm{M})$ caused a slight increase of the frequency, but did not restore the frequency of the respiratory rhythm to a normal level, and this high concentration of bicuculline was described to block also glycine receptors (Jonas et al, 1998), thus the effect can be due to GlyR blockade. This shows that strychnine elicited its effect on glycine receptors, GABA-inhibition is not important in the severe phenotype of the GlyT1 KO mice. Bicuculline had no effect on the in vitro respiratory rhythm of wild type mice, similar to other experiments on very young (p1) mice, and in contrast to older animals (Ritter and Zhang, 2000). 
Similar to the effect of the genetic ablation of the GlyT1 in GlyT1 KO mice, the pharmacological inhibition of GlyT1 with sarcosine also reduced the in vitro respiratory rhythm in newborn mice. However, sarcosine, N-methyl-glycine, is a glycine homologue, therefore the effect of sarcosine can be due not only to GlyT1 inhibition, but also to direct activation of glycine receptors. Data from whole-cell voltage clamp experiments on hypoglossus motoneurons showed that sarcosine induced current is mainly due to its effect on glycine receptors, rather than the effect on GlyT1 blockade (Data not shown). This raises the question of whether the effect of sarcosine on the in vitro respiratory rhythm might be due to direct effect on glycine receptors, especially since glycine itself produces a similar effect.

\subsection{GlyT1 is glial specific in the respiratory network}

GlyT1 was originally described as glial specific according to immunohistochemistry and in situ hibridization results (Zafra et al, 1995a, Adams 1995), however, neuronal GlyT1 was also discovered later. GlyT1 expressing neurons were described in retinal transplants (Sharma, 2000), in this context it is important to mention that already Zafra described GlyT1 expressing neurons in the retina as exception. Recently neuronal GlyT1 was found in cortex and cerebellum (Jones et al, 2004, conference abstract, Cubelos et al, 2005). Therefore, the question arose whether the critical role of GlyT1 in the respiratory rhythm generation is due to neuronal GlyT1. Our data with TgN (Thy1.2/EYFP) mice, which have fluorescently labelled neurons, including respiratory neurons, located at important areas of the respiratory network (Winter et al, 2005, conference abstract), suggest that the GlyT1 in the respiratory network is glial specific, since the staining was localised exclusively on nonfluorescent cells within the ventral respiratory group as well as in the Nucleus hypoglossus. Although not every neuron was labelled with the fluorescent marker, our other data showing strong expression of GlyT1 on passive and intermediate astrocytes support this view.

\subsection{Expression of GlyR in different glial cell types}

In whole-cell voltage-clamp experiments the main parts of the inward currents that glycine evoked in passive and intermediate astrocytes and oligodendrocytes were strychnine sensitive receptor currents, indicating that these cells express functional glycine receptors. The current recordings were similar to those described in astrocytes and oligodendrocytes of the spinal cord (Pastor et al, 1995), although in those experiments morphological criteria were 
used for the identification of the cells. The expression of mRNA of different GlyR subunits was also shown in these cells by single-cell PCR (Kirchhoff et al, 1996). In our experiments, no glycine induced current was detected in outwardly rectifying astrocytes of the respiratory network, in contrary to the previous results where glycine induced currents were recorded from cells with outwardly rectifying IV relationship. However, due to the lack of the fluorescent marker, it is not clear whether those cells are identical to our outwardly rectifying astrocytes, and NG2 staining which would have helped to identify the cells was not performed.

Bath application has disadvantages: first, the initiation of the drug effect is delayed and can not always be determined exactly as there could be slight differences in the flow, in the recording of the application etc., second, it takes long time and finally the applied substance acts on the whole preparation, not only in our place of interest. Therefore, experiments were done with a perfusion system in which the fluid flow could be changed quickly from control to substance-containing solution. To make the effect local, the application capillary was placed near to the cell. With longer application time similar currents were recorded than with bath application, but when we tried to close to a more synaptic-like short application by reducing the application time, the recorded currents were close to the detection level, making an exact analysis impossible. This might be due to limitations of the application system, since glutamate currents recorded under these conditions were also very small.

Finally, glycine induced currents were recorded from passive and intermediate astrocytes using pressure-ejection of glycine (Oku et al, 1999) in the presence of blockers for GABA and glutamate receptors and for synaptic transmission, to exclude the possibility of any indirect effect, as well as make the application synaptic-like. This confirmed that the glycine effect is not an indirect effect due to for example neuronal glycine response, which was suspected as neurons express much larger currents in response to glycine, and in cell culture the glycine effect on glial cells was described as indirect effect from neurons (Hosli et al, 1981).

GlyR expression was studied also by immunohistochemistry on fluorescently labeled cells. In TgN (hGFAP/EGFP) mice GlyR staining was found primarily on non-labelled big cells, supposedly neurons. However, numerous fluorescently labelled cells were found to express GlyR as well. The GlyR staining of the astrocytes was weaker than the neuronal GlyR staining, which correlates with the results showing that astrocytes express much smaller currents in response to glycine than neighbouring neurons. While in the case of astrocytes the 
expressed currents just rarely exceed 200 pA, neurons showed currents in the range of more $\mathrm{nA}$, indicating that neurons express much more functional glycine receptors than astrocytes.

In contrast to the electrophysiology showing no glycine response in outwardly rectifying astrocytes, GlyR-staining was found not only in bright fluorescent cells but also in dark fluorescent astrocytes. However, we can not be sure that these cells are outwardly rectifying astrocytes, since there are passive and intermediate dark cells also and no clear NG2/GlyR co-staining was found. Some NG2+ dark cells seemed to show a weak GlyR staining but the majority of the fluorescently labelled cells did not show co-staining for GlyR and NG2. It is important to notice that the staining procedure was not perfect, since to prevent possible cross-reaction of the second antibodies raised against related species, consecutive staining was performed. The immunohistochemistry results, however, do not exclude the possibility of GlyR expression on outwardly rectifying astrocytes.

As in images of the green fluorescent astrocytes we often see bright cells in close proximity with a dark cell, and there are data of processes of bright cells enwrapping the dark cell, the GlyR staining often seen on dark cells might be staining on the enwrapping processes of neighbour passive (or intermediate) cells, which are not fluorescently labelled.

An other possibility, that outwardly rectifying astrocytes also express GlyRs similarly to passive and intermediate astrocytes, but since the expression is weak, the currents expressed by outwardly rectifying astrocytes are too small to be separated from the noise. Passive cells, however, were shown to be coupled to many others via gap junctions (Wallraff et al, 2004). Similarly, immunohistochemistry against connexin 43, the main astrocytic connexin, showed staining on bright fluorescent astrocytes (passive and intermediate), and no NG2-connexin co-staining was found. Therefore in passive and intermediate astrocytes recording might show currents from neighbouring cells of the astroglial syntitium, while outwardly rectifying cells are not connected by gap junctions, one might only see the currents of the recorded cell. The facts that just some of the fluorescent cells show GlyR staining, while with bath application all of them expressed glycine currents, that the glycine current decreases if the passive conductance of the cell decreases (data not shown), and less glycine currents were detected with local application of glycine, support this theory.

Finally, there is also a possibility that only very few outwardly rectifying cells express glycine receptor and we did not found these cells in the electrophysiology experiments. 


\subsection{The functional role of glycine receptors on glial cells}

The previous electrophysiology data suggest that the same passive and intermediate astrocytes express both GlyT1 and glycine receptors within the respiratory network, which was also confirmed by immunohistochemistry, where cells with high levels ofEGFP fluorescence showed GlyR co-staining with GlyT1. According to the electrophysiology data, oligodendrocytes might also co-express glycine receptor and transporter. While the role of GlyT1 is quite clear because of its vital effect on the respiratory rhythm generation, the role of GlyR on glial cells is unknown. Our hypothesis was that glycine induce GlyT1 synthesis in glial cells through the glial GlyR, this would explain the co-expression. However, preliminary data of astrocytic culture showed that neither application of additional glycine, nor application of strychnine to the cell culture medium affected the GlyT1 expression noticeably by western blot, the difference found could be explained with difference in protein amount. Immunocytochemistry was also performed in cell culture, but no specific staining was found even in astrocytic-neuronal mixed cultures as suggested by Zafra et al (1997). To analyse the effect of decreased glycine in brain stem preparation, GlyT1 immunostaining of wild type mice was compared with GlyT1 immunostaining of mice KO for GlyT2. Although in these mice the extracellular glycine concentration is strongly decreased (Gomeza et al, 2003b), the GlyT1 immunostaining was decreased only in one out of three slices from different KO animals in comparison to slices from wild type littermates. This finding is comparable to the western blot results showing no difference in expression of GlyT1 (Gomeza et al, 2003b), which was repeatable in our hands. In summary, we could not support the theory with experimental data so far.

\subsection{Outwardly rectifying astrocytes express large GABA receptor currents}

Similarly to glycine, the other main inhibitory neurotransmitter, GABA also induced inward currents in passive and intermediate astrocytes, as well as in oligodendrocytes. In contrast, however, GABA induced significantly larger currents in outwardly rectifying astrocytes than in the other cell types. While in passive astrocytes a significant part of the GABA-induced current remained after the blockede of the two main GABA-receptor types, $\mathrm{GABA}_{\mathrm{A}}$ and $\mathrm{GABA}_{\mathrm{B}}$, suggesting the presence of GABA transporters, the large current of the outwardly rectifying astrocytes almost disappeared after the receptor blockade, therefore thought to be receptor-mediated current. This finding is in line with recent findings of 
GABAergic EPSCs in outwardly rectifying astrocytes (Jabs et al, 2005) and fits to the results of NG2+ precursor cells differentiating into GABAergic neurons (Belachew et al, 2003)

These results together with the glycine currents show that outwardly rectifying astrocytes are different from passive and intermediate cells not only in the excitatory (glutamate, described in Graß et al, 2004) but also in inhibitory (glycinergic and GABAergic) neurotransmission, supporting the theory that these cells represent a different cell population.

\subsection{Glial cell identity}

Two transgenic mice were used as a tool to identify the different glial cell types: the TgN (hGFAP/EGFP) mice, expressing green fluorescence in cells which are supposed to be astrocytes, and the TgN (mPLP/DsRed) mice, expressing red fluorescence in oligodendrocytes. In the TgN (mPLP/DsRed) mice none of the cells labelled with red fluorescence showed neuron-like electrophysiological features in our experiments, despite the fact that PLP was shown to be expressed in neurons in the developing brain stem (Miller et al, 2003). The cells labelled with red fluorescence were all oligodedrocytes according to the electrophysiology. However, the cell identity is less clear in the transgenic mice expressing the EGFP under the control of the GFAP promoter. In these mice, cells express green fluorescence with different intensity, which shows correlation with the electrophysiology. Bright fluorescent cells are electrophysiologically almost exclusively passive or intermediate astrocytes, while outwardly rectifying astrocytes are very dark fluorescent cells (Graß et al, 2004). Outwardly rectifying astrocytes showed numerous significant difference when compared with passive and intermediate astrocytes, suggesting that they might be a different group of cells. First, they were described to have significantly larger input resistance and less negative membrane potential in comparison to passive and intermediate astrocytes (Graß et al, 2004), which is supported by the similar results found in our experiments. An additional new data we obtained, that oligodendrocytes showed slightly less membrane potential, although having similar input resistance than passive and intermediate astrocytes, might be explained if outwardly rectifying astrocytes, which express an oligodendrocyte precursor marker, NG2, can differentiate into oligodendrocytes. The second significant difference of outwardly rectifying astrocytes is that of in the glutamatergic neurotransmission. Both in the hippocampus, and in the lower brain stem (respiratory network) outwardly rectifying astrocytes were shown to express significantly less glutamate transporter currents and conversely, more glutamate receptor currents than passive and intermediate astrocytes (Matthias et al, 2003, Graß et al, 2004). In contrast to passive astrocytes, outwardly rectifying 
astrocytes were described not coupled through gap-junctions (Wallraff et al, 2004), which is supported by our finding that NG2+ cells do not show immunostaining against connexin 43, the main astrocytic connexin type; connexin 43 was localized to cells with high EGFP expression levels. Recently the role of outwardly rectifying astrocytes in the GABAergic neurotransmission became interesting as NG2+ cells were described to develop into GABAergic neurons, and outwardly rectifying astrocytes were shown to express GABA receptor currents. Finally, our data show that outwardly rectifying astrocytes do not respond to glycine in contrast to the passive and intermediate astrocytes. All these facts point to the direction that outwardly rectifying astrocytes might be a distinct cell type. The theory is supported by findings that the A-type currents, which differentiate between passive and intermediate astrocytes, are depending on the intracellular chloride concentration (Bekar and Walz, 2002), and the disappearance of A-type current in passive astrocytes was also considered as artefact due to the outflow of the low-Ca2+ intracellular solution from the patch-pipette (Bordey and Sontheimer, 1998), suggesting that passive and intermediate cells are a homogenous cell population and the existence of A-type current is depending on extraand intracellular conditions. GlyT1/GLAST co-staining and GlyT1/GlyR co-staining was localized also

The glial precursor marker NG2, which was described first as a marker of the oligodendrocyte precursors in vivo and oligodendrocyte/type2 astrocyte progenitors in vitro, labels cells with very low expression levels of EGFP in the TgN (hGFAP/EGFP) mouse, therefore it might be considered as a marker of the outwardly rectifying astrocytes. Recently three research groups found evidences of mature NG2+ glial cells which can be considered as a fourth main type of glial cells beside the astrocytes, oligodendrocytes and microglia. First, Butt named them synantocytes, which refers only a population of the NG2 positive cells sitting close to synapses or nodes of Ranvier (Butt et al, 2002, Berry et al, 2002). In contrast to the NG2+ oligodendrocyte precursors the synantocytes are considered as a mature cell type with special fuction and localization, described already by Cajal as "cellules nèvrogliques pèricellulaires”, which means pericellular glia or perineuronal glia. In the same time Nishiyama named them polydendrocytes due to the morphology, and in contrast to Butt's definition they consider these cells as oligodendrocyte progenitor cells and as a homogenous population (Nishiyama et al, 2002). Recently Peters found according to appearance in electronmicroscopy a distinct cell type, called ß-neuroglial cells, similar to protoplasmic astrocytes and often lying next to neurons, probably identical to the mature NG2+ glia. 


\subsection{Final conclusions}

There are two main conclusions of this work. First, GlyT1 is expressed on passive and intermediate astrocytes, but not on outwardly rectifying astrocytes, similar to the glutamate transporter. Both whole-cell voltage clamp experiments and immunocytochemistry showed that the passive astrocytes co-express GlyT1 and glutamate transporter, and GlyR and GlyT (Figure 41). This leads to another main conclusion: as outwardly rectifying astrocytes were significantly different not only in the expression of glutamate transporters and receptors but also in the expression of glycine trasporters and receptors, and GABA receptors, they might be considered as a different cell type with special functions. According to the electrophysiology results, oligodendrocytes may also contribute to the glycine uptake. Second, GlyT1 has vital role in the respiratory rhythm generation of newborn mice, as GlyT1 KO mice die during the first day of life due to severe respiratory failure.

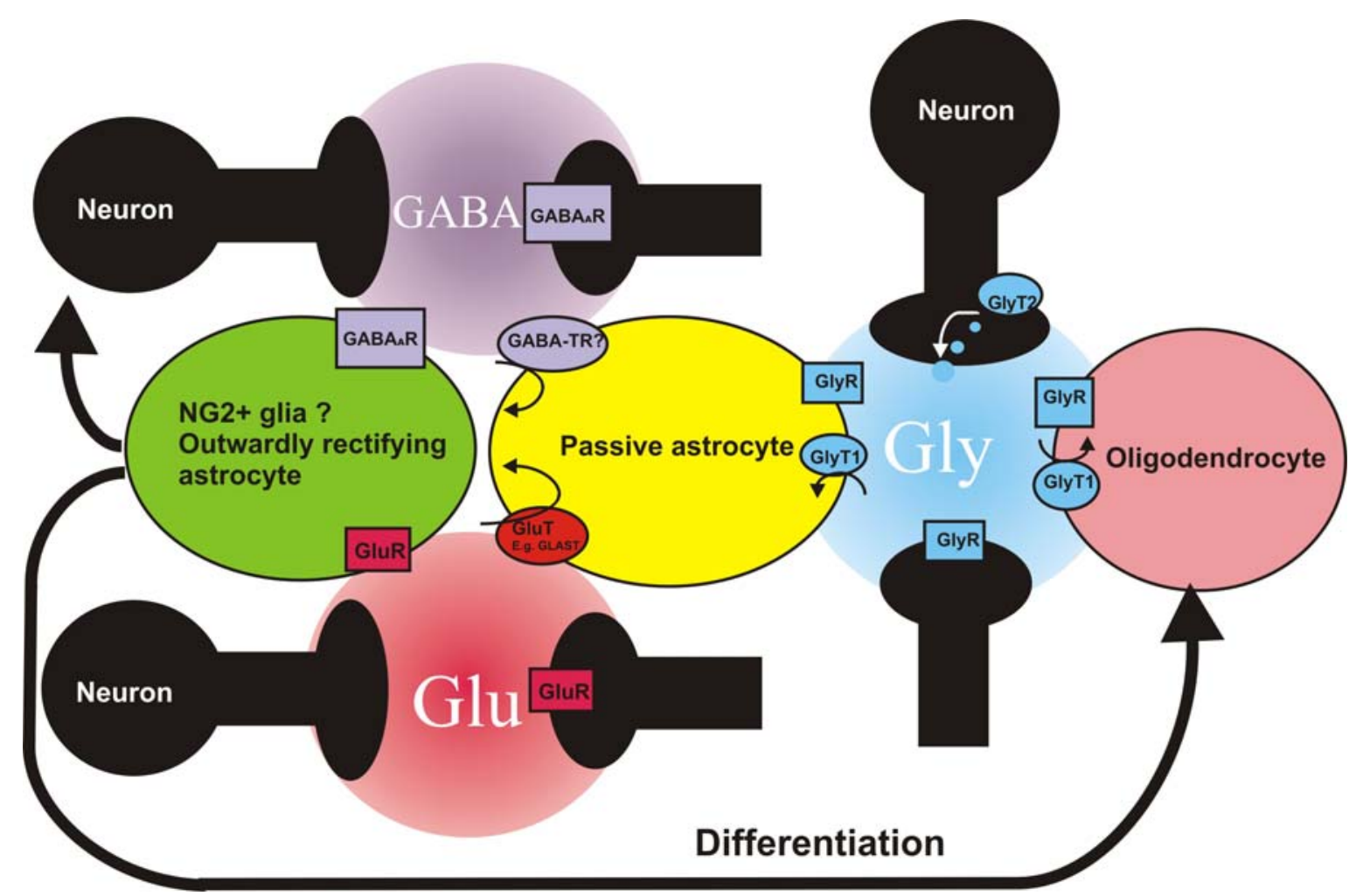

Figure 41. Schematic figure of the fuctions of passive and outwardly rectifying astrocytes/NG2 glia in the neurotransmission.

Passive astrocytes co-express GlyT1, GlyR and glutamate transporters (GluT), possibly also GABA transporters (GABA-TR), suggesting a role mainly in neurotransmitter uptake. Outwardly rectifying astrocytes co-express $\mathrm{GABA}_{\mathrm{A}}$ receptor and glutamate receptors (GluR), suggesting a role in acquiring information through neurotransmitter receptors. 


\section{Summary}

Glial cells of the respiratory network are necessary for the rhythm generation. They are believed to modulate the different neurotransmission pathways via their neurotransmitter transporters and receptors. The participation of astrocytes in the excitatory (glutamatergic) neurotransmission was already analyzed in previous studies. In the present work, we aimed to study the role of glial cells in the inhibitory neurotransmission of the respiratory network.

First, we analyzed how the different types of astrocytes and oligodendrocytes are involved in the inhibitory neurotransmission in the respiratory network using three different approaches: whole-cell voltage clamp recordings, immunohistochemistry and single-cell RTPCR in acute slices from 0-9 days old transgenic mice, in which astrocytes (TgN (hGFAPEGFP)) and oligodendrocytes (TgN (mPLP-DsRed)) are labeled with fluorescent proteins.

Astrocytes with bright fluorescence and linear IV relationship, independently of the expression of an additional A-type potassium current, showed immunostaining for the glial glycine transporter (GlyT1) and expressed receptor- and transporter-related whole-cell currents in response to application of the endogenous agonist glycine. One part of the whole glycine current was transporter-mediated. In contrast, additional population of astrocytes with reduced EGFP expression, large A-type currents and outwardly rectifying IV relationship did neither show GlyT1 immunostaining nor any response to glycine. However, these cells displayed much larger and mainly receptor-related currents in response to GABA. Oligodendrocytes, showing linear IV relationship, elicited both receptor and small transporter mediated glycine currents, but most of them did not show immunostaining. The mRNA of the GlyT1 was detected by single cell reverse transcription PCR in all types of glial cells.

Second, we analyzed the effect of genetical ablation of GlyT1 on the respiration of newborn mice. Both the breathing and the in vitro respiratory rhythm was strongly reduced in GlyT1 KO mice, and the mice died within the first day of life due to respiratory failure. The fact that the glycine receptor blocker strychnine restored a near normal in vitro respiratory rhythm in KO mice while had no effect on the normal rhythm in wild type mice show that the fatal effect of GlyT1 inhibition on the respiratory rhythm is due to increased glycine concentration. Conversely, both glycine and the GlyT1 blocker sarcosine reduced the normal respiratory rhythm of wild type mice.

Taken together, the data suggest, that modulation of the glycinergic inhibition through GlyT1 is critical in the respiratory network as its inhibition has fatal consequence, and passive and intermediate astrocytes, possibly also oligodendrocytes are responsible for the glycine uptake. 


\section{References}

Adams RH, Sato K, Shimada S, Tohyama M, Puschel AW, Betz H (1995) Gene structure and glial expression of the glycine transporter GlyT1 in embryonic and adult rodents. J. Neurosci., 15, 2524-2532

Becker CM, Hoch W, Betz H (1988) Glycine receptor heterogeneity in rat spinal cord during postnatal development (1988) EMBO J., 7(12), 3717-3726

Bekar LK and Walz W (2002) Intracellular chloride modulates A-type potassium channels in astrocytes. Glia, 39(3), 207-216

\section{Belachew S, Malgrange B, Rigo JM, Rogister B, Coucke P, Mazy-Servais C, Moonen G} (1998a) Developmental regulation of neuroligand-induced responses in cultured oligodendroglia. Neuroreport, 9(6), 973-980

Belachew S, Rogister B, Rigo JM, Malgrange B, Mazy-Servais C, Xhauflaire G, Coucke P, Moonen G (1998b) Cultured oligodendrocyte progenitors derived from cerebral cortex express a glycine receptor which is phartmacologically distinct from the neuronal isoform. Eur. J. Neurosci., 10(11), 3556-3564

Belachew S, Malgrange B, Rigo JM, Rogister B, Leprince P, Hans G, Nguyen L, Moonen G (2000) Glycine triggers an intracellular calcium influx in oligodendrocyte progenitor cells which is mediated by the activation of both the ionotropic glycine receptor and $\mathrm{Na}^{+}$-dependent transporters. Eur. J.Neurosci., 12(6), 1924-1930

Belachew S, Chittajallu R, Aguirre AA, Yuan X, Kirby M, Anderson S, Gallo V (2003) Postnatal NG2 proteoglycan-expressing progenitor cells are intrinsically multipotent and generate functional neurons. J. Cell Biol. 161(1), 169-186

Berger AJ, Dieudonne S, Ascher P (1998) Glycine uptake governs glycine site occupancy at NMDA receptors of excitatory synapses. J Neurophysiol, 80(6), 3336-3340 
Berger AJ and Isaacson JS (1999) Modulation of motoneuron N-methyl-D-aspartate receptors by the inhibitory neurotransmitter glycine. J. Physiol. Paris, 93(1-2), 23-27

Bergles DE, Roberts JD, Somogyi P, Jahr CE (2000) Glutamatergic synapses on oligodendrocyte progenitor cells in the hippocampus. Nature 405 (6783), 187-191

Berry M, Hubbard P, Butt AM (2002) Cytology and lineage of NG2-positive glia. J. Neurocytology, 31(6-7), 457-467

Betz H, Schmitt B, Becker CM, Grenningloh G, Rienitz A (1986) The vertebrate glycine receptor protein. Biochem. Soc. Symp., 52, 57-63

Bianchi AL, Denavit-Saubie M, Champagnat J (1995) Central control of breathing in mammals: neuronal circuitry, membrane properties, and neurotransmitters. Physiol Rev, 75, $1-45$

Bignami A, Eng LF, Dahl D, Uyeda CT (1972) Localization of the glial fibrillary acididc protein in astrocytes by immunfluorescence. Brain Research, 43(2), 429-435

Büsselberg D, Bischoff AM, Becker K, Becker CM, Richter DW (2001) The respiratory rhythm in mutant oscillator mice. Neurosci. Lett., 316(2), 99-102

Butera RJ, Rinzel J, Smith JC (1999) Models of respiratory rhythm generation in the preBötzinger complex. II. Populations of coupled pacemaker neurons. J. Neurophysiol., 82(1), 398-415

Butt AM, Duncan A, Hornby MF, Kirvell SL, Hunter A, Levine JM, Berry M (1999) Cells expressing the NG2 antigen contact nodes of Ranvier in adult CNS white matter. Glia, 26(1), 84-91

Butt AM, Kiff J, Hubbard P, Berry M (2002) Synantocytes: New functions for novel NG2 expressing glia. J. Neurocytology, 31(6-7), 551-565 
Bordey A and Sontheimer H (1998) Passive glial cell, fact or arifact? J. Membr. Biol., 166, 213-222

Borowsky B, Mezey E, Hoffmann BJ (1993) Two glycine transporter variants with distinct localization in the CNS and peripheral tissues are encoded by a common gene. Neuron, 10(5), 851-863

Bradaia A, Schlichter R, Trouslard J (2004) Role of glial and neuronal glycine transporters in the control of glycinergic and glutamatergic synaptic transmission in lamina $\mathrm{x}$ of the rat spinal cord. J. Physiol. 559, 169-186

Cascio M (2004) Structure and function of the glycine receptor and related nicotinicoid receptors. J. Biol. Chem., 279(19), 19383-19386

Connelly CA, Dobbins EG, Feldman JL (1992) Pre-Bötzinger complex in cats: respiratory neuronal discharge patterns. Brain Res 590(1-2), 337-340

Cubelos B, Gimenez C, Zafra F (2005) Localization of the GlyT1 glycine transporter at glutamatergic synapses in the rat brain. Cereb. Cortex, 15(4), 448-459

Du JL, Xu LY, Yang XL (2002) Glycine receptors and transporters on bullfrog retinal Müller-cells. Neuroreport, 13(13), 1653-1656

Eng LF, Vanderhaeghen JJ, Bignami A, Gerstl B (1971) An acidic protein isolated from fibrous astrocytes. Brain Research 28(2), 351-354

Eng LF, Ghimikar RS, Lee YL (2000) Glial fibrillary acidic protein: GFAP-thirty-one-years (1969-2000). Neurochem. Res. 25(9-10), 1439-1451

Feldman JL, Mitchell GS, Nattie EE (2003) Breathing: rhythmicity, plasticity, chemosensitivity. Annu Rev Neurosci 26, 239-266 
Gabernet L, Pauly-Evers M, Schwerdel C, Lentz M, Bluethmann H, Vogt K, Alberati D, Mohler H, Boison D (2005) Enhancement of the NMDA receptor function by reduction of glycine transporter 1 expression. Neurosci. Lett., 373(1), 79-84

Gomeza J, Hülsmann S, Ohno K, Eulenburg V, Szöke K, Richter D, Betz H (2003a) Inactivation of the glycine transporter 1 gene discloses vital role of glial glycine uptake in glycinergic inhibition. Neuron, 40 (4), 785-796

Gomeza J, Ohno K, Hülsmann S, Armsen W, Eulenburg V, Richter DW, Laube B, Betz H (2003b): Deletion of the mouse glycine transporter 2 results in a hyperekplexia phenotype and postnatal lethality. Neuron, 40 (4), 797-806

Graham D, Pfeiffer F, Simler R, Betz H (1985) Purification and characterization of the glycine receptor of pig spinal cord. Biochemistry, 24(4), 990-994

Greer JJ, Smith JC, Feldman JL (1991) Role of excitatory amino acids in the generation and transmission of respiratory drive in neonatal rat. J. Physiol., 437, 727-749

Graß D, Pawlowski PG, Hirrlinger J, Papadopoulos N, Richter DW, Kirchhoff F, Hülsmann S (2004) Diversity of functional astroglial properties in the respiratory network J. Neurosci 24 (6), 1358-1365

Gray PA, Janczewski WA, Mellen N, McCrimmon DR, Feldman JL (2001) Normal breathing requires preBötzinger complex neurokinin-1 receptor-expressing neurons. Nat. Neurosci. ,4(9), 927-930

Grenningloh G, Rienitz A, Schmitt B, Metfessel C, Zensen M, Beyreuther K, Gundelfinger ED, Betz H (1988) Molecular cloning of the antagonist-binding subunit of the glycine receptor. J. Recept. Res., 8(1-4), 183-193

Grenningloh G, Schmieden V, Schofield PR, Seeburg PH, Siddique T, Mohandas TK, Becker CM, Betz H (1990) Alpha subunit variants of the human glycine receptor: primary structures, functional expression and chromosomal localization of the corresponding genes. EMBO J., 9(3), 771-776 
Hosli L, Hosli E, Andres PF, Landolt H (1981) GABA and glycine receptors in CNS cultures: autoradiographic binding and electrophysiological studies, Adv. Biochem. Psychopharmacol., 29, 437-443

Huang H, Barakat L, Wang D, Bordey A (2004) Bergmann glial GlyT1 mediates glycine uptake and release in mouse cerebellar slices. J. Physiol., 560, 721-736

Hülsmann S, Oku Y, Zhang W, Richter DW (2000) Metabolic coupling between glia and neurons is necessary for maintaining respiratory activity in transverse medullary slices of neonatal mouse. Eur. J. Neurosci., 12 (3), 856-862

Jabs R, Pivneva T, Hüttmann K, Wyczynski A, Nolte C, Kettenmann H, Steinhauser C (2005) Synaptic transmission onto hippocampal glial cells with hGFAP promoter activity. J. Cell Sci., 118, 3791-3803

Javitt DC, Hashim A, Sershen H (2005) Modulation of striatal dopamine release by glycine transport inhibitors. Neuropsychopharmacology, 30(4), 649-656

Jonas P, Bischofberger J, Sandkuhler J (1998) Corelease of two fast neurotransmitters at a central synapse. Science, 1988, 281(5375), 419-424

Jones CK, Gordon K, Roth A, Hoffmann BJ (2004) Characterization of a glycine transporter 1A (GlyT1a)-specific antiserum reveals that GlyT1a is expressed in neurons and is the major GlyT1 isoform in the mouse forebrain. Poster at the Society for Neuroscience $34^{\text {th }}$ annual meeting in San Diego.

Jursky F, Tamura S, Tamura A, Mandiyan S, Nelson H, Nelson N (1994) Structure, function and brain localization of neurotransmitter transporters. J. Exp. Biol. 196, 283-295

Jursky F and Nelson N (1995) Localization of glycine neurotransmitter transporter (GLYT2) reveals correlation with the distribution of glycine receptor J. Neurochem, 64 (3), 1026-1033

Kandel ER (2000) Nerve cells and behavior. Chapter 2 in Principles of neural science, McGraw-Hill Comp Inc, $4^{\text {th }}$ edition, 19-35 
Kirchhoff F, Mulhardt C, Pastor A, Becker CM, Kettenmann H (1996) Expression of glycine receptor subunits in glial cells of the rat spinal cord. J. Neurochem., 66 (4), 1383-1390

Kuhse J, Schmieden V, Betz H (1990) Identification and functional expression of a novel ligand binding subunit of the inhibitory glycine receptor. J. Biol. Chem., 265(36), 2231722320

Kuhse J, Kuryatov A, Maulet Y, Malosio ML, Schmieden V, Betz H (1991) alternative splicing generates two isoforms of the alpha 2 subunit of the inhibitory glycine receptor. FEBS Lett., 283(1), 73-77

Langosch D, Thomas L, Betz H (1988) Conserved quaternary structure of ligand-gated ion channels: the postsynaptic glycine receptor is a pentamer. PNAS, 85(19), 7394-7398

Levine JM; Stincone F, Lee YS (1993) Development and differentiation of glial precursor cells in rat cerebellum. Glia, 7(4), 307-321

Lipina T, Labrie V, Weiner I, Roder J (2005) Modulators of the glycine site on NMDA receptors, D-serine and ALX 5407, display similar beneficial effects to clozapine in mouse models of schizophrenia. Psychopharmacology (Berl), 179(1), 54-67

Liu QR, Lopez-Corcuera B, Mandiyan S, Nelson H, Nelson N (1993) Cloning and expression of a spinal cord- and brainspecific glycine transporter with novel structural features. J Biol Chem, 268(30), 22802-22808

Lynch JW (2004) Molecular structure and function of the glycine receptor chloride channel. Physiol. Rev., 84(4), 1051-1095

Malosio ML, Grenningloh G, Kuhse J, Schmieden V, Schmitt B, Prior P, Betz H (1991) Alternative splicing generates two variants of the alpha1 subunit of the inhibitory glycine receptor. J. Biol. Chem., 266(4), 2048-2053

Masson J, Sagne C, Hamon M, El Mestikawy S (1999) Neurotransmitter transporters in the central nervous system. Pharmacol. Rev., 51(3), 439-464 
Matthias K, Kirchhoff F, Seifert G, Huttmann K, Matyash M, Kettemann H, Steinhauser C (2003) Segregated expression of AMPA-type glutamate receptors and glutamate transporters defines distinct astrocyte populations in the mouse hippocampus $\mathrm{J}$ of Neuroscience, 23 (5), 1750-1758

Matzenbach B, Maulet Y, Sefton L, Courtier B, Avner P, Guenet JL, Betz H (1994) Structural analysis of mouse glycine receptor alpha subunit genes. Identification and chromosomal localization of a novel variant.J. Biol. Chem, 269(4), 2607-2612

Miller MJ, Haxhiu MA, Georgiadis P, Gudz TI, Kangas CD, Macklin WB (2003) Proteolipid protein gene mutation induces altered ventilatory response to hypoxia in the myelin-deficient rat. J. Neurosci., 23(6), 2265-2273

Mortola JP, Frappell PB (1998) On the barometric method for measurements of ventilation and its use in small animals. Can. J. Physiol. Pharmacol., 76(10-11), 937-944

Niehaus A, Stegmüller J, Diers-Fenger M, Trotter J (1999) Cell-surface glycoprotein of oligodendrocyte progenitors involved in migration. J. Neurosci. 19(12) 4948-4961.

Nishiyama A, Watanabe M, Yang Z, Bu J (2002) Identity, distribution and development of polydendrocytes: NG2-expressing glial cells. J. Neurocytol., 31 (6-7) 437-455

Nolte C, Matyash M, Pivneva T, SchipkeCG, Ohlenmeyer C, Hanisch UK, Kirchhoff F, Kettenmann H (2001) GFAP promoter-controlled EGFP-expressing transgenic mice: a tool to visualize astrocytes and astrogliosis in living brain tissue. Glia, 33 (1), 72-86

Oku Y, Hülsmann S, Zhang W, Richter DW (1999) Modulation of glycinergic synaptic current kinetics by octanol in mouse hypoglossal motoneurons. Pflügers Arch., 438 (5), 656664

Ong WY and Levine JM (1999) A light and electron microscopic study of NG2 chondroitin sulfate proteoglycanpositive oligodendrocyte precursor cells in the normal and kainatelesioned rat hippocampus. Neuroscience, 92(1), 83-95 
Onimaru H and Homma I (2003) A novel functional neuron group for respiratory rhythm generation in the ventral medulla. J. Neurosci 23(4), 1478-1486

Pastor A, Chvatal A, Sykova E, Kettenmann H (1995) Glycine- and GABA-activated currents in identified glial cells of the developing rat spinal cord slice. Eur. J. Neurosci., 7(6), 1188-1198

Paton JF and Richter DW (1995) Role of fast inhibitory synaptic mechanisms in respiratory rhythm generation in the maturing mouse. J. Physiol., 484, 505-521

Peters A (2004) A fourth type of neuroglial cells in the adult central nervous system $\mathrm{J}$. Neurocytol, 33(3), 345-357

Pierrefiche O, Schwarzacher SW, Bischoff AM, Richter DW (1998) Blockade of synaptic inhibition within the pre-Bötzinger complex in the cat suppresses respiratory rhythm generation in vivo. J. Physiol 509, 245-254

Ponce J, Poyatos I, Aragon C, Gimenez C, Zafra F (1998) Characterization of the 5`region of the rat brain glycine transporter GlyT2 gene: identification of a novel isoform. Neurosci. Lett. 242 (1), 25-28

Prior P, Schmitt B, Grenningloh G, Pribilla I, Multhaup G, Beyreuther K, Maulet Y, Werner P, Langosch D, Kirsch J, Betz H (1992) Primary structure and alternative splice variants of gephyrin, a putative glycine receptor-tubulin linker protein (1992) Neuron, 8(6) ,1161-1170

Raff MC, Miller RH, Noble M. (1983) A glial progenitorcell that develops in vitro into an astrocyte or an oligodendrocyte depending on culture medium. Nature 303(5916), 390-396

Raff MC, Lillien LE, Richardson WD, Burne JF, Noble MD (1988) Platelet-derived growth factor from astrocytes drives the clock that times oligodendrocyte development in culture, Nature 333(6173), 562-565

Raff MC (1989) Glial cell diversification in the optic nerve. Science 243(4897), 1450-1455 
Rekling JC, Feldman JL (1998) PreBotzinger complex and pacemaker neurons: hypothesized site and kernel for respiratory rhythm generation. Annu. Rev. Physiol. 60, 385405

Reynolds $\mathbf{R}$ and Herschkowitz $\mathbf{N}$ (1986) Selective uptake of neuroactive amino acids by both oligodendrocytes and astrocytes in primary dissociated culture: a possible role for oligodendrocytes in neurotransmitter metabolism. Brain Res., 371(2), 253-266

Richter DW (2000) Rhythmogenese der atmung und atmungsregulation; Chapter 26 in Physiologie des Menschen (Schmidt RF, Thews G, Lang F) Springer-Verlag Berlin Heidelberg New York, $28^{\text {th }}$ edition, 592-603

Richter DW and Spyer KM (2001) Studying rhythmogenesis of breathing: comparison of in vivo and in vitro models. Trends Neurosci, 24(8), 464-472

Ritter B and Zhang W (2000) Early postnatal maturation of $\mathrm{GABA}_{\mathrm{A}}$ mediated inhibition in the brainstem respiratory rhythm-generating network of the mouse. Eur. J. Neurosci., 12(8), 2975-2984

Schneider S, Bosse F, D’Urso D, Müller H, Sereda MW, Nave K, Niehaus A, Kempf T, Schnolzer M, Trotter J. (2001) The AN2 protein is a novel marker for the Schwann cell lineage expressed by immature and nonmyelinating Schwann cells. J. Neurosci. 21(3) 920933

Schwarzacher SW, Smith JC, Richter DW (1995) Pre-Bötzinger complex in the cat. J. Neurophysiol, 73(4), 1452-1461

Sharma RK (2000) Development of glycine-accumulating neurons in retinal transplants. Ophtalmologica, 214(4), 264-270

Singer JH, Talley EM, Bayliss DA, Berger AJ (1998) Development of glycinergic synaptic transmission to rat brain stem motoneurons. J. Neurophysiol., 80(5), 2608-2620 
Smith FO, Rauch C, Williams DE, March CJ, Arthur D, Hilden J, Lampkin BC, Buckley JD, Buckley CV, Woods WG, Dinndorf PA, Soresen P, Kersey J, Hammond D, Bernstein ID (1996) The human homologie of rat NG2, a chondroitine sulfate proteoglycan, is not expressed on the cell surface of normal hematopoietic cells but is expressed by acute myeloid leukemia blasts from poor-prognosis patients with abnormalities of chromosome band 11q23. Blood, 87(3), 1123-1133

Smith JC, Ellenberger HH, Ballanyi K, Richter DW, Feldman JL (1991) Pre-Bötzinger complex: a brainstem region that may generate respiratory rhythm in mammals. Science, 254 (5032), 726-729

Smith JC, Butera RJ, Koshiya N, Del Negro C, Wilson CG, Johnson SM (2000) Respiratory rhythm generation in neonatal and adult mammals: the hybrid pacemakernetwork model. Respir.Physiol., 122(2-3), 131-147

Solomon IC, Edelman NH, Neubauer JA (1999) Patterns of phrenic motor output evoked by chemical stimulation of neurons located in the pre-Bötzinger complex in vivo. $\mathrm{J}$ Neurophysiol, 81(3), 1150-1161

Spike RC, Watt C, Zafra F, Todd AJ (1997) An ultrastructural study of the glycine transporter GlyT2 and its association with glycine in the superficial laminae of the rat spinal dorsal horn. Neuroscience, 77(2), 543-551

Stallcup WB, Beasley L (1987) Bipotential glial precursor cells of the optic nerve express the NG2 proteoglycan. J. Neurosci, 7(9), 2737-2744

Supplisson S and Roux MJ (2002) Why glycine transporters have different stoichiometries. FEBS Lett., 529(1), 93-101

Valdes F, Munoz C, Feria-Velasco A, Orrego F (1977) Subcellular distribution of rat brain cortex high-affinity, sodium dependent, glycine transport sites. Brai Res., 122(1), 95-112

Wallraff A, Odermatt B, Willecke K, Steinhauser C (2004) Distinct types of astroglial cells in the hippocampus differ in gap junction coupling. Glia, 48(1), 36-43 
Williams JB, Mallorga PJ; Jeffrey Conn P, Pettibone DJ, Sur C (2004) Effects of typical and atypical antipsychotics on human glycine transporters. Schizophr. Res., 71(1), 103-112

Winter S, Hirrlinger J, Kirchhoff F, Hülsmann S (2005) Thy1.2 driven transgenic expression of fluorescent proteins in neurons of the mouse respiratory network. Poster at the Society for Neuroscience $34^{\text {th }}$ annual meeting in Washington.

Zafra F, Aragon C, Olivares L, Danbolt NC, Gimenez C, Storm-Mathisen J (1995a) Glycine transporters are differentially expressed among CNS cells. J. Neurosci., 15 (5), 39523969

Zafra F, Gomeza J, Olivares L, Aragon C, Gimenez C (1995b) Regional distribution and developmental variation of the glycine transporter GlyT1 and GlyT2 in the rat CNS. Eur.J.Neurosci., 7(6), 1342-1352

Zafra F, Poyatos I, Gimenez C (1997) Neuronal dependency of the glycie transporter GlyT1 expression in glial cells. Glia, 20, 155-162

Zhou M and Kimelberg HK (2001) Freshly isolated hippocampal CA1 astrocytes comprise two populations differing in glutamate transporter and AMPA receptor expression. J. Neurosci, 21 (20), 7901-7908 


\section{Acknowledgements}

I wish to thank first of all my supervisor, Priv. Doz. Dr. Swen Hülsmann for the given possibility to work on this project and for providing me all the support and guidance. I am also grateful to Prof. Dr. D.W. Richter for the opportunity to work in his department.

I thank the members of my PhD committee, Priv. Doz. Dr. Swen Hülsmann, Prof. Dr. Klaus-Amin Nave, Prof. Dr. D.W. Richter and Prof. Dr. Christian Rosenmund for the discussions.

I also thank all of my colleagues for creating a friendly atmosphere in the lab, and especially for Dennis Graß and Dr. Eugenia Butkevich for the interesting discussions.

My special thank goes to all members of the Glia Roundtable Göttingen for all of their help, comments, and discussions. I would like to thank Dr. Johannes Hirrlinger for helping me with valuable advices, and Melanie Handschuh for providing help with the single-cell PCR.

I am thankful to Dr. Frank Kirchhoff for providing me the transgenic mice to work with, and Prof. Heinrich Betz for the possibility to work with the GlyT1 KO mice.

Furthermore, I thank our technical assistant, Anja-Annett Grützner for providing optimal background for my work.

At last but not least, I would like to thank my family for the love and support I received from them during all the time. 


\section{Curriculum vitae}

Name: $\quad$ Szőke

First name: $\quad$ Katalin

Date of birth: $\quad$ 02.05.1977

Place of birth: $\quad$ Kaposvár (Hungary)

Parents: $\quad$ Szőke József

Szőke Józsefné Csáti Margit

Education: 1983-1991 Ground school (Bartók Béla Általános Iskola, Kaposvár) 1991-1995 High school (Táncsics Mihály Gimnázium, Kaposvár) 1995-2001 The Pécs University, School of Medicine (Pécs, Hungary)

22.10.2001. $\quad$ Diploma (Medical Degree)

2001- $\quad$ Member of the International Masters/PhD Program "Neuroscience”

$2002 \quad$ Masters Exam

2002- $\quad$ PhD student at the Department of Neuro- and Sensory Physiology of the University of Göttingen 


\section{Publication list}

Gomeza J, Hülsmann S, Ohno K, Eulenburg V, Szöke K, Richter DW, Betz H: Inactivation of the glycine transporter 1 gene discloses vital role of glial glycine uptake in glycinergic inhibition, Neuron, 2003, 40(4), 785-796

\section{Talks}

Katalin Szőke, Johannes Hirrlinger, Melanie Handchuh, Dennis Graß, Clemes Neusch, Frank Kirchhoff, Swen Hülsmann: Role of glial cells in the inhibitory synaptic transmission of the respiratory network, $12^{\text {th }}$ Symposium of Cell- and Developmental Biology, Pécs, 2004

Katalin Szőke, Dennis Graß, Melanie Handschuh, Johannes Hirrlinger, Clemens Neusch, Frank Kirchoff and Swen Hülsmann: Glial cells of the respiratory network express functional glycine transporters and receptors, Neurizons International Student Symposium, Göttingen, 2004

\section{Poster presentations}

Katalin Szőke, Frank Kirchhoff, Swen Hülsmann: Function of astrocytes in the inhibitory synaptic transmission in the respiratory network, $1^{\text {st }}$ International Student Symposium Horizons in Molecular Biology, Göttingen, 2003

Katalin Szőke, Johannes Hirrlinger, Frank Kirchhoff, Swen Hülsmann: Function of astrocytes in inhibotory synaptic transmission in the respiratory network, $83^{\text {rd }}$ Meeting of the German Physiological Society, Leipzig, 2004

Katalin Szőke, Johannes Hirrlinger, Melanie Handschuh, Clemens Neusch, Frank Kirchhoff, Swen Hülsmann: Function of glial cells for inhibitory synaptic transmission in the respiratory network, FENS Neuroscience Conference, Lisbon, 2004

Katalin Szőke, Johannes Hirrlinger, Melanie Handschuh, Clemens Neusch, Frank Kirchoff, Swen Hülsmann: Role of glial cells in the inhibitory synaptic transmission of the respiratory network, Society for Neuroscience $34^{\text {th }}$ annual meeting, San Diego, 2004 
Swen Hülsmann, Marco Seyfarth, Katalin Szőke, Kai Härtel: Effect of sarcosine and fluoroacetate on glycinergic IPSCs in hypoglossal motoneurons, Society for Neuroscience $34^{\text {th }}$ annual meeting, San Diego, 2004

Melanie Handschuh, Iris Maletzki, Katalin Szöke, Swen Hülsmann, Frank Kirchhoff, Matthias Bähr, Clemens Neusch: Colocalisation of the Kir4.1 potassium channes subunit and aquaporin 8 channels in spinal cord oligodendocytes, Society for Neuroscience $34^{\text {th }}$ annual meeting, San Diego, 2004

Katalin Szőke, Johannes Hirrlinger, Melanie Handschuh, Clemens Neusch, Frank Kirchhoff and Swen Hülsmann: Glial cells in the respiratory network express functional transporters and receptors for glycine, Sixth Meeting of the German Neuroscience Society-30 ${ }^{\text {th }}$ Göttingen Neurobiology Conference, Göttingen, 2005

Melanie Handschuh, Katalin Szöke, Swen Hülsmann, Frank Kirchhoff, Matthias Bähr, Clemens Neusch: Differential cellular expression of aquaporin 4 and 8 in mouse spinal cord culture and coenrichment with the Kir4.1 channel, Sixth Meeting of the German Neuroscience Society-30 ${ }^{\text {th }}$ Göttingen Neurobiology Conference, Göttingen, 2005

Katalin Szőke, Johannes Hirrlinger, Melanie Handschuh, Clemens Neusch, Frank Kirchhoff and Swen Hülsmann: Glial cells in the respiratory network express functional transporters and receptors for glycine, Satellite symposium V. of the Sixth Meeting of the German Neuroscience Society- Joint symposium of the DFG Neuroscience Graduate Schools, Göttingen, 2005 